\title{
Integração de Redes Neurais Artificiais \& Métodos Estocásticos para Previsão de Séries Temporais
}

\author{
Helio Diniz \\ Orientação: Prof. Dr. André C. P. L. F. de Carvalho \\ Versão Corrigida
}

Dissertação apresentada ao Instituto de Ciências Matemáticas e de Computação - USP, como parte dos requisitos para a obtenção do título de Mestre em Ciências - Área de Ciências de Computação e Matemática Computacional.

USP - São Carlos

Junho de 1999 


\section{$\Lambda$ gradecimentos}

Esta seção é devotada aos agradecimentos às pessoas que contribuíram diretamente ou indiretamente para a realização desta dissertação de mestrado.

Agradeço primeiramente ao Prof. Dr. André C. P. L. F. de Carvalho pela dedicação e esforços gastos na minha orientação de mestrado e por partilhar seu conhecimento teórico e prático sobre Redes Neurais Artificiais.

Agradeço aos meus pais o apoio e o incentivo dado sem o qual não estaria hoje escrevendo esta dissertação.

Agradeço aos colegas do Laboratório de Inteligência Artificial (LABIC) pela amizade e companheirismo praticados diariamente em um convívio muito agradável.

Agradeço ao corpo docente do Instituto de Ciências Matemáticas e Computação (ICMC) do campus de São Carlos pela boa formação teórica e técnica que adquiri dentro da Universidade de São Paulo.

Agradeço ao Prof. Dr. Marinho G. de Andrade pela atenção dedicada e auxílio teórico e prático sobre métodos estocásticos de análise e previsão de séries temporais.

Agradeço à Fundação de Amparo à Pesquisa do Estado de São Paulo (FAPESP) pelo apoio financeiro que foi fundamental para concretização das atividades de mestrado.

Finalmente, agradeço aos funcionários do ICMC por proporcionarem e manterem uma estrutura sólida para o desenvolvimento científico. 


\section{Índice}

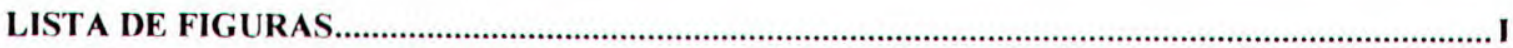

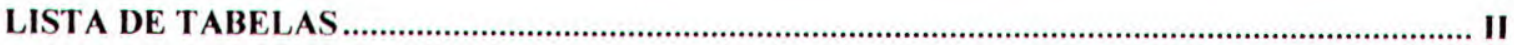

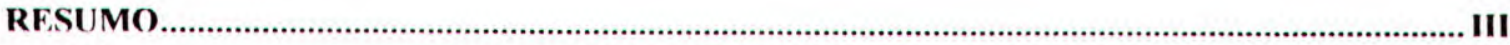

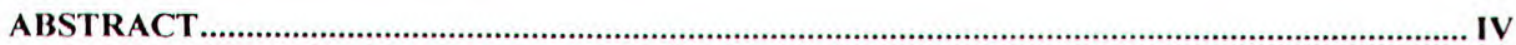

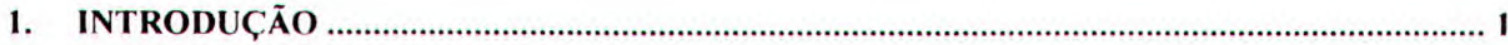

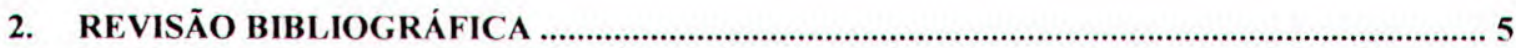

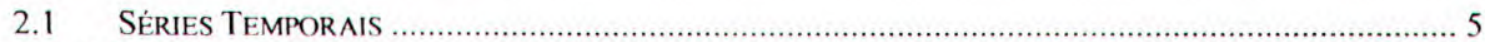

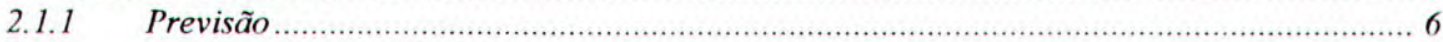

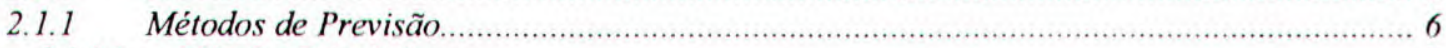

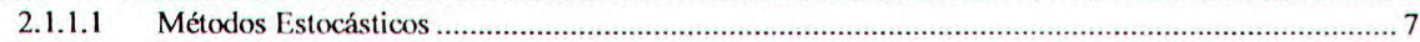

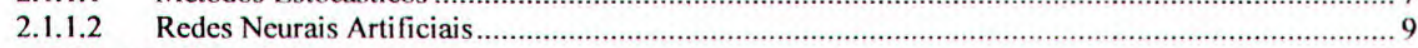

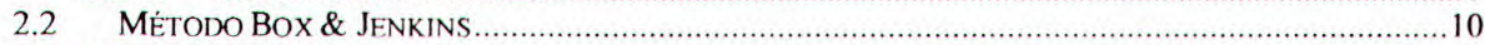

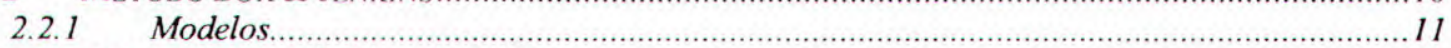

2.2.1.1 Modelos Lineares Estacionário .......................................................................................... 13

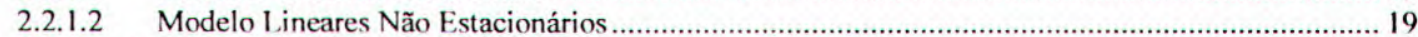

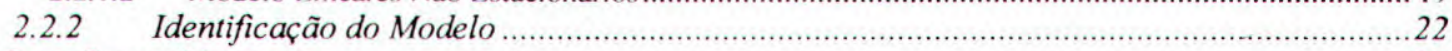

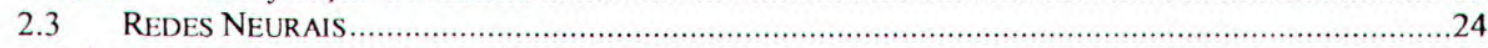

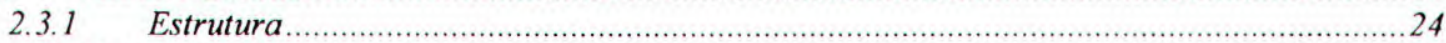

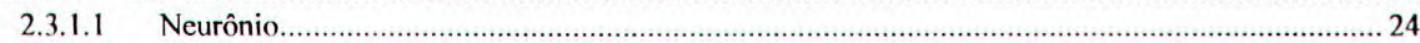

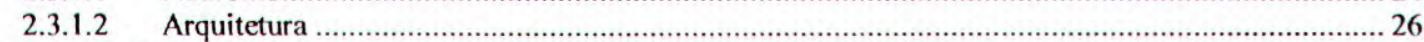

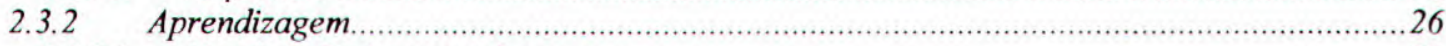

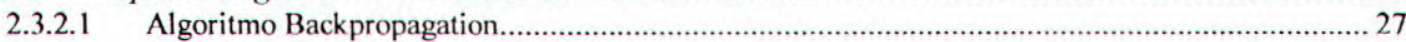

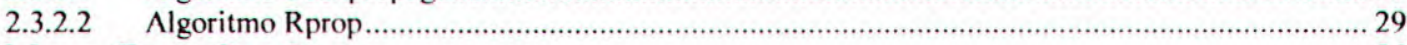

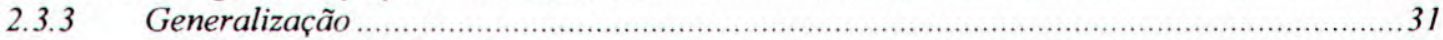

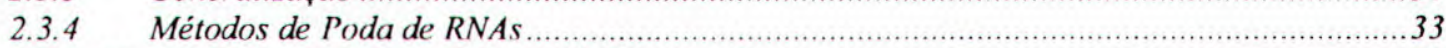

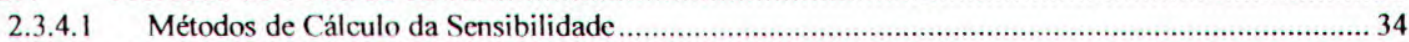

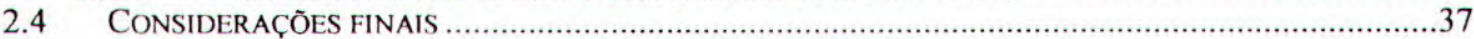

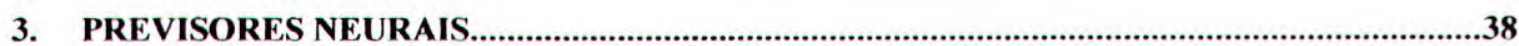

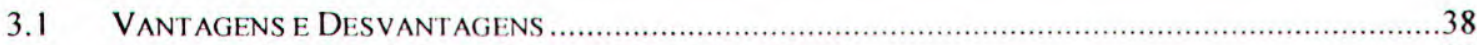

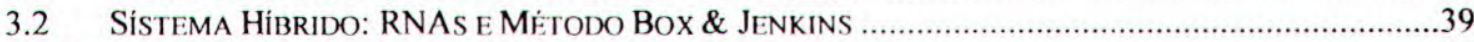

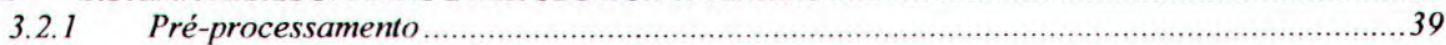

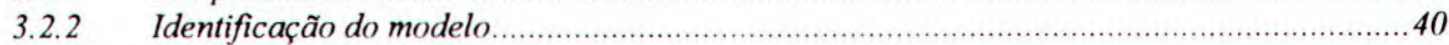

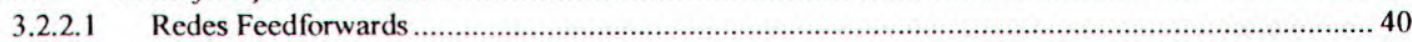

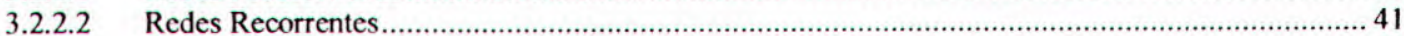

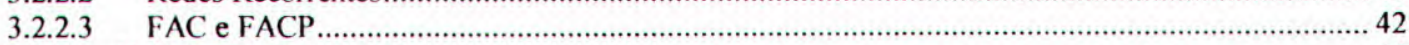

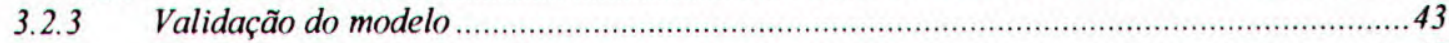

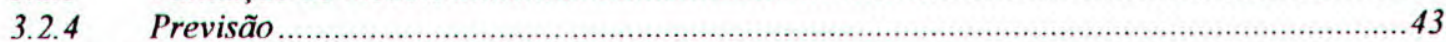

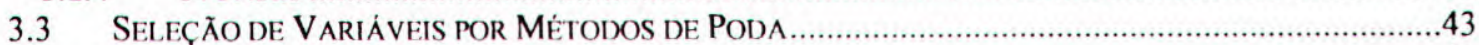

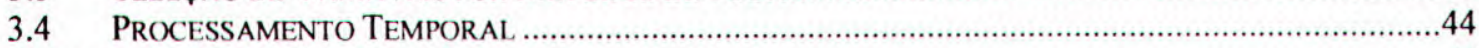

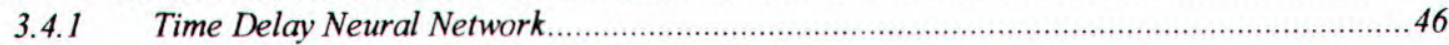

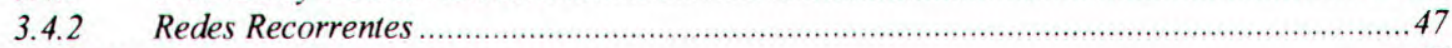

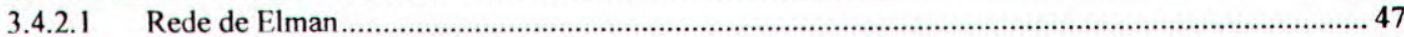

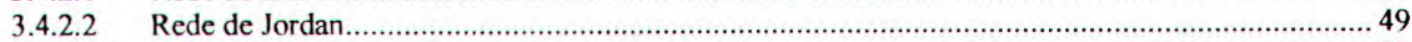

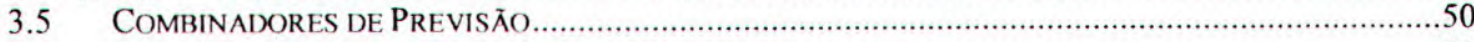

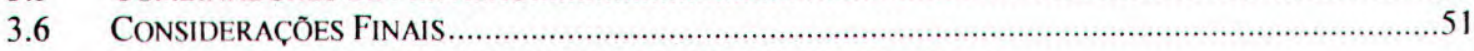

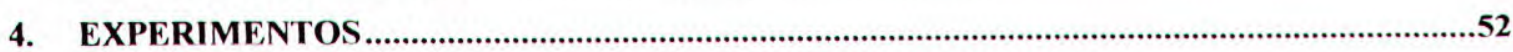

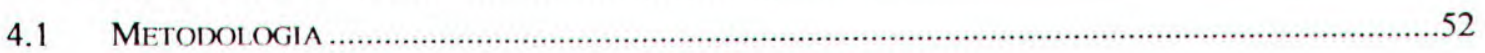




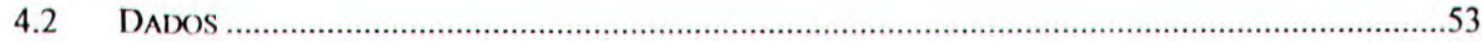

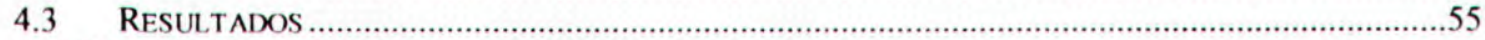

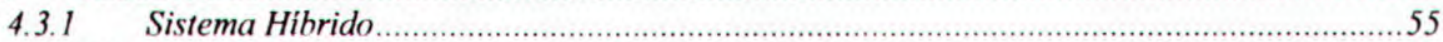

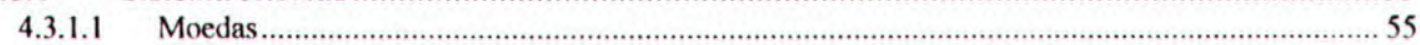

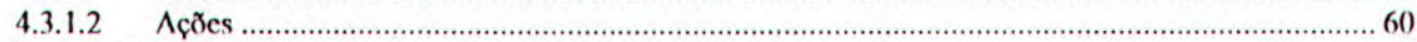

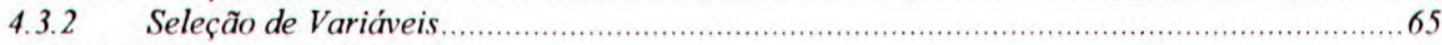

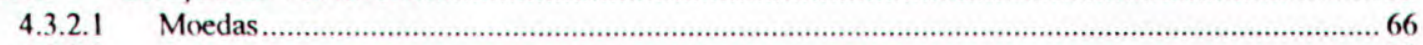

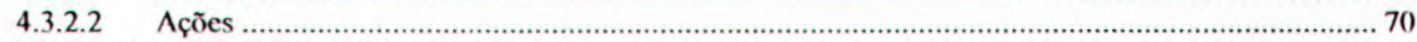

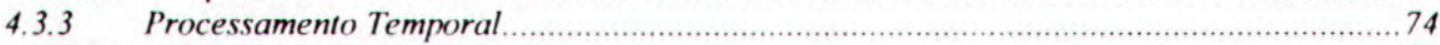

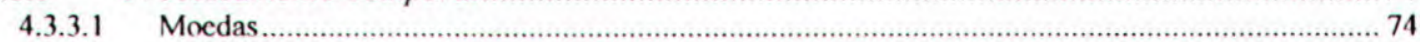

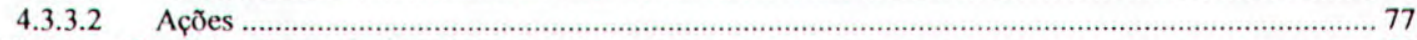

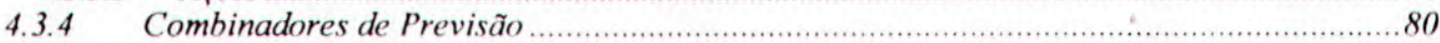

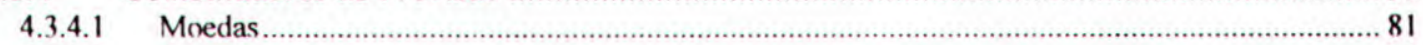

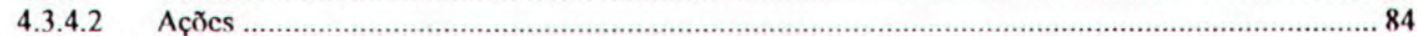

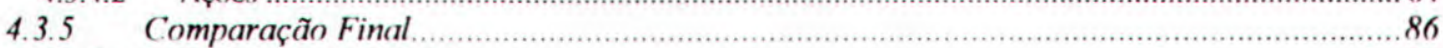

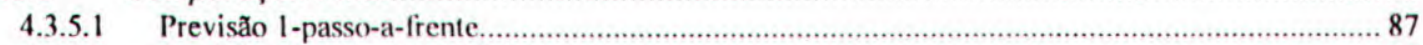

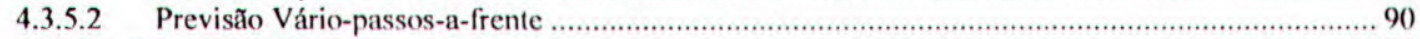

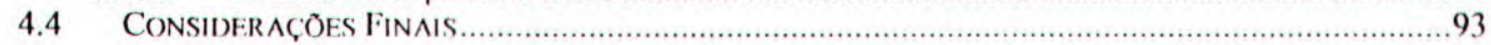

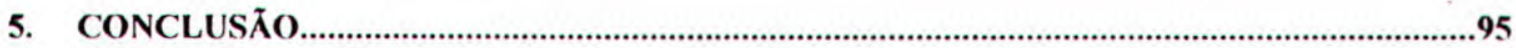

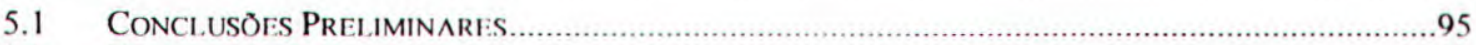

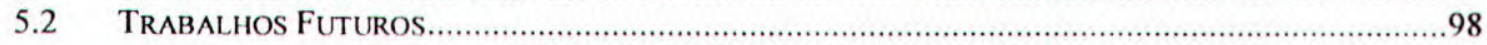

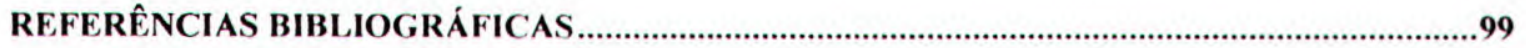




\section{Lista de Figuras}

Figura 2.1:Estrutura dos modelos de Função de Transferência.................................................................... 7

Figura 2.2: Estrutura dos modelos Multivariados............................................................................ 8

Figura 2.3: Etapas para Previsão de Séries Temporais através do método Box \& Jenkins......................... 10

Figura 2.4: Filtro Linear................................................................................................................. I

Figura 2.5: Comportamento da função de auto-correlação de um $\Lambda R(p)$................................................ 15

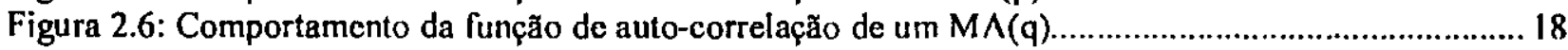

Figura 2.7: Comportamento da função de auto-correlação de um Random Walk....................................... 21

Figura 2.8: Neurônio Artificial....................................................................................................... 25

Figura 3.I: Procedimento de projeto de RNAs para previsão............................................................. 39

Figura 3.2: RNA feedforward para aproximação do modelo NAR(p) .............................................. 41

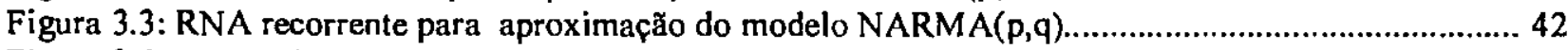

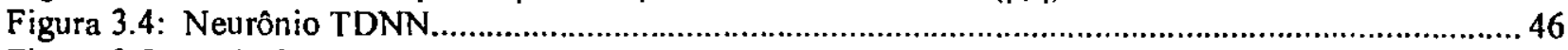

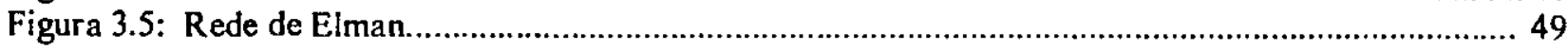

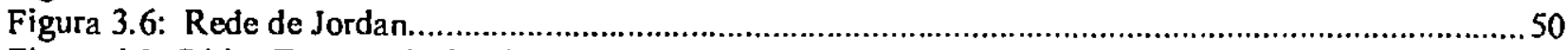

Figura 4.1: Séries Temporais da Libra Esterlina e Marco Alemão.......................................................... 54

Figura 4.2: Séries temporais de preço mínimo e máximo. ........................................................................55

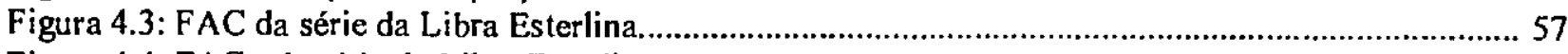

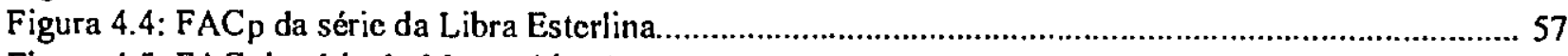

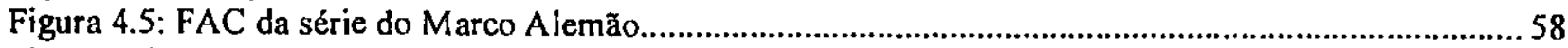

Figura 4.6: FACp da série do Marco Alemão................................................................................... 58

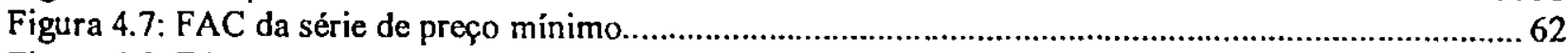

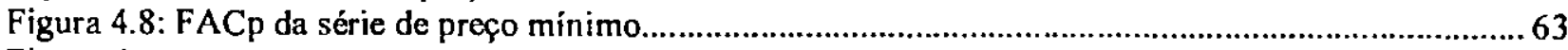

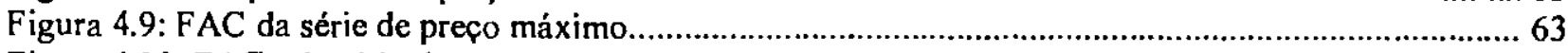

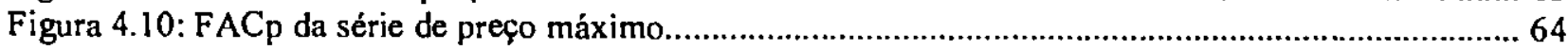

Figura 4.11: Seleção de variáveis para a série da Libra Esterlina...........................................................69

Figura 4.12: Seleção de variáveis para a série da Marco Alemão......................................................... 69

Figura 4.13: Seleção de variáveis para a série do mínimo.......................................................................... 72

Figura 4.14: Seleção de variáveis para a série do máximo..................................................................... 73

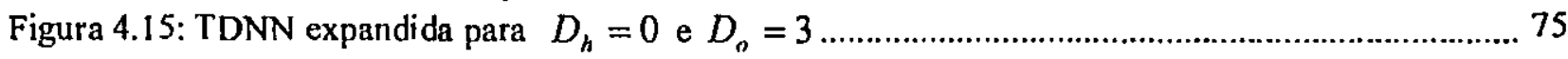

Figura 4.16: Previsర̃es I-passo-a-frente da Libra Esterlina........................................................................ 88

Figura 4.17: Previsões 1-passo-a-frente do Marco Alemão........................................................................8 88

Figura 4.18: Previsões !-passo-a-frente do prę̧o mínimo de ações............................................................ 89

Figura 4.19: Previsões 1-passo-a-frente do preço máximo de ações........................................................... 90

Figura 4.20: Previsões vários-passos-a-frente da Libra Esterlina............................................................... 91

Figura 4.21: Previsões vários-passos-a-frente do Marco Alemão................................................................ 91

Figura 4.22: Previsões vários-passos-a-frente das séries do prę̧o mínimo.................................................92

Figura 4.23: Previsões vários-passos-a-frente das séries do preço máximo.................................................. 93 


\section{Lista de Tabelas}

Tabela 4.1: Parâmetros e desempenhos dos modelos Box \& Jenkins ajustados.......................................56

Tabela 4.2: Desempenho de previsão (MRE) das RNAs para a Libra Esterlina.......................................59

Tabela 4.3:Desempenho de previsão (MRE) das RNAs para a série do Marco Alemão com

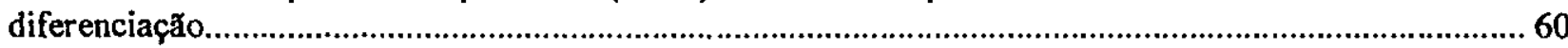

Tabela 4.4:Desempenho de previsão (MRE) das RNAs para a série do Marco Alemão sem

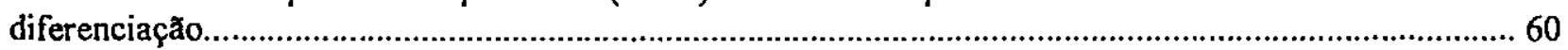

Tabela 4.5: Parâmetros e desempenhos dos modelos Box \& Jenkins ajustados.........................................61

Tabela 4.6: Desempenho de previsão (MRE) das RNAs para o preço mínimo com diferenciação............. 64

Tabela 4.7: Desempenho de previsão (MRE) das RNAs para o preço mínimo sem diferenciação..............64

Tabela 4.8:Desempenho de previsão (MRE) das RNAs para o preço máximo com diferenciação..............65

Tabela 4.9: Desempenho de previsão (MRE) das RNAs para o preço máximo sem diferenciação............ 65

Tabela 4.10a: Variáveis adicionais para a Libra Esterlina.......................................................................67 67

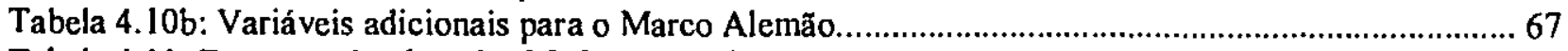

Tabela 4.11: Desempenho de redes MLP para a Libra Esterlina considerando variáveis adicionais............ 67

Tabela 4.12: Desempenho de redes MLP para o Marco Alemão considerando variáveis adicionais.......... 68

Tabela 4.13a: Variáveis selecionadas para a Libra Esterlina.............................................................. 70

Tabela 4.1 3b: Variáveis selecionadas para o Marco Alemao................................................................... 70

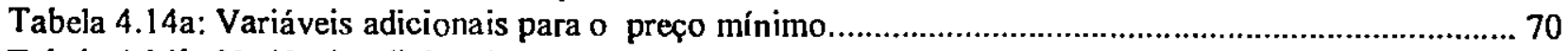

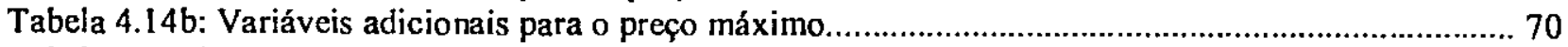

Tabela 4.15: Desempenho de redes MLP para a série do mínimo considerando variáveis adicionais.........71

Tabcla 4.16: Desempenho de redes MLP para a séric do máximo considerando variáveis adicionais........ 71

Tabela 4.17a Variáveis selecionadas para o preço mínimo.................................................................... 73

Tabela $4.17 \mathrm{~b}$ Variáveis selecionadas para o preço máximo................................................................... 73

Tabela 4.18: Desempcnho das redes TDNN para a série da Libra ............................................................. 75

Tabela 4.19: Desempenho das redes TDNN para a série do Marco diferenciada.......................................75

Tabela 4.20: Desempenho das redes Elman para a série da Libra Esterlina................................................76

Tabela 4.21: Desempenho das redes Jordan para a série da Libra Esterlina............................................. 76

Tabela 4.22: Desempenho das redes Elman para a série do Marco diferenciada...................................... 77

Tabela 4.23: Desempenho das redes Jordan para a série do Marco diferenciada.................................... 77

Tabela 4.24: Desempenho das redes TDNN para a série do mínimo diferenciada....................................78

Tabela 4.25: Desempenho das redes TDNN para a série do máximo diferenciada..................................... 78

Tabela 4.26: Desempenho das redes Elman para a série do mínimo diferenciada..................................... 79

Tabela 4.27: Desempenho das redes Jordan para a série do mínimo diferenciada..................................... 79

Tabela 4.28: Desempenho das redes Elman para a série do máximo diferenciada.................................... 80

Tabela 4.29: Desempenho das redes Jordan para a série do máximo diferenciada....................................8 80

Tabela 4.30: Desempenho comitê por média para as séries da Libra Esterlina e Marco Alemão................ 81

Tabela 4.31: Desempen ho das redes MLP usadas como comitês para a Libra Esterlina........................... 82

Tabela 4.32: Desempenho das redes de Elman usadas como comitês para a Libra Esterlina..................... 82

Tabela 4.33: Desempenho das redes de Jordan usadas como comitês para a Libra Esterlina..................... 82

Tabela 4.34: Desempenho das redes MLP usada como comitês para o Marco Alemão............................ 83

Tabela 4.35: Desempenho das redes de Elman usada como comitês para o Marco Alemão...................... 83

Tabela 4.36: Desempenho das redes de Jordan usada como comitês para o Marco Alemão....................... 83

Tabela 4.37: Desempenho de comitês por média dos preços mínimo e máximo........................................ 84

Tabela 4.38: Desempenho das redes MLP usadas como comitês para o preço mínimo.............................. 85

Tabela 4.39: Desempenho das redes de Elman usadas como comitês para o preço mínimo.........................85

Tabela 4.40: Desempenho das redes de Jordan usadas como comitês para o preço mínimo....................... 85

Tabela 4.41: Desempenho das redes MLP usadas como comitês para o preço máximo............................... 86

Tabela 4.42: Desempcnho das redes de Elman usadas como comitês para a o preço máximo.................... 86

Tabela 4.43: Desempenho das redes de Jordan usadas como comitês para o preço máximo......................... 86 


\section{Resumo}

Esta disscrtação investiga a possibilidade de integração de Redes Neurais Artificiais (RNAs) e Método Estocásticos para previsão de séries temporais. O problema de previsão é gcralmente abordado através de Métodos Estocásticos. Ultimamente, as RNAs têm sido muito utilizadas para a construção de previsores não lineares em diferente áreas de aplicações. Contudo, as arquiteturas da RNAs devem também ser parcimoniosas, ou seja, apenas considerar as entradas mais relevantes para realizar uma boa previsão. Assim, várias abordagens vêm sendo propostas para melhorar o projeto de arquitetura em problemas de previsão. Alguns exemplos destas abordagens são a combinação de RNAs e métodos Box \& Jenkins, as técnicas de seleção usando métodos de poda de RNAs e modelos de RNAs com capacidade de processamento temporal. Além disso, as vantagens particulares dos previsores construídos seguindo tais abordagens podem ser combinadas através de comitês ou combinadores de previsão. Os experimentos desta dissertação foram realizados com dados sobre séries temporais de cotação de moedas e ações. 


\begin{abstract}
This work investigates the potential integration of Artificial Neural Networks (ANNs) and Stochastic Methods for time series prediction. The prediction problem is usually solved through stochastic methods. Recently, ANNs have been used in order to create nonlinear predictors in different areas of application. However, the ANNs architectures should also be parsimonious, e. g., they should just consider the most relevant inputs so as to carry out good predictions. Therefore, several approaches have been proposed in order to improve the architecture design in this realm. Some examples of those approaches are the combination of ANNs the Box \& Jenkins method, the variable selection techniques using pruning methods and ANNs dynamic models with processing temporal skills. Besides, the particular advantages of each individual predictor that are created following those approaches can be combined through a forecasting committee. The experiments of this dissertation were carried out using real-world data sets of exchange rate and stock markets time series.
\end{abstract}




\section{Introdução}

Esta dissertação apresenta as atividades desenvolvidas pelo candidato Hélio Diniz referentes a utilização de Modelos Fstocásticos e Redes Neurais Artificiais para a previsão de séries temporais.

Uma série temporal ć um conjunto seqüencial de observações de um dado fenômeno que são amostradas de acordo com algum parâmetro como, por exemplo, o tempo. Uma série temporal é dita estacionária se suas observações giram em torno de um nível médio constante e seus parâmetros não se alteram ao longo do tempo. Entretanto, muitas séries temporais são não estacionárias, apresentando comportamentos como tendência linear ou exponencial.

A previsão de séries temporais é um assunto que atrai o interesse das mais diversas áreas de pesquisas como transporte, energia, administração, saneamento, finanças, etc. As aplicações de cotação de moedas (Mostafa, 1996; Diniz et al., 1997), cotação do ouro (Abelém, 1995), commodities (Mostafa, 1996), demanda de passageiros em viagens áreas (Fernandes et al., 1996), valores de ações (White, 1988) e vazões mensais de rios (Kadowaki et al., 1997; Ballini et al., 1997) são alguns exemplos que podem ser encontrados na literatura sobre o assunto. Este interesse em conhecer o futuro de certos fenômenos geralmente está relacionado com a redução de custos e/ou o aumento dos lucros que estas atividades podem proporcionar.

Os problemas de previsão são geralmente tratados sob a perspectiva de métodos estocásticos. Até o inf́cio da década dc 70, haviam poucas alternativa metodológicas para análise e previsões de séries temporais, como por exemplo os métodos de Decomposição Clássica e os métodos de Caixa-Preta (regressão linear simples, regressão linear múltipla, etc.). A fundamentação teórica da área iniciou fortemente a sua consolidação em 1970 a partir dos trabalhos realizados por Box \& Jenkins (Box et al., 1970). Quase que simultaneamente, surge em 1971 o lado bayesiano dos modelos de previsão proposto por Harisson e Stevens (Harrisson e Stevens, 1971). Assim, tanto do lado clássico quanto do lado bayesiano, toda a década de 70 foi dedicada à implementação prática dos modelos propostos $\mathrm{e}$ às conseqüentes melhorias metodológicas sugeridas pela aplicação real destes métodos. Por conseguinte, várias alternativas metodológicas foram desenvolvidas e continuam ainda sendo propostas a todo instante.

A maioria dos métodos estocásticos ajustam modelos que apenas utilizam informações passadas sobre a série temporal que se deseja prever. Estes métodos são chamados Univariados. Contudo, existem ainda outras metodologias estocásticas cujos modelos são capazes de empregar 
informações passadas sobre outras séries temporais adicionais em sua entrada. Tais métodos estão divididos em duas outras classes: métodos de Função de Transferência e métodos Multivariados. A diferença entre estes método está na restrição de causa-efeito existente entre a série de interesse $\mathrm{e}$ as demais sćrics.

Apesar de existirem outros métodos estocásticos com modelos um pouco mais sofisticados, como o ARCH (Eagle, 1982; Eagle e Gonzales-Rivera, 1986) e o GARCH (Bollerslev, 1986), que vem sendo mais atualmente aplicados em previsס̃es financeiras, o método de Box \& Jenkins será mais detalhadamente abordado devido a sua grande importância e o fato de ser base destas inovações. Este método é do tipo univariado c rcaliza a análise e previsão de uma série temporal atravćs da aplicação de uma sequêencia de etapas de identificação do modelo, estimação dos seus parâmctros e de sua validação. Seus modelos são lineares e podem representar tanto séries temporais estacionárias como não cstacionárias. Esta representação é realizada de maneira parcimoniosa, isto é, emprega o menor número de parâmetros possível. Além disso, a previsão é fundamentada em informações passadas da própria série temporais (observações e ruídos passados).

Na última década, vários modelos não lineares foram propostos para resolver a limitação ( $\phi k s e n d a l, 1992)$. Infelizmente, a maioria destes métodos estocásticos realizam a modelagem de séries temporais assumindo que existe uma relação linear entre as variáveis de entradas. $\mathrm{Na}$ prática, esta suposição pode prejudicar a precisão da previsão de valores futuros de processos reais. Alternativamente, tem surgido um crescente e considerável interesse na investigação de Redes Neurais Artificiais (RNAs) para a previsão de séries temporais.

Uma das primeiras arquiteturas de RNAs projetada para a previsão de séries temporais foi concebida por Lapedes e Faber (Lapedes e Faber, 1987). Tratava-se de uma Rede Neural MultiLayered Perceptron (MLP) cujos neurônios da camada de saída possuiam uma função de ativação linear. Tal função permitia que a rede reproduzisse qualquer observação de uma sćrie temporal $z_{t}$ que poderia assumir valores entre $(-\infty, \infty)$. Se fosse usada uma função logística, a saída ficaria restrita ao intervalo [0,1]. Para criar um modelo dependente do tempo, Lapedes e Farber utilizaram algumas observações passadas $z_{t-1}, z_{t-2}, \ldots, z_{t-n}$ como variáveis de entrada. Inicialmente, o candidato utilizou uma arquitetura deste tipo para previsão de cotação de moedas (Diniz et al, 1997). Foi verificado que a abordagem de Lapedes e Faber não é parcimoniosa e a quantidade de informação passada era determinada empiricamente. Por esta razão, diversas variações visando melhorias foram investigadas. 
Uma destas variações é uma utilização conjunta de Redes Neurais Artificias e do método Box \& Jenkins, que foi esquematizada por Drossu \& Obradovic (Drossu \& Obradovic, 1996). Basicamente, esta abordagem emprega o pré-processamento e as ferramentas de identificação de modelos Box \& Jenkins para determinar alguns parâmetros livres da arquitetura neural. O préprocessamcnto é empregado para transformar uma série temporal não estacionária em estacionária. As ferramentas de identificação permitem escolher o tipo de arquitetura apropriado e dimensionar a camada de entrada da rede para realizar a previsão de um passo a frente. Esta linha foi seguida por diversos trabalhos para modelar as arquiteturas das Redes Neurais em previsão de vazões mensais de rios (Ballini et al, 1997; Kadowaki et al., 1997), e preços diários de açốes (Diniz et al, 1998).

Os métodos de poda de RNAs constituem um outro exemplo de recursos que têm sido utilizados para tornar suas arquiteturas mais parcimoniosas em previsão de séries temporais. Estes métodos são geralmente cmpregados como ferramentas de seleção de variáveis através da diminuição sucessiva de arquitetura da Rede Neural em busca de uma melhor generalizaçăo. Diversos trabalhos têm aplicado métodos de poda com esta finalidade (Moody, 1992; Goute, 1996; Diniz, et al, 1998; Diniz et al, 1999).

Uma outra característica interessante, que alguns modelos de Redes Neurais possuem, é a capacidade de extrair e representar relacionamentos temporais. Isto é realizado através da adição de memória às arquiteturas das redes. Esta memória pode ser de curto prazo ou de longo prazo. Os modelos de Time Delays Neural Netwoks (TDNN) utilizam memórias de curto prazo nas camadas intermediárias e de saída. As redes recorrentes de Elman e Jordan fazem o uso de memórias de longo prazo. Originalmente, estas redes foram desenvolvidas para o reconhecimento de linguagem natural. Entretanto, vários artigos empregam estes modelos em outras aplicações, como previsões de tendências de ações (Saad, 1998), de carga elétrica (Teixeira et. al, 1998), etc...

As previsões realizadas por cada uma das três abordagens citadas anteriormente podem ainda ser combinadas na forma de comitês de previsores, visando a redução das taxas de erro e um comportamento mais estável na previsão.

O principal objetivo almejado por esta dissertação é obter informações, a partir da análise estocástica de uma série temporal, para o projeto de arquiteturas de RNAs. Para tanto, vários experimentos com séries reais provenientes da área financeira foram realizados. Tais experimentos envolveram o uso RNAs feedforward e recorrentes para a previsão de séries temporais de cotações diárias de moedas e preços de ações. As arquiteturas das redes 
feedforward foram projetadas através dos conceitos do metódo Box \& Jenkins e da utilizaçăo de métodos de poda. As redes com memória (TDNNs c redes recorrentes) foram inicialmente destinadas à exıração da não estacionariedade das séries de ações, como, por exemplo, um possfvel relacionamento temporal.

Esta dissertação está organizada em cinco capítulos principais. O primeiro caṕtulo corresponde à esta introdução sobre o principais assuntos abordados. $O$ segundo capítulo apresenta a definição de séric temporais c dois métodos emprcgados para prevê-las: métodos Box \& Jenkins e Redes Neurais Artificiais. O terceiro capitulo discute três maneiras plausiveis de definir as arquitetura das RNAs para realizar previsão. O quarto capítulo relata os experimentos realizados com as séries temporais de moedas e ações. Finalmente, o quinta e último capítulo apresenta algumas conclusões obtidas durante o trabalho realizado nesta disscrtação. 


\section{Revisão Bibliográfica}

Este capitulo aprescnta os conceitos básicos sobre análise e previsão de séries temporais. A seção 2.1 define o que são séries temporais e apresenta um breve histórico dos métodos estocásticos e das RNAs empregados para prevê-las. A seção 2.2 apresenta os conceitos básicos relacionados ao método Box \& Jenkins de previsão. A estrutura e funcionamento das RNAs são apresentados pela seção 2.3. Finalmente, a seção 2.4 apresentam algumas consideração finais delineadas sobre os tópicos abordados neste capitulo.

\subsection{Séries Temporais}

A observação de resultados passados de um fenômeno para antecipar o seu comportamento futuro constitui a essência da previsão. Se existir um modelo matemático capaz de descrever completamente tal fenômeno, este modelo é chamado determinístico. Por outro lado, se o modelo é incompleto ou desconhecido, elc é não-determinístico e variáveis probabilisticas devem ser consideradas em sua representação. Tais modelos são chamados processos ou modelos estocásticos.

Uma série temporal é um conjunto de observações dos resultados de um fenômeno colhidos seqüencialmente ao longo do tempo (Box et al., 1970). Existem diversos exemplos de séries temporais em áreas como economia, administração, engenharia, química, física, ciências naturais e ciências sociais. Alguns destes exemplos são as séries de quantidade anual de passageiros de uma dada companhia área, volume mensal de vendas de um determinado produto, número semanal de acidentes de carros, preço diário de ações, cotação de commodities (preço da arroba do boi, prcço da saca do café, etc.) etc. Uma caracteristica intrínseca das séries temporais é que suas observações consecutivas são dependentes entre si. A natureza desta dependência é de considerável interesse prático.

Em termos matemáticos, uma série temporal é um conjunto de $N$ sucessivas observações $\left\{z_{1}, z_{2}, \ldots, z_{N}\right\}$ que representa uma possível realização, de uma população infinita de realizações, que poderiam ter sido geradas a partir de um processo estocástico. A questão mais importante é que o comportamento futuro de uma série temporal não pode ser previsto com exatidão, como é o caso das funções deterministicas.

Uma série temporal é estacionária se o processo estocástico oscila em torno de um nível médio constante (Box et al., 1970). Em outras palavras, uma série temporal é estacionária se seus parâmetros não mudam com o passar do tempo. Contudo, a maioria dos exemplos reais de séries 
temporais (cotação de ações e moedas) exibem um comportamento não estacionário, não oscilando em torno de um média fixa. A sazonalidade, e a tendência linear ou exponencial são exemplos deste tipo comportamento.

A tarefa de determinação de relações de dependência temporal existentes entre as observações de uma série temporal através de uma análise estatística detalhada é conhecida como Análise de Série Temporal. Uma vez determinadas tais relaçóes de dependência, um modelo matemático pode ser proprosto para representação e previsão da série. As ferramentas empregadas para a análise, modelagem e previsão de uma série consitutuem os chamados métodos de previsão.

\subsubsection{Previsão}

A previsão de uma série temporal é a determinação dos prováveis valores que serão assumidos pelas variáveis aleatórias $z_{t+1}, z_{t+2}, \ldots, z_{t+l}$, sendo $l$ o horizonte máximo de previsão. A previsão pode ser classificada como de curto, médio ou longo prazo dependendo do valor associado ao horizonte máximo de previsão. Seja $z_{t+k}$ a previsão de $k$ passos a frente, sendo $1 \leq k \leq l$. Além disso, em rclação ao valor de $k$, a previsão pode ser do tipo 1-passo-à-frente (single-step), quando $k=1$, ou vários-passos-à-frente (mulli-slep), quando $k>1$.

A maioria dos métodos de previsão permite uma visão razoável do futuro próximo através de uma extrapolação direta do que havia ocorrido no passado.

É interessante ressaltar que qualquer que seja o horizonte de previsão (curto, médio, ou longo prazo), não existe um forma de definir claramente o horizonte máximo $l$ (Souza, 1989). Este valor dependerá do grau de previsibilidade da série, que, por sua vez, está intimamente relacionado ao erro de previsão de l-passo-à-frente (Souza, 1989).

\subsubsection{Métodos de Previsão}

Os problemas de previsão de séries temporais são geralmente abordados sob a perspectiva de métodos estocásticos. Estes métodos são na maioria das vezes fáceis de serem usados e seus parâmetros podem ser rapidamente estimados. Contudo a sua funcionalidade ć limitada, dada a natureza linear de seus modelos.

Alternativamente, há um crescente interesse na investigação de Redes Neurais Artificiais para este tipo de tarefa. As RNAs são modelos não-lineares cujos parâmetros são ajustados através de um processo de aprendizado. Entretanto, as RNAs possuem algumas desvantagens, 
como a determinação de scus parâmetros e dificuldades de lidar com séries não estacionárias. Estas dificuldades podem ser amenizadas átravés de uma análise estocástica da série temporal.

\subsubsection{Métodos Estocásticos}

As diversas metodologias estocástica existentes na literatura, independente do tipo de estatística na qual elas se baseiam (clássica ou bayesiana), podem ser classificadas em três grandes categorias distintas: Univariadas, Função de Transferência e Multivariadas (Souza, 1989). Esta classificação é baseada no número de séries temporais utilizadas para a modelagem.

A primeira categoria compreende todos o métodos que se baseiam somente em dados sobre uma série temporal para então prevê-la. A grande maioria dos métodos estocásticos encontra-se nesta categoria.

A categoria de Função de Transferência inclui as metodologias nas quais a série de interesse é descrita, não só pelo seu passado histórico, como também por informações sobre outras séries temporais. A estrutura dos modelos dos métodos de Função de Transferência é ilustrado através da Figura 2.1 .

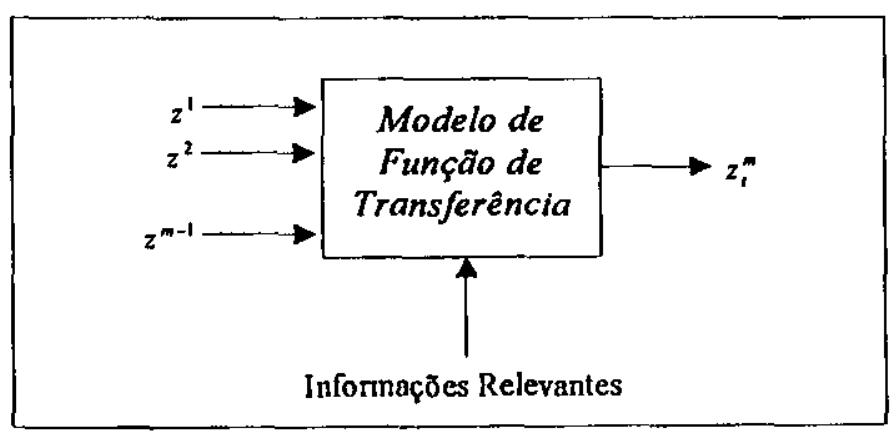

Figura 2.l:Estrutura dos modelos de Função de Transferência.

É importante ressaltar que tais modelos consideram o sentido da causa-efeito unidirecional. Em outras palavras, as séries $z^{1}, z^{2}, \ldots, z^{m-1}$, ilustradas como entradas do esquema da Figura 2.1, causam diretamente as observações da série $z^{m}$, o que não ocorre no sentido inverso.

Finalmente, o último caso engloba as metodologias cujos modelos envolvem mais de uma série temporal para descrição da série de interesse, mas sem qualquer imposição da direção da causa-efeito existente entre elas. A estrutura básica dos modelos dos métodos multivariados pode ser representada através do diagrama da Figura 2.2. Nesta figura, 0 vetor $Z=\left[z^{1}, z^{2}, \ldots, z^{m}\right]^{T}$ representa informações tanto sobre a série de interesse $z^{m}$ quanto as demais 
séries adicionais $z^{1}, z^{2}, \ldots, z^{m-1}$. Nos modelos multivariados, as séries adicionais podem tanto influenciar a série de interesse, como sofrer influência da série de interesse em qualquer série adicional.

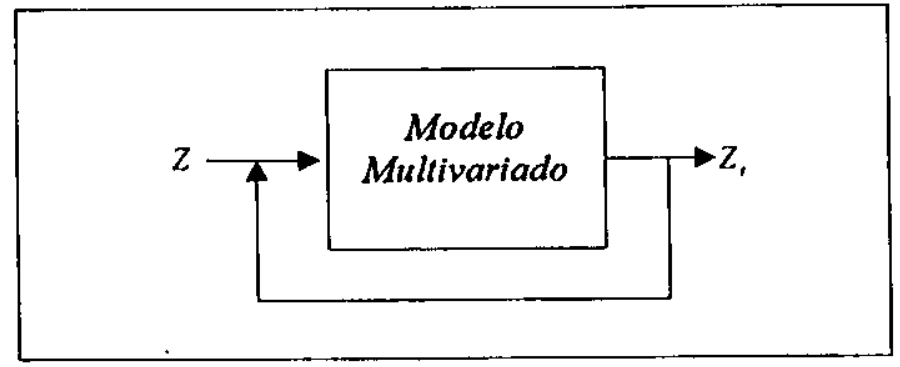

Figura 2.2: Estrutura dos modelos Multivariados.

Até a década de 60, a única alternativa disponível para a previsão de séries temporais era o método de Decomposição Clássica. Esta metodologia foi uma das pioneiras na formulação univariada e considerava uma série $z$ como sendo composta por quatro componentes nãoobserváveis distintos: $T$, (Tendência), $S_{t}$ (Sazonalidade), $C_{1}$ (Ciclo) e $a_{t}$ (Ruído aleatório). Assim, assumia-se para uma dada observação $z$, desta série o seguinte modclo geral :

$$
z_{1}=f\left(T_{1}, S_{1}, C_{1}, a_{1}\right)
$$

em que, a forma da função $f$ especificava a maneira pela qual estes componentes se relacionam. Estes métodos utilizavam operadores aritméticos para extraírem, sucessivamente, estimadores de cada componente.

No início da década de 60, sugiram os métodos Automáticos ou do tipo Caixa-Preta. Tratam-se de metodologias que podem ser diretamente programadas no computador e exigem a mínima intervenção de usuários. Estas métodologias podem ser vistas como métodos de ajustamento de curvas com parâmetros sequencialmente atualizados no tempo. Dentre os métodos do tipo Caixa-Preta, podem ser citados, como por exemplo, os modelos de regressão linear simples, regressão linear múltipla e com transformações de Box \& Cox, modelos de Médias Móveis, e os métodos de Amortecimento (ou Alisamento) Exponencial (MAE) (Souza, 1989).

Em 1970, surgiu o método Box \& Jenkins que foi um dos grande responsáveis pela formalização da área de análise e previsão de série temporais. O método Box \& Jenkins é o principal marco de referência de tempo neste campo e provocou um processo de grande 
desenvolvimento, atraindo a atenção dos estatísticos. Devido a sua grande importância, este método será mais detalhadamente estudado na seção 2.2 .

Em 1971 é lançado na literatura o primeiro método de previsão univariado e bayesianos que foi proposto por Harrison e Stevens (Harrison e Stevens, 1971). Os métodos bayesianos causaram um grande impacto na área, pois ofereceram uma alternativa clara e promissora para a formulação de verdadeiros sistemas de previsão. A filosofia bayesiana permitiu o relaxamento das restrinções de estacionariedade exigidas por quase todo os métodos elássicos. Isto ocorre através de uma evolução dinâmica dos parâmetros de seus modelos.

Nos anos seguintes, outras inovações metodológicas univariadas foram desenvolvidas, tanto para abordagem clássica quanta para a bayesiana. Os métodos de Filtro Adaptativo, Combinação de Previsão e modelos Bayesianos Não Gaussianos (Souza, 1989) são apenas alguns exemplos de tentativa de melhorias desenvolvidas para os métodos univariados.

Os métodos de Função de Transferência sugiram também logo após o aparecimento do método Box \& Jenkins. Alguns exemplos desta categoria são o Método Box \& Jenkins de Função de Transferência, o Método de Função de Transferência Bayesiana e os Modelos Estruturados (Souza, 1989).

A operacionalização dos métodos multivariados ainda não está colocada de forma elara e acessível para qualquer tipo de usuário. A literatura especializada existente é bastante escassa, podendo apenas ser citados como exemplos os modelos MARMA de Box \& Tío e Espaço de Estados de Mehra (Souza, 1989).

\subsubsection{Redes Neurais Artificiais}

As Redes Neurais Artificiais são modelos matemáticos baseados na estrutura e funcionamento do cérebro humano. Originalmente, elas foram aplicadas em tarefas em que sua fonte inspiradora possui bom desempenho, como, por exemplo, reconhecimento de padrões. Contudo, a característica não linear, a capacidade de mapeamento de entrada-saída e a habilidade de representação de relacionamentos temporais de seus modelos têm chamado a atenção dos pesquisadores da área de previsão de série temporais.

Uma das arquiteturas de RNAs que foi pioneiramente empregada para a previsão de séries temporais foi proposta por Lapedes e Faber (Lapedes e Faber, 1987). Lapedes e Faber criaram uma RNA do tipo MLP cujos neurônios da camada de entrada representavam algumas observações passadas $z_{t-1}, z_{t-2}, \ldots, z_{t-n}$ de uma série temporal. Estas observações eram utilizadas pela rede para gerar sua previsão em um neurônio da camada de saída. Infelizmente, esta 
abordagem não é parcimoniosa e a quantidade de informação passada $n$ tem que ser determinada empiricamente. Consequentemente, várias melhorias têm sido propostas.

Uma destas melhoria é a aplicação conjunta de Redes Neurais Artificias e do método Box \& Jenkins (Drossu \& Obradovic, 1996). O objetivo desta abordagem é a utilização de recursos do método Box \& Jenkins para a definição de alguns parâmetros livres da arquitetura neural.

Os métodos de poda de RNAs têm sido vastamente utilizados para tornar as Redes Neurais mais parcimoniosas em previsão de séries temporais. Estes métodos são geralmente empregados como uma técnica de seleção de variáveis através da redução sucessiva de arquitetura de rede neural em busca de uma generalização melhor.

Uma outra característica interessante, que alguns modelos de Redes Neurais possuem, é a capacidade de extrair e representar relacionamentos temporais. Isto é realizado através da atribuição de memória às arquiteturas das RNAs. Esta memória pode ser de curto prazo ou de longo prazo. O modelo TDNN utiliza memórias de curto prazo nas camadas intermediárias e de saída. As redes recorrentes de Elman e Jordan fazem o uso de memórias de longo prazo.

\subsection{Método Box \& Jenkins}

O método Box \& Jenkins (Box et al., 1970) utiliza integralmente informações teóricas e práticas para construção de modelos para previsão de séries temporais. Grande parte das informações que alimentam este processo são derivadas a partir de dados experimentais. A Figura 2.3 ilustra as etapas de identificação, estimação e checagem de modelos que formam o método.

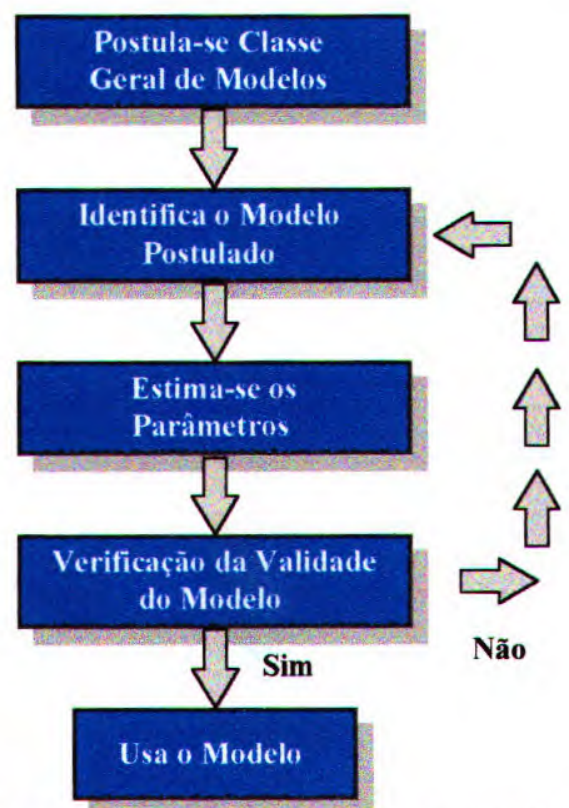

Figura 2.3: Etapas para Previsão de Séries Temporais através do método Box \& Jenkins. 
A fase de identificação inicia-se a partir da escolha de uma classe geral de modelos (por exemplo, os modelos lineares). Dentro desta classe, métodos de identificação são empregados para a determinação da subclasse de modelo mais apropriada como, por exemplo, modelos autoregressivos de ordem $p$. Esta identificação de subclasse permite ainda a determinação de alguns parâmetros preliminares, como a ordem do modelo.

Em seguida, o modelo identificado é adaptado à série temporal através da estimação de seus parâmetros em termos da maximização da função de verosemelhança.

Finalmente, a validade do modelo selecionado pode ser verificada, buscando identificar eventuais falhas e suas possíveis causas. Se o modelo escolhido não for adequado, os estágios de identificação, estimação e verificação são repetidos até que uma representação aceitável seja obtida.

Como um dos objetivos de trabalho é utilizar um método de construção de arquiteturas de Redes Neurais baseados no método Box \& Jenkins, as duas próximas subseções enfocarão os principais componentes, que são os modelos Box \& Jenkins e a técnica empregada para identificá-los, para execução desta tarefa.

\subsubsection{Modelos}

Os modelos de Box \& Jenkins são baseados no pressuposto de que uma série temporal com valores sucessivos altamente dependentes pode ser gerada a partir de uma série de ruídos brancos $a_{t}$ independentes (Box et al., 1970). Esses ruídos geralmente assumem uma distribuição Normal com média $E\left(a_{t}\right)=0$ e variância $\operatorname{Var}\left(a_{t}\right)=\sigma_{a}^{2}$. O processo de ruídos $a_{t}$ é transformado em um processo $z_{t}$ através de um filtro linear, conforme mostra a Figura 2.4.

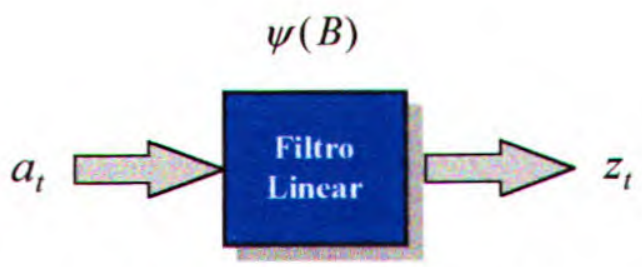

Figura 2.4: Filtro Linear.

Este filtro linear simplesmente realiza uma soma ponderada dos ruídos das observações anteriores, resultando em um modelo genérico, ilustrado pela Equações 2.2. 


$$
z_{1}=\mu+a_{1}+\psi_{1} a_{t-1}+\psi_{2} a_{t-2}+\ldots=\mu+\psi(B) z_{t}
$$

em que $\mu$ é um parâmetro que determina o nível médio do processo, $B$ é um operador de retardo $\left(B^{k} z_{t}=z_{t-k}\right)$ e $\psi(B)$ é o polinômio caractcrístico ou função de transferência do filtro linear, dado pela Equação 2.3 .

$$
\psi(B)=1-\psi_{1} B-\psi_{2} B^{2}-\ldots
$$

O modelo da Equação 2.2 pode ainda ser simplificado aplicando a construção da Equação 2.4, o que resultaria na representação ilustrada pela Equação 2.5.

$$
\begin{gathered}
\widetilde{z}_{\mathfrak{\prime}}=z_{\imath}-E\left(z_{\imath}\right) \\
\widetilde{z}_{\mathfrak{t}}=\psi(B) a
\end{gathered}
$$

Se o polinômio $\psi(B)$, seja ele finito ou infinito, for convergente para $|B| \leq 1$, o filtro linear é estável e o processo $\widetilde{z}$ é estacionário.

Uma série temporal pode também ser equivalentemente representada como uma combinação linear de seus valores passados, como ilustram as Equações 2.6 e 2.7.

$$
\begin{gathered}
z_{t}=\mu+a_{t}+\pi_{1} z_{t-1}+\pi_{2} z_{t-2}+\ldots= \\
\left(1-B \pi_{1}-B^{2} \pi_{2}-\ldots\right) z_{t}=\pi(B) z_{t}=\mu+a_{t} \\
\pi(B) \tilde{z}_{t}=a_{t}
\end{gathered}
$$

O processo representado pela Equação 2.7 é inversível se o polinômio $\pi(B)$ for convergente para $|B|<1$.

Os modelos genéricos das Equações 2.5 e 2.7 não são muito úteis na prática, devido ao número infinito de parâmetros $\psi_{j}$ e $\pi_{j}$ que devem ser estimados. Assim, são necessários modelos que sejam parcimoniosos. Em outras palavras, tais modelos devem ser capazes de representas uma série temporal da maneira mais simplificada possível. Os modelos Box \& Jenkins seguem este pressuposto. Suas principais características serão apresentadas a seguir. 


\subsubsection{Modelos Lineares Estacionário}

Os dois modelos Box \& Jenkins primordiais que podem ser usados para representar séries tcmporais estacionárias são o Modelo Auto-regressivo de ordem $p(A R(p))$ e o Modelo Médias Móveis de ordem $q(M A(q))$. O modelo Auto-regressivo e Médias Móveis de ordem $p$ e $q$ $(A R M A(p, q))$ é apenas uma combinação das características dos modelos anteriores.

\subsection{Modelo AR(p)}

O modelo $A R(p)$ descreve basicamente a observação $z$, de uma série temporal como uma soma ponderada de $p$ valores passados $z_{t-1}, z_{t-2}, \ldots, z_{t-n}$ adicionado a um ruído branco atual $a_{t} \mathrm{e}$ a uma constante $\mu . \wedge$ Equação 2.8 ilustra formalmente tal descrição:

$$
z_{t}=\mu+a_{t}+\phi_{1} z_{t-1}+\phi_{2} z_{t-2}+\ldots+\phi_{p} z_{t-p}
$$

em que $\phi_{1}, \phi_{2}, \ldots, \phi_{p}$ são os parâmetros ajustáveis e $p$ é a ordem do modelo. $O$ ruído branco $a_{t}$ geralmente possui distribuição normal com $E\left(a_{t}\right)=0$ e $\operatorname{Var}\left(a_{t}\right)=\sigma_{a}^{2}$.

A aplicação da construção ilustrada pela Equação 2.4 resulta em um modelo simplificado, mostrado pela Equações 2.9 e 2.10 .

$$
\begin{gathered}
\widetilde{z}_{t}=a_{t}+\phi_{1} \widetilde{z}_{t-1}+\phi_{2} \widetilde{z}_{t-2}+\ldots+\phi_{p} \widetilde{z}_{t-p} \\
\phi_{n}(B) \widetilde{z}_{t}=a_{t}
\end{gathered}
$$

em que $\phi_{n}(B)$ é o polinômio característico do modelo $A R(p)$ ilustrado através da Equação 2.11 .

$$
\phi_{p}(B)=1-\phi_{1} B-\phi_{2} B^{2}-\ldots-\phi_{p} B^{p}
$$

A comprovação da estacionaridade do modelo $\widetilde{z}$, é realizada verificando se o polinômio $\psi(B)=\phi_{p}^{-1}(B)$ é convergente para $|B| \leq 1$. Isto significa que os módulos das raizes $G_{f}^{-1}, i=1,2, \ldots, p$ do polinômio da Equação 2.11 devem estar fora do círculo de raio unitário $\left(\left|G_{i}^{-1}\right|>1\right)$. 
A média de um modelo auto-regressivo estacionário é calculada pela Equação 2.12 a partir do processo $z$, da Equação 2.8 , uma vez que a sua versão simplificada $\tilde{z}$, possui média nula. Ambas as representações apresentam a mesına variância, cujo cálculo pode ser mais facilmente realizado a partir da versão simplificada, conforme ilustra a Equação 2.13 .

$$
\begin{gathered}
E\left(z_{1}\right)=\frac{\mu}{1-\phi_{1}-\phi_{2}-\ldots-\phi_{p}} \\
\operatorname{Var}\left(\widetilde{z}_{l}\right)=\gamma_{0}=\sigma_{a}^{2}+\sum_{j=1}^{p} \phi_{j} \gamma_{j}=\frac{\sigma_{a}^{2}}{1-\sum_{j=1}^{p} \phi_{j} \rho_{j}}
\end{gathered}
$$

A auto-covariância $\gamma_{1}$ ć detcrminada através do valor esperado $E\left(\widetilde{z}_{1} \widetilde{z}_{t+j}\right)$ o que resulta no cálculo recursivo dacko pela liquaçấo 2.14.

$$
\begin{gathered}
\gamma_{j}=E\left[\left(\widetilde{z}_{i}\right)\left(a_{i+j}+\sum_{i=1}^{p} \phi_{i} \widetilde{z}_{l+l-1}\right)\right]=E\left(\widetilde{z}_{i} a_{l}\right)+E\left(\sum_{i=1}^{p} \phi_{i} \widetilde{z}_{l+j-i} \widetilde{z}_{l}\right)= \\
=\sum_{i=1}^{p} \phi_{i} E\left(\widetilde{z}_{i+j-l} \widetilde{z}_{l}\right)= \\
=\sum_{i=1}^{p} \phi_{i} \gamma_{j-i}
\end{gathered}
$$

A auto-correlação $\rho_{j}$ é facilmente calculada a partir da divisão da auto-covariância da Equação 2.14 pela variância do processo determinada pela Equação 2.13.

$$
\rho_{j}=\frac{\gamma_{j}}{\gamma_{0}}=\sum_{i=1}^{p} \phi_{i} \frac{\gamma_{j-1}}{\gamma_{0}}=\sum_{i=1}^{n} \phi_{i} \rho_{j-1}
$$

As equações geradas a partir da definição da auto-correlação $\rho_{j}$ para diferentes valores de $j=1,2, \ldots, p$ são conhecidas como equações de Yule-Walker. Estas equações podem também ser representada através da Equação 2.16.

$$
\phi_{p}(B) \rho_{j}=0
$$


A solução das equações de Yule-Walker em função das raízes $G_{l}^{-1}, i=1,2, \ldots, p$ do polinômio $\phi_{p}(B)=0$ é escrita pela Equação 2.17 , que permite analisar o comportamento da função de auto-correlação (FAC).

$$
\rho_{j}=A_{1} G_{1}^{j}+A_{2} G_{2}^{j}+\ldots+A_{p}, G_{p}^{j}
$$

em que $A_{1}, A_{2}, \ldots, A_{p}$ são constantes. Se o modelo é estacionário, as raízes $G_{i}^{-1}, i=1,2, \ldots, p$ são números complexos com módulos $\left|G_{\imath}^{-1}\right|>1$ e, por conseqüência, $\left|G_{i}\right| \leq 1$. Isto significa que $\rho_{j}$ decai exponencialmente e/ou oscilando a medida que o valor de $j$ aumenta. Tal fato resulta em um comportamento similar ao ilustrado pela Figura 2.5.

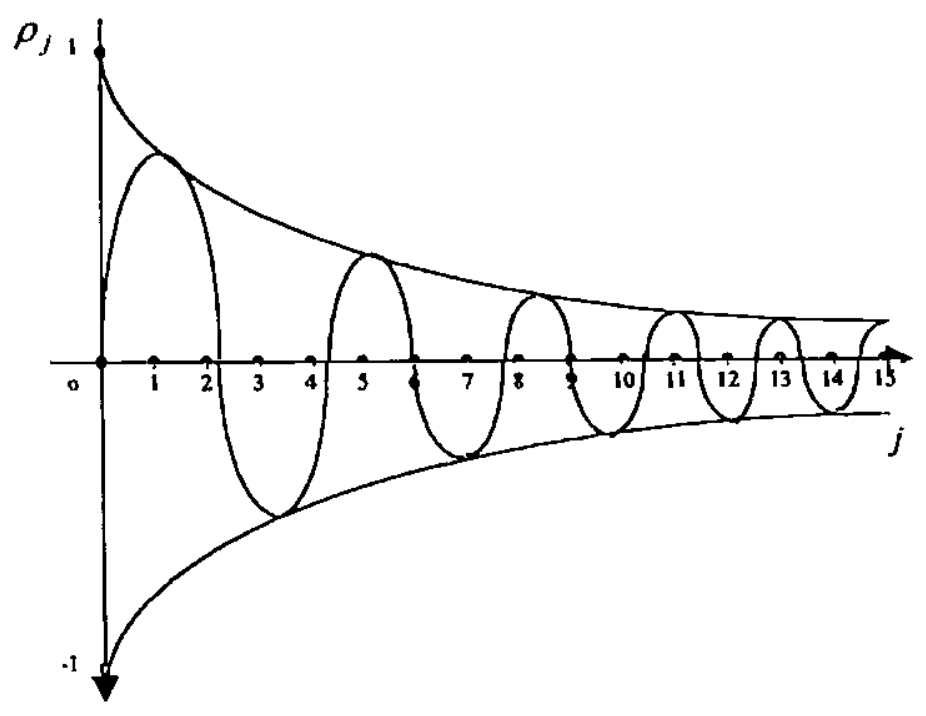

Figura 2.5: Comportamento da função de auto-correlação de um $A R(p)$.

A ordem $p$ do modelo $A R(p)$ é determinada através da verificação do comportamento da função de auto-correlação parcial (FACp). Dado um modelo $A R(k)$, pode-se denotar $\phi_{k j}$ e $\phi_{k k}$ como sendo respectivamente o j-ésimo e o último coeficiente deste modelo. Assim, a Equação 2.18 representa a Equação de Yule-Walker para o processo considerado.

$$
\rho_{j}=\phi_{k 1} \rho_{j-1}+\phi_{k 2} \rho_{j-2}+\ldots+\phi_{k k} \rho_{j-k}
$$


A função de auto-correlação parcial (FACp) é determinada pelo valor do parâmetro $\phi_{k k}$ que é calculado a partir da função de auto-correlação, através da suposição de que o processo é gerado por um modelo $A R(k)$. Desta forma, a função de auto-correlação parcial possui o comportamento ilustrado através da Equação 2.19.

$$
\begin{aligned}
& \phi_{k k} \neq 0, k \leq p \\
& \phi_{k k}=0, k>p
\end{aligned}
$$

$O$ valor da FACp é diferente de zero somente para valores de $k$ menores do que a ordem $p$ do processo auto-regressivo $A R(p)$. Os valores da função de auto-correlação parcial se anulam para qualquer valor de $k$ maior do que a ordem do processo.

\subsection{Modelo MA(q)}

O modelo $M A(q)$, ilustrado pela Equação 2.20, representa o valor $z_{t}$ de uma série temporal como a média do processo $\mu$ e o ruído branco $a$, adicionados a uma soma ponderada de $q$ ruidos brancos passados independentes $a_{t-1}, a_{t-2}, \ldots a_{t-q}$ :

$$
z_{1}=\mu+a_{1}+\theta_{1} a_{t-1}+\theta_{2} a_{t-2}+\ldots+\theta_{q} a_{t-q}
$$

em que $\theta_{1}, \theta_{2}, \ldots, \theta_{q}$ são os parâmetros e $q$ é a ordem do modelo.

A transformação da Equação 2.4 permite simplificar o modelo da Equação 2.20, produzindo as representações equivalentes ilustradas pelas Equações 2.21 e 2.22.

$$
\begin{gathered}
\widetilde{z}_{1}=a_{1}+\theta_{1} a_{t-1}+\theta_{2} a_{t-2}+\ldots+\theta_{q} a_{t-q} \\
\widetilde{z}_{1}=\theta_{q}(B) a,
\end{gathered}
$$

em que $\theta_{q}(B)$ é o polinômio característico do modelo $M A(q)$ definido pela Equação 2.23 .

$$
\theta_{q}(B)=1-\theta_{1} B-\theta_{2} B^{2}-\ldots-\theta_{q} B^{q}
$$


Um modelo $M A(q)$ é sempre estacionário, pois o polinômio $\theta_{q}(B)$ é finito, o que torna $\psi(B)=\theta_{q}(B)$ sempre convergente para $|B| \leq 1$.

Pelas mesmas razões do processo $A R(p)$, a média e a variância de um modelo $M A(q)$ são calculadas respectivamente a partir da representação original e da versão simplificada do processo, conforme ilustram as Equações 2.24 e 2.25 .

$$
\begin{gathered}
E\left(z_{l}\right)=\mu \\
\operatorname{Var}\left(\widetilde{z}_{l}\right)=\gamma_{0}=\sigma_{a}^{2}\left(1+\sum_{j=1}^{q} \phi_{j}^{2}\right)
\end{gathered}
$$

A auto-covariância $\gamma_{j}$ é calculada detcrminando-sc o valor espcrado $E\left(\tilde{z}_{1} \tilde{z}_{t+j}\right)$ através da Equação 2.26.

$$
\begin{gathered}
\gamma_{j}=E\left[\left(a_{t}-\theta_{1} a_{t-1}-\ldots-\theta_{q} a_{t-q}\right)\left(a_{t+j}-\theta_{1} a_{t+j-1}-\ldots-\theta_{q} a_{t+j-q}\right)=\right. \\
=\left\{\begin{array}{c}
\sigma_{a}^{2}\left(-\theta_{j}+\sum_{i=1}^{q} \theta_{l} \theta_{j}\right), j \leq q \\
0, j>q
\end{array}\right.
\end{gathered}
$$

O cálculo da auto-correlação $\rho$, se dá diretamente a partir da razão entre a autocovariância da Equação 2.26 e variância ilustrada pela Equação 2.25:

$$
\rho_{j}=\left\{\begin{array}{r}
\frac{-\theta_{j}+\sum_{i=1}^{q} \theta_{i} \theta_{1}}{1+\sum_{j=1}^{q} \theta_{j}^{2}}, j \leq q \\
0, j>q
\end{array}\right.
$$

A observação do comportamento da função de auto-correlação, ilustrado pela Figura 2.6, fornece subsídios suficientes para identificar um modelo médias móveis e, além disso, determinar a sua ordem $q$. Ao contrário do modelo $A R(p)$, a queda exponencial não se prolonga infinitamente. A partir de valores de $j$ maiores que a ordem $q$ do processo, os valores da função de auto-correlação se anulam, conforme ilustra a Equação 2.27. 


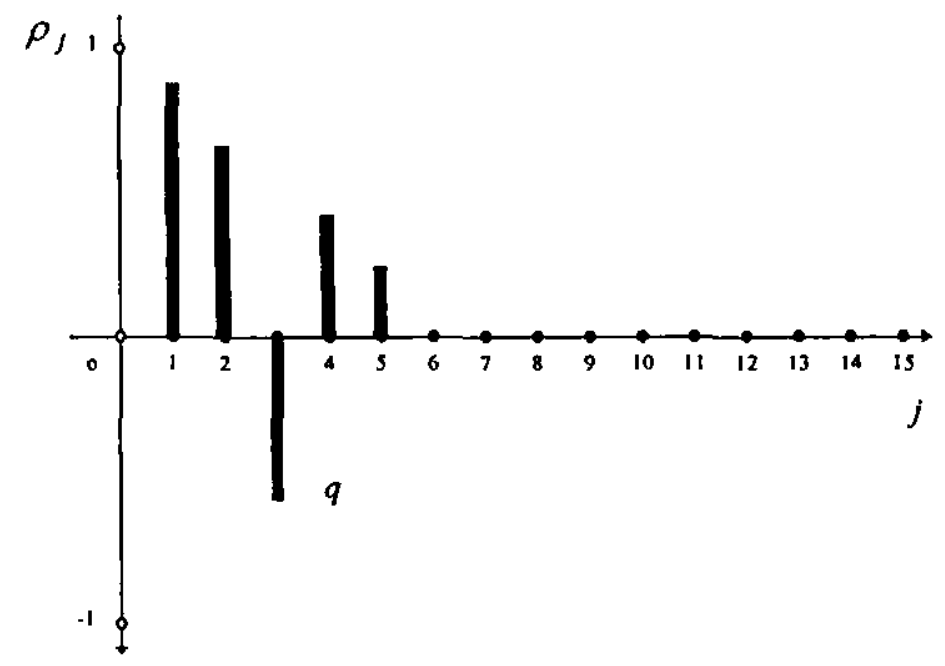

Figura 2.6: Comportamento da função de auto-correlação de um $M A(q)$.

\subsection{Modelo ARMA(p,q)}

O modelo $\operatorname{ARMA}(p, q)$ é uma combinação das características dos dois modelos anteriores. Como pode-se observar na Equação 2.28, um valor de uma série temporal representada por este modelo é definido a partir de uma soma ponderada de $p$ valores e $q$ ruídos independente anteriores.

$$
z_{t}=\mu+\phi_{1} z_{t-1}+\ldots+\phi_{p} z_{t-p}+a_{t}-\theta_{1} a_{t-1}-\ldots-\theta_{q} a_{t-q}
$$

A descrição do modelo dada pela Equação 2.28 pode ser simplificada, resultando nas Equações 2.29 e 2.30 .

$$
\begin{gathered}
\tilde{z}_{t}=\phi_{1} \tilde{z}_{t-1}+\phi_{2} \tilde{z}_{t-2}+\ldots+\phi_{n} \tilde{z}_{t-n}+a_{t}-\theta_{1} a_{t-1}-\theta_{2} a_{t-2}-\ldots-\theta_{q} a_{t-q} \\
\phi_{n}(B) \tilde{z}_{t}=\theta_{q}(B) a_{t}
\end{gathered}
$$

O modelo $A R M A(p, q)$ é estacionário se o polinômio $\psi(B)=\theta_{q}(B) \phi_{p}^{-1}(B)$ converge para $|B| \leq 1$. Assim, este modelo é estacionário se a sua parte auto-regressiva for estacionária.

A função de auto-covariância é calculada como o valor esperado da multiplicação de $\widetilde{z}_{t}$ por $\widetilde{z}_{t-k}$, resultando na fórmula genérica ilustrada pela Equação 2.31 . 


$$
\gamma_{j}=\phi_{1} \gamma_{j-1}+\phi_{2} \gamma_{j-2}+\ldots+\phi_{p} \gamma_{j-p}+\gamma_{z a}(j)-\theta_{1} \gamma_{z a}(j-1)-\theta_{2} \gamma_{z a}(j-2)-\ldots-\theta_{q} \gamma_{z a}(j-q)(2
$$

em que $\gamma_{z a}(j)=E\left(\widetilde{z}_{t-j} a_{t}\right)$ é a função de correlação cruzada entre a série $z$ e o ruído $a_{1}$. Uma vez que $\widetilde{z}_{t-j}$ depende somente de ruídos que ocorreram até o instante $t-j$, esta função de correlação cruzada possui o comportamento ilustrado pela Equação 2.32.

$$
\begin{aligned}
& \gamma_{z a}(j)=0, j>0 \\
& \gamma_{z a}(j) \neq 0, j \leq 0
\end{aligned}
$$

A função auto-correlação do modelo $\operatorname{ARMA}(p, q)$ é sempre influenciada pcla sua porção auto-regressiva. A parte médias móveis apenas atuará efetivamente no comportamento da FAC quando existir a correlação cruzada entre a série $\tilde{z}$ e o ruído $a_{\imath}$. Isso acontece somente para valores de $j$ menores que a ordem $q$ da porção médias movéis. A Equação 2.33 resume tal comportamento da função de auto-correlação.

$$
\rho_{j}=\left\{\begin{array}{l}
\phi_{1} \rho_{j-1}+\phi_{2} \rho_{j-2}+\ldots+\gamma_{p} \rho_{j-p}, j \geq q+1 \\
\phi_{1} \rho_{j-1}+\phi_{2} \rho_{j-2}+\ldots+\gamma_{p} \rho_{j-p}+\frac{\gamma_{z a}(j)}{\gamma_{0}}-\theta_{1} \frac{\gamma_{z a}(j-1)}{\gamma_{0}}-\theta_{2} \frac{\gamma_{z a}(j-2)}{\gamma_{0}}-\ldots-\theta_{q} \frac{\gamma_{z a}(j-q)}{\gamma_{0}}, j \leq q
\end{array}\right.
$$

\subsubsection{Modelo Lineares Não Estacionários}

Os modelos Box \& Jenkins não-estacionários foram elegantemente extendidos a partir do modelos estacionários. A idéia principal consiste em aplicar transformações sobre uma dada série temporal no sentido de torná-la estacionária. Assim sendo, é possível identificar e ajustar um dos modelos descritos na seção anterior para a série modificada.

O mais famoso representante desta subclasse de modelos é o Auto-regressivo e Média Moveis Integrado de ordens $p$ e q e o número de operações de diferenciação $d(A R I M A(p, d, q))$. Contudo, antes de apresentar os aspectos mais relevantes do $\operatorname{ARIMA}(p, d, q)$ será discutido um exemplo bastante simples de modelo não estacionário conhecido como random walk. Tal exemplo permitirá ilustrar mais facilmente os conceitos básicos do modelo $\operatorname{ARIMA}(p, q, d)$.

\subsection{Modelo Random Walk}

Seja o modelo $A R(I)$ ilustrado pela Equação 2.34: 


$$
\tilde{z}_{1}=a_{1}+\phi_{1} \tilde{z}_{1}
$$

onde $\phi_{1}(B)=1-\phi_{1} B$ é o polinômio característico do processo. () modelo é cstacionário sc o polinômio $\psi(B)=\frac{1}{1-\phi_{1} B}$ for convergente para $|B| \leq 1$. Isso significa que a estacionaridade será garantida quando $\left|\phi_{1}\right|<1$ para $|B| \leq 1$. Supondo que o parâmetro $\phi_{1}$ seja igual a 1 , o modelo da Equação 2.35 passa a ser não estacionário.

$$
\widetilde{z}_{t}=a_{1}+\widetilde{z}_{t-1}
$$

Este modelo é conhecido como random walk e utiliza somente o valor anterior da série para previsão do próximo passo. A média e a variância de um modelo random walk são nulas e as funções de auto-covariância e auto-correlação são constantes, conforme ilustram as Equações 2.36 e 2.37 .

$$
\begin{gathered}
\gamma_{j}=E\left(\tilde{z}_{t} \tilde{z}_{t-j}\right)=E\left[\left(\widetilde{z}_{t-1}+a_{t}\right) \widetilde{z}_{t-j}\right]=E\left(\tilde{z}_{t-1} \tilde{z}_{t-j}\right)=\gamma_{j-1} \\
\rho_{j}=\frac{\gamma_{j}}{\gamma_{0}}=\frac{\gamma_{j-1}}{\gamma_{0}}=\rho_{j-1}
\end{gathered}
$$

O cálculo recursivo da auto-correlação realizada pela Equação 2.37 e o fato de que $\rho_{0}=1$ provocam o comportamento apresentado pela Figura 2.7. 


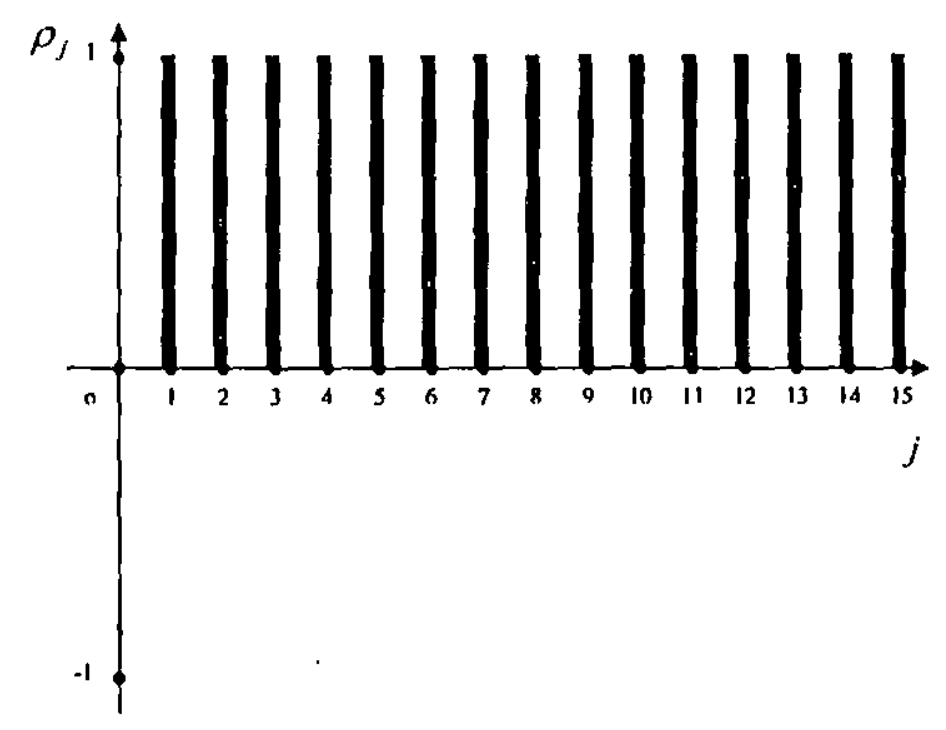

Figura 2.7: Comportamento da função de auto-correlação de um Random Walk.

Assim, para concluir que um processo com média nula, variância nula e função de autocorrelação constante é random walk, basta construir o processo $\widetilde{w}_{t}=\widetilde{z}_{t}-\widetilde{z}_{t-1}$ e provar que se trata de um ruído branco.

\subsection{Modelo ARIMA(p,d,q)}

O modelo $A R I M A(p, q, d)$ é derivado a partir do modelo $A R M A(p, q)$ e pode eliminar tendências lineares e mudança de níveis. Como foi visto anteriormente, o modelo $A R M A(p, q)$ é estacionário se sua parte auto-regressiva for estacionária. Em outras palavras, as raizes $G_{l}^{-1}$ do polinômio $\phi_{p}(B)$ têm que estar fora do raio de círculo unitário para $|B|<1$. Assim, seja o modelo ilustrado pela Equação 2.38:

$$
\varphi(B) \tilde{z}_{i}=\theta_{q}(B) a_{i}
$$

em que $\varphi(B)$ é o polinômio da parte auto-regressiva do processo. Vamos supor que $\varphi(B)$ possui $p$ raízes fora do círculo de raio unitário e $d$ raizes iguais a 1 . Assim, pode-se escrever:

$$
\varphi(B)=\phi_{p}(B)(1-B)^{d}
$$


em que $\phi_{p}(B)$ é o polinômio característico da parte auto-regressiva estacionaria definido através da Equação 2.11. Denotando o operador de diferença $\nabla=(1-B)$, o modelo da Equação 2.38 pode ser representado através da Equação 2.40:

$$
\phi_{p} \nabla^{d} \widetilde{z}_{i}=\theta_{q}(B) a_{1}
$$

que é chamado de modelo Auto-Regressivo e Médias Móveis Integrado de ordens $p$ e $q$ e diferenciação $d(A R I M A(p, d, q))$.

Em termos práticos, o modelo $\operatorname{ARIMA}(p, d, q)$ transforma uma série temporal não-

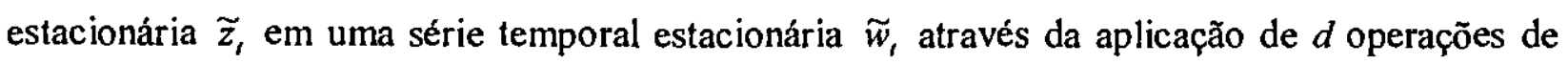
diferenciação, con forme ilustrada pela Equação 2.41.

$$
\widetilde{w}_{1}=\nabla^{d} \widetilde{z}_{t}=(1-B)^{d} \widetilde{z}_{1}
$$

Desta forma, a série $\widetilde{w}$, pode ser representada por alguns dos modelos estacionários descritos anteriormente. A título de exemplo, as Equações 2.42 e 2.43 apresentam como seria definido $\widetilde{w}_{\text {, }}$ para uma ou duas operações de diferenciação, respectivamente.

$$
\begin{gathered}
w_{t}=(1-B) z_{\imath}=z_{t}-B z_{t}=z_{t}-z_{t-1} \\
w_{t}=(1-B)^{2} z_{t}=\left(1-2 B+B^{2}\right) z_{t}=z_{t}-2 z_{t-1}+z_{t-2}
\end{gathered}
$$

\subsubsection{Identificação do Modelo}

Um dos métodos de identificação do modelo Box \& Jenkins mais apropriados para representar uma dada série temporal é baseado no comportamento das funções de autocorrelação e auto-correlação parcial. Esta análise consiste na comparação do comportamento teórico destas funções com o comportamento de seus estimadores calculados a partir da série (Box et al., 1970).

$\Lambda$ ocorrência de uma queda exponencial lenta da FAC indica não estacionaridade, levando à necessidade de executar derivações na série temporal. O comportamento da FAC de um $A R(p)$ é completamente diferente da FAC de um $M A(q)$, conforme ilustram as Figuras 2.3 e 2.4. A FAC de um $A R(p)$ apresenta uma queda exponencial, com ou sem oscilações, que 
prossegue até o infinito. A FAC de um $M A(q)$ apresenta valores nulos a partir da ordem $q$ do processo. Mesmo assim, é necessário avaliar a função de auto-correlação parcial para distinguir entre um modelo $A R(p)$ e um $A R M A(p, q)$.

A avaliação do comportamento das funções de auto-correlação e auto-correlação parcial é realizada a partir de suas estimativas. Dadas as amostragens $z_{1}, z_{2}, \ldots, z_{N}$ de uma série temporal, é possível calcular o estimador $r$, da FAC (Box et. al, 1970) através da Equação 2.44.

$$
r_{j}=\frac{c_{j}}{c_{0}}
$$

em que $c_{k}$ e $c_{o}$ são os estimadores da função de auto-covariância e da variância da série temporal que são calculados através da Equação 2.45.

$$
c_{j}=\frac{1}{N-j} \sum_{i=1}^{N-j}\left(z_{i}-\bar{z}\right)\left(z_{i+j}-\bar{z}\right)
$$

O valor $\bar{z}$ é a média estimada através da Equação 2.46 .

$$
\bar{z}=\frac{1}{N} \sum_{t=1}^{N} z_{t}
$$

O estimador da função de auto-correlação parcial é calculado através da aplicação recursiva das Equações 2.47 e 2.48 .

$$
\begin{aligned}
& \hat{\phi}_{k+1, j}=\hat{\phi}_{k, j}-\hat{\phi}_{k+1, k+1} \hat{\phi}_{k, k-j+1} \\
& \hat{\phi}_{k+1, k+1}=\frac{r_{k+1}-\sum_{j=1}^{k} \hat{\phi}_{k, j} r_{p+1-j}}{1-\sum_{j=1}^{k} \hat{\phi}_{k, j} r_{j}}
\end{aligned}
$$

A seguir serão apresentadas as Redes Neurais Artificiais que é um método alternativo de previsão que vêm atraindo a atenção de diversos pesquisadores da área. 


\subsection{Redes Neurais}

Historicamente, as Redes Neurais Artificiais surgiram do interesse de produzir um modelo computacional capaz de desempenhar funções similares àquelas realizadas pelo cérebro humano. Desta forma, uma RNA pode ser sucintamente definida como:

Um processador paralelo e distribuido que possui uma tendência natural de armazenar conhecimento experimental e torná-lo disponivel para o uso. Ele se assemelha ao cérebro humano em dois aspectos:

1. O conhecimento é adquirido pela rede através de um processo de aprendizagem;

2. A força de conexão entre as unidades ou neurônios, conhecidos como pesos sinápticos ou simplesmente pesos, são utilizados para armazenar o conhecimento. (Haykin, 1994).

A estrutura e a capacidade de aprendizagem das RNAs são apresentadas em maiores detalhes a seguir:

\subsubsection{Estrutura}

A unidade fundamental de processamento de informação de uma RNA é conhecida como neurônio. A organização e estrutura das conexões existentes entre os neurônios definem a arquitetura da rede.

\subsubsection{Neurônio}

O neurônio artificial é um processador muito simples que é responsável pelo processamento do conhecimento adquirido pela rede. Em termo estruturais, tais neurônios são genericamente compostos por um conjunto de conexões de entrada, um corpo celular, uma função de ativação, uma função de saída e um terminal de saída, conforme ilustra a Figura 2.8. 


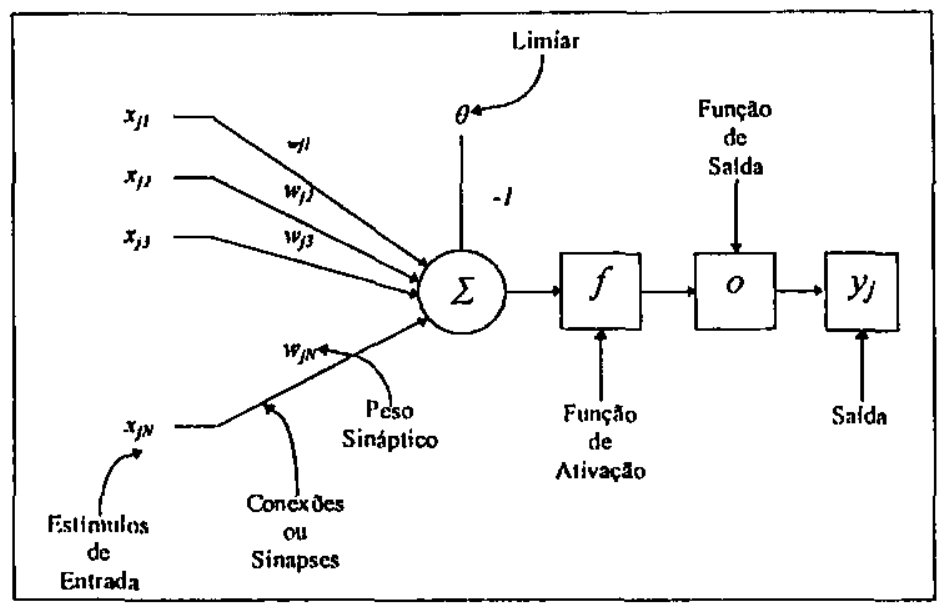

Figura 2.8: Neurônio Arlificial

$\Lambda$ s conexões são canais de comunicação entre ncurônios. $\Lambda$ cada conexão é associada um peso sináptico que representa a sua intensidade.

O corpo celular realiza uma soma ponderada de cada estímulo de entrada pelo seu peso correspondente. Esta soma quando subtraida de um termo $\operatorname{limiar} \theta$ (threshold) produz a entrada da rede, conforme ilustra a Equação 2.49.

$$
n e l_{j}(1)=\sum_{i=1}^{N} w_{j}(l) x_{i}-\theta
$$

A função de ativação $f\left(n e t_{j}(l)\right)$ determina o estado de ativação de um neurônio. O estado de ativação pode assumir valores binários ( 0 para inativo e 1 para ativo), bipolares $(-1$ e 1$)$ ou reais. As funções de ativação mais conhecidas são:

1. Função Sinal $\left(f(x)=\left\{\begin{array}{l}-1, \text { se } x \leq 0 \\ +1, \text { se } x>0\end{array}\right)\right.$ que gera saídas binárias ou bipolares.

2. Função Identidade $(f(x)=x)$ que gera estados de ativação com valores reais.

3. Função Logística $\left(f(x)=\frac{1}{1+e^{-x}}\right)$ que produz valores reais entre 0 e 1 como estados de ativação.

4. Função Tangente Hiperbólica $(f(x)=\tanh (x))$ que produz valores reais entre -1 e 1 como estado de ativação. 
A função de saída $o\left(f\left(\right.\right.$ net $\left.\left._{j}(t)\right)\right)$ é computada sobre o seu estado de ativação e geralmente é uma função identidade.

\subsubsection{Arquitetura}

Os neurônios de uma RNA são geralmente dispostos em camadas. De uma maneira genérica, as arquiteturas apresentam uma camada de entrada, zero ou mais camadas intermediárias ou escondidas e uma camada de saída.

A camada de entrada é responsável apenas pela captação dos estímulos externos e sua distribuição para a camada intermediária ou de saída seguinte. A camada de saída apresenta apenas a resposta produzida pela rede para uma dada entrada. Entre as camadas de entrada e saída pode haver uma ou mais camadas intermediárias, cujas saídas dos neurônios não são acessadas por procedimentos externos à rede.

Estas camadas são geralmente completamente conectadas. Isto significa que os neurônios de uma dada camada, excluindo a camada de saída, estão interligados a todos os neurônios da camada posterior.

As arquiteturas das primeiras RNAs não apresentavam camadas intermediárias, como por exemplo, as Single Layered Perceptron (SLP), Adaptative Linear Element (ADALINE) e Many ADALINE (MADALINE) (Haykin,1994). Posteriormente, surgiram as redes Multi Layered Percepton (MLP) com uma ou mais camadas intermediárias que permitem a realização de mapeamentos não lineares de funções mais complexas. Estes tipos de arquiteturas são chamadas de feedforward, uma vez que os estímulos exteriores produzem sinais dentro da rede que fluem da camada de entrada em direção à saída.

Além de RNAs feedforward, existem redes recorrentes, cujos os neurônios são realimentados com as saídas geradas em instantes anteriores por neurônios da mesma camada ou de camadas posteriores (Haykin,1994).

\subsubsection{Aprendizagem}

As Redes Neurais possuem a habilidade de "aprender" relacionamentos pertencentes a um dado conjunto de exemplos ou padrões, melhorando seu desempenho ao longo do tempo. Esta aprendizagem ocorre através de um processo iterativo de ajustes dos parâmetros livres da sua arquitetura (pesos sinápticos e limiares).

Ao conjunto de regras bem utilizadas para ajustar os parâmetros da RNA dá-se o nome de algoritmo de aprendizagem. Os algoritmos podem ser por correção de erros, competição, 
hebbianos ou máquinas de Boltzmann. A maneira como os exemplos são apresentados para a rede define os três paradigmas de aprendizado: supervisionado, reforço e não supervisionado. No aprendizado supervisionado, existe a figura externa de um professor indicando exatamente o que a Rede Neural deve aprender. No paradigma de aprendizagem por reforço a rede aprende através de um processo de recompensa, quando seu desempenho é melhorado, ou punição, caso contrário. No aprendizado não supervisionado, a Rede Neural aprende exemplos por si próprio, sem nenhum auxílio externo.

A maioria das aplicações de RNAs envolvem algoritmos de aprendizagem supervisionada por correção de erros. Backpropagation (Rumelhart et. al, 1986) é o algoritmo mais empregado para a treinamento deste tipo de redes. As seções seguintes apresentam maiores detalhes sobre este algoritmo e suas possíveis estratégias de aperfeiçoamento.

\subsubsection{Algoritmo Backpropagation}

A versão original do algoritmo Backpropagation ajusta os pesos de uma RNA para cada padrão ou exemplo apresentado individualmente. O processo continua até que se obtenha um desempenho global aceitável.

Os padrões podem ser representados por um vetor $X_{n}=\left[x_{p_{1}}, x_{p 2}, \ldots, x_{p N}\right]^{T}$ e são submetidos à RNA através da sua camada de entrada que simplesmente os redistribui para a primeira camada intermediária. Cada neurônio da próxima camada recebe os sinais provenientes da camada anterior, pondera-os pelos pesos das suas conexões e gera um novo sinal para a camada posterior. O processo continua até chegar à camada de saída, onde os neurônios irão produzir a resposta da RNA para o padrão em questão. Neste ponto, inicia-se os ajustes de pesos e limiares que irão acontecer da camada de saída em direção à camada de entrada.

Os ajustes são realizados de maneira a minimizar a função de erro para um dado padrão, que é ilustrada pela Equação 2.50:

$$
E_{p}=\frac{1}{2} \sum_{j}\left(d_{n j}-y_{n j}\right)^{2}
$$

em que $d_{p}$ é a saída desejada para o padrão $p$ e $y_{p}$ é a saída produzida pela RNA para o padrão em questão. 
A derivada parcial $\frac{\partial E_{p}}{\partial w_{j l}}$ rege o ajuste dos pesos, denotando o aspecto de gradiente descendente do algoritmo. Esta derivada mede a contribuição do peso $w_{j l}$ no erro da RNA para um dado padrão $p$. Se esta derivada for positiva, o peso $w_{f i}$ está provocando um aumento da diferença entre a saída da rede e a saida desejada. Assim, a sua intensidade tem que ser diminuida para aproximá-las e, consequentemente, reduzir o etro. Se a derivada for negativa, o peso $w_{f t}$ está contribuindo para que a reposta produzida pela rede seja mais próxima da desejada. Desta forma, o seu valor deve ser aumentado. A Equação 2.51 define matematicamente como os pesos da rede são modificados.

$$
\Delta w_{j l}=w_{j l}(t+1)-w_{j l}(t)=\eta\left(-\frac{\partial E_{p}}{\partial w_{j i}}(t)\right)
$$

em que $w_{f i}$ é o peso da conexão existente entre os neurônios $i$ e $j, j$ é o neurônio cujo o peso se deseja ajustar, $i$ é um neurônio da camada anterior e $\eta$ é a taxa de aprendizagem. $O$ cálculo da derivada da Equação 2.51 resulta na regra genérica de ajuste de pesos do algoritmo Backpropagation ilustrada pela Equação 2.52 .

$$
w_{j l}(t+1)=w_{j l}(t)+\eta \delta_{\mathrm{j}} y_{l}
$$

em que $\delta_{j}=\left(d_{p j}-y_{p j}\right)$ se o neurônio $j$ pertencer a camada de saída e $\delta_{j}=\sum_{k} \delta_{k} w_{j k}$ se o neurônio $j$ pertencer a qualquer camada intermediária da RNA.

A escolha de uma taxa de aprendizagem $\eta$ apropriada influencia fortemente o tempo necessário para a convergência do algoritmo. Se esta taxa for muito pequena, muitos passos podem ser necessários para alcançar uma solução aceitável. Por outro lado, a escolha de uma taxa elevada pode provocar oscilações que impediriam a convergência. Uma possível medida para amenizar este problema é a introdução do termo momentum $\alpha$ que quantifica o grau de importância da variação de peso do passo anterior no passo atual:

$$
w_{j l}(t+1)=w_{j l}(t)+\eta \delta_{\mathrm{j}} y_{1}+\alpha\left\lfloor w_{j l}(t)-w_{j l}(t-1)\right\rfloor
$$


Embora o termo momentum teoricamente torne o algoritmo de aprendizagem mais estável e acelere a convergência em regiões planas da função de erro, a escolha otimizada do parâmetro $\alpha$ também não é uma tarefa simples.

\subsubsection{Algoritmo Rprop}

Diversos algoritmos têm sido propostos para otimizar o algoritmo Backpropagation através de algum tipo de adaptação de seus parâmetros de aprendizagem. Estes algoritmos podem basicamente ser divididos em duas categorias: adaptação global e local (Schiffmann et al., 1992).

As técnicas de adaptação global utilizam conhecimento da situação da RNA como um todo (direção dos ajustes anteriores dos pesos) para modificar parâmetros globais. Em outras palavras, elas tentam encontrar parâmetros de aprendizagem adequados (taxa de aprendizagem e termo momentum) durante a execução do algoritmo.

As técnicas de adaptação local empregam somente informações específicas sobre cada peso (derivada parcial) para adaptar parâmetros que lhe são relacionados. Estas estratégias de adaptação local se mostraram superiores aos algoritmos de adaptação global em um relatório técnico recentemente publicado (Schiffmann et al., 1992). Entre estas técnicas, podem ser citados os algoritmos Delta-Bar-Delta (Haykin, 1994), Quickprop (Schiffmann et al., 1992) e o RPROP(Riedmiller e Braun, 1993).

O algoritmo de aprendizagem RPROP (Relisient Backpropagation) foi proposto por Martin Riedmiller e Hieinrich Braun e executa uma adaptação direta do ajuste dos pesos baseada em informações do gradiente local. Ao contrário do Backpropagation, este algoritmo emprega uma regra de treinamento batch, que utiliza a função de erro da Equação 2.54 calculada sobre todos os padrões de treinamento para direcionar o ajuste de pesos.

$$
E=\sum_{p} \sum_{j}\left(d_{p j}-y_{p j}\right)^{2}
$$

em que $p$ é índice para os padrões ou exemplos de treinamento e $j$ é o índice para os neurônios da camada de saida.

Ao contrário de outras técnicas de adaptação local desenvolvidas anteriormente, o esforço de adaptação do algoritmo RPROP não é determinado diretamente pelo procedimento de gradiente descendente. Um valor de adaptação individual $\Delta_{f l}(t)$ foi introduzido para determinar 
o tamanho do ajuste de cada peso. Estes valores de adaptação evoluem durante o processo de aprendizagem de acordo com uma visão local da função de crro. $O$ ajuste destes valores é ilustrado pela Equação 2.55 .

$$
\Delta_{j l}(t)=\left\{\begin{array}{cl}
\eta^{+} \Delta_{j l}(t-1), \text { se } & \frac{\partial E}{\partial w_{j l}}(t-1) \frac{\partial E}{\partial w_{j l}}(t)>0 \\
\eta^{-} \Delta_{f l}(t-1), \text { se } & \frac{\partial E}{\partial w_{j l}}(t-1) \frac{\partial E}{\partial w_{j t}}(t)<0 \\
\Delta_{j l}(t-1), & \text { caso contrário }
\end{array}\right.
$$

em que $0<\eta^{-}<1<\eta^{+}$. No início da execução do algoritmo, os valores de atualização são inicializados com $\Delta_{0}$, o que determina o tamanho do primeiro ajuste dos pesos. A escolha de $\Delta_{0}$ não é tão crucial e o valor sugerido em (Riedmiller e Braun, 1993) é $\Delta_{0}=0.1$. Para que não haja problemas de estouro de variáveis de ponto flutuante, os valores de atualização $\Delta_{j}$ são limitados inferiormente e superiormente por $\Delta_{\min }$ e $\Delta_{\max }$, respectivamente. Os valores sugeridos (Riedmiller e Braun, 1993) para estes parâmetros são $\Delta_{\min }=1.0 \times 10^{-6}$ e $\Delta_{\max }=50.0$.

Se a derivada parcial da função de erro em relação ao peso $w_{j}$ mantém o seu sinal, o valor de atualização $\Delta_{j l}$ é suavemente incrementado por um fator $\eta^{+}$para acelerar a convergência em regiões planas. Por outro lado, se esta derivada muda de sinal, o valor de atualização é decrementado por um fator $\eta^{-}$, pois o último ajuste foi maior do que o necessário e o algoritmo ultrapassou um ponto de mínimo. Se uma das derivadas parciais do instante $t$ ou $t+l$ for nula, $o$ valor de atualização se mantém. Com o intuito de reduzir o número de parâmetros livres do algoritmo, as taxas de decréscimo $\bar{\eta}$ e acréscimo $\eta^{+}$dos valores de atualização foram fixadas pelos autores (Riedmiller e Braun, 1993) em 0.5 e 1.2, respectivamente. Uma vez calculados os valores de atualização, o ajuste dos pesos é dado pelas Equações 2.56 e 2.57 .

$$
\Delta w_{j l}(t)=\left\{\begin{array}{c}
-\Delta_{j}(t), \text { se } \frac{\partial E}{\partial w_{j}}(t)>0 \\
+\Delta_{j l}(t), \text { se } \frac{\partial E}{\partial w_{j}}(t)<0 \\
0, \text { caso contrário }
\end{array}\right.
$$




$$
w_{j l}(t+1)=w_{j l}(t)+\Delta w_{j l}(t)
$$

Se a derivada parcial for positiva (indicando que o erro está aumentando), o peso é decrementado pelo seu valor de atualização $\Delta_{j i}$. Se esta derivada for negativa (erro está diminuindo), o peso é incrementado por $\Delta_{\mu}$. Caso contrário, o peso permanece constante. Contudo, existc uma exceção à regra que ocorre quando a derivada parcial altera seu sinal. Neste caso, o ajuste de peso do passo anterior foi muito grande e um ponto de mínimo foi ultrapassado. Assim, é necessário inverter o sinal do último ajuste de peso através da Equação 2.58.

$$
\Delta w_{l y}(t)=-\Delta w_{l y}(t-1), \text { se } \frac{\partial E}{\partial w_{l y}}(t-1) \frac{\partial E}{\partial w_{l j}}(t)<0
$$

Tal inversão pode novamente provocar a alteração do sinal da derivada no próximo passo, resultando em uma dupla punição do valor de atualização. Para que isto seja evitado, é necessário que não haja uma outra adaptação do valor de atualização no passo seguinte. $\mathrm{Na}$ prática, isto pode ser realizado determinando $\frac{\partial E(t-1)}{\partial w_{j l}}=0$ na regra de adaptação de $\Delta_{j i}$ da Equação 2.55 .

Durante a execução dos algoritmos Backpropagation, Rprop ou outras regras de aprendizagem supervisionadas, as saídas da rede vão gradativamente se aproximando das saídas desejadas para um conjunto de padrões de treinamento. Embora esta característica seja importante, o aspecto mais desejado da utilização de Redes Neurais é a sua capacidade de generalizar. Em outras palavra, uma RNA deve também manter um desempenho adequado para os padrões que não estavam presentes em seu conjunto de treinamento.

A generalização nem sempre pode ser alcançada e seria interessante que a estabilização do processo de aprendizagem não fosse apenas determinada pelo desempenho alcançado para o conjunto de treinamento. Assim sendo, a capacidade de generalização precisa também ser assegurada.

\subsubsection{Generalização}

A generalização de uma Rede Neural Artificial diz respeito a sua capacidade de produzir respostas adequadas e coerentes para padrões ou exemplos de teste diferentes daqueles empregados em seu treinamento. A avaliação da generalização pode ser utilizada como critério 
de parada do processo de aprendizagem (Haykin, 1994). Assim é estabelecido um compromisso entre o desempenho de treinamento e teste da RNA. Se a RNA extrai relacionamentos demasiadamente específicos do conjunto de treinamento (memorização), seu desempenho de resposta é afetada mesmo para padrões de teste suavemente diferentes dos padrões de treinamento.

Existem três condições que são tipicamente necessárias, embora não suficientes, para a obtenção de uma boa generalização.

A primeira condição exige que as entradas da rede contenham informações suficientes que permitam o aprendizado de uma função matemática capaz de correlacionar-lhes às saídas corretas com um certo grau de precisão. Não se pode esperar que uma RNA aprenda funções que não existem no conjunto de treinamento. A seleção de boas variáveis de entrada e a coleta de dados de treinamento suficientes pode geralmente requisitar mais tempo e esforço gasto do que o próprio treinamento da rede.

A segunda condição determina que a função, que a rede esta tentando aprender, deve de ser um tanto suave. Em outras palavras, pequenas alterações nas entradas não devem, na maior parte do tempo, provocar modificações bruscas em suas saidas. Funções sem este tipo de comportamento apresentam dificuldades para serem generalizadas por RNAs.

Finalmente, a terceira condição determina que os padrões selecionados para o treinamento formem um subconjunto suficientemente grande e representativo a partir de um conjunto total de padrões que se deseje generalizar. A importância desta condição está relacionada ao fato de existir dois tipos de generalização: interpolação e extrapolação. A interpolação se aplica aos casos que estão mais ou menos ao redor dos exemplos de treinamento. Por outro lado, a extrapolação é requisitada para os exemplos que estão fora do alcance dos dados de treinamento. A interpolação é geralmente bastante confiável, o que não se pode dizer da extrapolação. Desta forma, seria adequado possuir um conjunto de treinamento suficientemente grande para evitar a necessidade de extrapolação.

Assim sendo, três fatores influenciam diretamente a capacidade de generalização de uma RNA:

\section{Arquitetura;}

2. Tamanho e abrangência do conjunto de treinamento;

3. Complexidade do problema em questão. 
As técnicas geralmente empregadas para assegurar uma generalização adequada basicamente se preocupam com a arquitetura e o conjunto de dados utilizados para realizar o treinamento. Existem diversas técnicas de estimativa do erro de generalização que podem basicamente ser divididas em duas classes: estimadores algébricos e métodos que particionam o conjunto de dados disponíveis (por exemplo, Random sub-sampling, v-fold cross-validation e bootstrapping). A técnica Random sub-sampling é as vezes apenas chamada de cross-validation (Prechelt, 1994) e consiste de aplicą̧ões sucessivas de particionamentos aleatórios dos dados disponiveis em dados de treinamento e validação. A média dos erros dos dados de validação é considerada como sendo a estimativa do erro de generalização.

$O$ processo de aprendizagem pode enfrentar problemas como underfiting e overfiting. Arquiteturas muito pequenas, com um número reduzido de parâmetros livres (pesos das conexões e limiares), muitas vezes não são capazes de extrair relacionamentos complexos do conjunto de treinamento, conduzindo ao problema de underfitting. Por outro lado, o treinamento de arquiteturas excessivamente grandes pode extrair relacionamentos extremamente especificos do conjunto de treinamento (memorização), até mesmo se confundindo com ruídos, o que provocaria o problema de overfitting.

A ocorrência de overfitting faz com que as saídas da RNA sejam excessivamente tendenciosas aos padrões de treinamento, enquanto underfitting ocasiona o aumento da variância das saídas da RNA. Uma arquitetura teoricamente otimizada deveria ser um meio termo entre estes dois problemas. Em outras palavras, tal arquitetura deveria ser grande suficiente para aprender o necessário sobre o conjunto de treinamento e pequena o suficiente para generalizar.

A escolha da melhor arquitetura através de abordagem empírica têm estimulado o surgimento de outras alternativas mais eficientes. Apesar da existência de outras técnicas, como redes construtivas e algoritmos genéticos, apenas os métodos de poda serão considerados nesta dissertação para desempenhar tal tarefa. $O$ interesse em métodos de poda também se deve a sua habilidade na seleção de variáveis que pode ser aplicado no contexto de séries temporais.

\subsubsection{Métodos de Poda de RNAs}

Os métodos de poda de RNAs (pruning methods) reduzem a quantidade de parâmetros livres das arquiteturas das RNAs com o intuito de minimizar o erro de generalização. De acordo com Reed (Reed, 1993), a maioria dos métodos de poda podem ser divididos em dois grandes grupos: 
1. Métodos de Cálculo de Sensibilidade. Estes métodos estimam a sensibilidade da função erro em relação a remoção de um elemento (conexão ou neurônio) e eliminam aquele que possui menor efeito. Este método apenas modifica as arquiteturas após elas serem treinadas.

2. Métodos de Termos de Penalidade. Tais métodos adicionam termos à função erro para compensar a rede pela escolha de soluções excessivamente eficientes em seu treinamento, evitando overfitting. Os métodos de termos de penalidade eliminam conexões durante o processo de aprendizagem, não permitindo que o ajuste de seus pesos ocasione uma queda demasiada do erro de treinamento. Os termos de penalização mais conhecidos são as funções weigh-decay (Haykin, 1994).

Embora ambos os grupos aparentem constituir soluções interessantes para o problema de generalização, os métodos de cálculo da sensibilidade parecem ser a escolha mais adequada para a seleção de variáveis em previsão de séries temporais. Esta decisão foi tomada porque tais métodos proporcionam a oportunidade de explicitamente visualizar os elementos de entrada mais relevantes. Isto ocorre em conseqüência da eliminação das outras entradas sem muita importância.

\subsubsection{Métodos de Cálculo da Sensibilidade}

O procedimento básico dos métodos de poda baseados no cálculo da sensibilidade inicia com o treinamento de uma arquitetura excessivamente grande, provocando overfitting. Em seguida, as sensibilidades são calculadas e o primeiro elemento é selecionado para a poda. A arquitetura resultante é então retreinada. Se este retreinamento convergir, novos parâmetros da arquitetura são podados e a rede retreinada. Caso contrário, a última arquitetura é pequena o suficiente para ter uma boa generalização e não levar ao overfitting, encerrando então o processo de poda.

Existem três aspectos fundamentais que os métodos de cálculo de sensibilidade devem considerar: quais conexões ou neurônios devem ser selecionados para poda, quando a poda deve ser executada e quando o processo deve terminar.

O aspecto crucial destes métodos é a heurística utilizada para determinar quais conexões ou neurônios devem ser removidos. Algumas heuristicas famosas de poda (Thimm e Fiesler, 1997) são apresentadas a seguir: 


\subsection{Método da menor magnitude.}

A heurística mais simples de poda considera o valor absoluto das conexões como estimativa de sua sensibilidade (Thimm e Fiesler, 1997). Às vezes, esta heurística simples pode conduzir a eliminação de pesos errados. Os menores pesos podem também ser necessários para baixar a taxa de erro.

\subsection{Skeletonization.}

O método skeletonization foi proposto por Mozer e Smolensky (Mozer e Smolensky, 1991) e estima a sensibilidade dos neurônios para podar os menos importantes. A medida de relevância $S_{i}$ é considerada como a diferença entre o erro ocasionado pela remoção do neurônio e o erro provocado pela sua permanência. $\mathrm{O}$ cálculo desta relevância é realizado através da adição de um termo $\alpha_{i}$ a saída do neurônio $i$. Assim, o somatório ponderado para neurônio $j$ da camada subsequente passa a ser calculado através da Equação 2.59.

$$
n e t_{j}=\sum_{i} w_{j} \alpha_{i} y_{i}
$$

Se $\alpha_{i}=0$, o neurônio não tem influência no desempenho da RNA. Por outro lado, se $\alpha_{i}=1$ o neurônio influencia o desempenho e deve ser mantido. Desta forma, a relevância $S_{i}$ pode ser expressa através da Equação 2.60 .

$$
S_{1}=E_{\alpha=0}-E_{\alpha=1}
$$

A estimativa de $S_{t}$ é definida pela derivada da Equação 2.61, que pode ser calculada de forma semelhante ao processo executado pelo algoritmo Backpropagation.

$$
\hat{S}_{i}=-\left.\frac{\partial E}{\partial \alpha_{i}}\right|_{\alpha_{i}=1}
$$

Se a estimativa da relevância cair abaixo de um certo nível, a unidade pode ser eliminada. O problema desta estimativa é que quando a derivada parcial tende a zero, o valor da função erro diminui. Apesar de ser um comportamento desejável pelos algoritmos de gradiente descendente, 
isto resulta em uma estimação fraca da sensibilidade. Assim Mozer e Smolensky sugeriram alterar a função de erro quadrática através da Equação 2.62.

$$
E=\sum_{p} \sum_{j}\left|d_{n j}-y_{n j}\right|
$$

\subsection{Método de Karnin}

E. D. Karnin (Karnin, 1990) propôs uma abordagem para estimar a sensibilidade em relação a remoção de cada conexão e podar os pesos com baixa sensibilidade. A sensibilidade $S_{j t}$ da conexão $w_{j l}$ é definida através da Equação 2.63.

$$
S_{j l}=-\frac{E\left(w_{j}=w_{j t}^{f}\right)-E\left(w_{j i}=0\right)}{w_{j i}^{f}-0} w_{j l}^{f}
$$

onde $w_{j i}^{f}$ é o valor do peso depois do treinamento. Em um típico processo de aprendizagem, os pesos das conexões são geralmente inicializados com pequenos valores aleatório não nulos. Uma vez que o valor de $E$ para $w_{i j}=0$ é desconhecido, a declividade da função de erro é aproximada pela declividade média calculada entre $w_{j t}^{\prime}$ e $w_{j t}^{f}$ ilustrado pela Equação 2.64.

$$
S_{j l} \approx-\frac{E\left(w_{j t}=w_{j i}^{f}\right)-E\left(w_{j t}=w_{j t}^{i}\right)}{w_{j t}^{f}-w_{j i}^{\prime}} w_{l j}^{f}
$$

onde $w_{j l}^{l}$ é o valor do peso da conexão no início do treinamento. A estimativa genérica da sensibilidade do método de Karnin é facilmente calculada através da Equação 2.65, cujos termos estão disponíveis durante o processo normal de treinamento.

$$
\hat{S}_{j t}=-\sum_{n=0}^{N-1} \frac{\partial E}{w_{j t}} \Delta w_{j t}(n) \frac{w_{j t}^{\prime}}{w_{j t}^{f}-w_{j t}^{\prime}}
$$

No caso especial do algoritmo backpropagation, os pesos șa ajustados através da Equação 2.5 I, o que simplifica o cálculo da estimativa ilustrado pela Equação 2.66. 


$$
\hat{S}_{j l}=-\sum_{n=0}^{N-1}\left[\Delta w_{j l}(n)\right]^{2} \frac{w_{\mu l}^{\prime}}{w_{j l}^{S}-w_{\mu l}^{\prime}}
$$

\subsection{Optimal Brain Damage}

O método Optimal Brain Damage foi proposto por LeCun, Denker e Solla (Le Cun et al, 1990) e seleciona conexões da rede cuja remoção produz pouco efeito no Erro Médio Quadrático (MSE) de treinamento. A heurística aproxima o valor do MSE em um ponto de mínimo do espaço de pesos através de uma expansão quadratica da diagonal da matriz Hessiana. Assim, a sensibilidade é calculada através da Equação 2.67,

$$
\hat{S}_{j l}=\frac{1}{2} h_{j} w_{j l}^{2}
$$

em que $h_{i j}$ é a diagonal da matriz de Hessiana definida através da Equação 2.68:

$$
h_{k l}=\frac{\partial^{2} M S E}{\partial w_{k} \partial w_{l}}
$$

\subsection{Consideraçōes finais}

Atualmente, previsão de séries temporais é uma área bem definida no campo de Estatística devido, em grande parte, ao surgimento do método Box \& Jenkins na década de 70. Além de ser responsável pela formalização dos métodos de análise e previsão de séries temporais, o método Box \& Jenkins serviu como base para o desenvolvimento metodológico da área. Diversos avanços metodológicos foram sugeridos, principalmente após ao seu aparecimento. A maioria dos modelos apenas se baseiam nos dados históricos da série de interesse. Entretanto, já existem modelos que são também capazes de correlacionar informações referentes a outras adicionais.

Infelizmente, a maioria dos modelos estocásticos de previsão são lineares. Esta limitação têm incentivado a busca por novos métodos alternativos. As RNAs aparentam ser promissoras em previsão de séries temporais. Originalmente, seus modelos são não lineares e, além disso, são capazes de extrair e representar relacionamentos temporais. Finalmente, as arquiteturas das RNAs podem ser modeladas para considerar informação tanto referente apenas a série de interesse quanto sobre séries adicionais. 


\section{Previsores Neurais}

Este capítulo apresenta algumas abordagens de projeto de Redes Neurais para previsão de séries temporais. Inicialmente, a seção 3.1 discute algumas vantagens e desvantagens de métodos de previsão baseados em RNAs. Em seguida, são apresentadas três abordagem de projeto de arquiteturas de Redes Neurais. $\Lambda$ seção 3.2 ilustra como as arquitetura das RNAs podem ser modeladas através da utilização de recursos provenientes do Método Box \& Jenkins. A seção3.3 apresenta uma técnica de seleção de variáveis baseadas nos métodos de poda de RNAs, que também pode ser aplicada no contexto de previsão. A seção 3.4 discute alguns modelos de RNAs com capacidade dinâmica que podem ser muito úteis para o tipo de tarefa em questão. Além disso, a seção 3.5 discute a finalidade e a utilidade de realizar combinações de previsão. Finalmente, a seção 3.6 apontam as principais considerações abordadas neste capítulo.

\subsection{Vantagens e Desvantagens}

Redes Neurais Artificiais supervisionadas têm sido empregadas na solução de diversos problemas práticos de regressão, como previsão de séries temporais. As RNAs apresentam algumas características atraentes que justificam tal interesse. Elas podem aproximar qualquer tipo de função contínua, inclusive funções não-lineares complexas, através de um processo de aprendizagem. Além disso, as RNAs podem generalizar, isto é, são capazes de produzir repostas coerentes e apropriadas para padrões ou exemplos que não foram utilizados em seu treinamento. Em se tratando de previsão, esta característica é bastante desejável.

A principio, qualquer modelo de RNA capaz de receber um vetor de números reais como entrada e produzir valores reais como saída pode ser utilizada para a previsão de série temporais.

Embora as RNAs consigam extrair um modelo próprio de previsão a partir de treinamento com dados da série temporal, este modelo deve ser sempre parcimonioso. Em outras palavras, ele deve sempre buscar ser o mais simples possível, utilizando somente as variáveis de entrada com maior grau de importância. Desta maneira, a generalização é melhorada e o tempo e esforço de projeto da arquitetura podem ser minimizados.

Assim, um dos pontos de partida para obtenção de uma previsão de qualidade é a busca desta arquitetura otimizada. As técnicas de identificação de modelos do método Box \& Jenkins e os método de poda como técnicas de seleção de variáveis podem ser ferramentas úteis nesta busca. Além disso, alguns modelos de RNAs possuem propriedades de extração e representação de relacionamentos temporais que podem ser utilizadas com sucesso em previsão de séries 
temporais. Finalmente, os resultados individuais dos previsores neurais podem ser combinados por comitês de estimadores visando reduzir a taxa de erro de previșão.

\subsection{Sístema Híbrido: RNAs e Método Box \& Jenkins}

O método Box \& Jenkins para análise e previsão de séries temporais pode ser utilizado para aperfeiçoar o projeto de arquiteturas de RNAs tornando-as mais eficientes e parcimoniosas. Uma possível forma de combinação destas duas metodologia foi proposta por Drossu \& Obradovic (Drossu e Obradovic, 1996) que definiram um procedimento para o projeto previsores neurais a partir das etapas do método Box \& Jenkins. Este procedimento é descrito pela Figura 3.1.

realizar o pré-processamento;

repitir

realizar a identificação do modelo;

realizar a estimação dos parâmetros em um conjunto de treinamento;

realizar a validação modelo;

até que o modelo seja adequado

realizar a previsão;

Figura 3.I:Procedimento de projelo de RNAs para previsão.

A seguir, serão mais detalhadamente apresentadas as etapas mencionadas na figura acima.

\subsubsection{Pré-processamento}

A etapa de pré-processamento consiste basicamente em transformar uma série não estacionária em outra estacionária e suavizar os dados resultantes. A aplicação de operações de diferenciação de ordem $d$ provenientes do modelo $\operatorname{ARIMA}(p, d, q)$ pode eliminar certos tipos de comportamentos não estacionários. A transformação logarítmica $\left(w_{t}=\log _{10}\left(z_{t}\right)\right)$ pode facilitar a generalização da rede, reduzindo a sua dificuldade em aprender dados em que pequenas alterações na entrada podem resultar em grandes diferenças na saída. 


\subsubsection{Identificação do modelo}

Teoricamente, as arquiteturas feedforward e recorrentes de RNAs podem aproximar uma variação dos modelos Box \& Jenkins para tratar os casos de não linearidade (Connor e Martin, 1994 ).

\subsubsection{Redes Feedforwards}

As RNAs feedforwards podem ser empregadas para a aproximação do modelo Não linear Auto-Regressivo de ordem p NAR(p) (Drossu e Obradovic, 1996; Connor e Martin, 1994 ). Este modelo é uma generalização natural do modelo linear $A R(p)$ para o caso não linear, conforme ilustra a Equação 3.1:

$$
z_{t}=h\left(z_{t-1}, z_{t-2}, \ldots, z_{t-p}\right)+a t
$$

em que $h$ é uma função não linear suave e desconhecida. Dado quc $a$ é um rúdo branco com valor esperado $E\left(a_{t}\right)=0$ e variância $\operatorname{Var}\left(a_{t}\right)=\sigma_{a}^{2}$, o previsor ótimo de $z_{t}$ com erro quadrático mínimo é o valor esperado condicional fornecido pela Equą̧ão 3.2.

$$
\hat{z}_{t}=E\left(z_{t} \mid z_{t-1}, z_{t-2}, \ldots, z_{t-p}\right)=h\left(z_{t-1}, z_{t-2}, \ldots, z_{t-p}\right)
$$

Este previsor possui a variância $\sigma_{a}^{2}$ do ruído $a$, como erro quadrático médio.

Uma RNA feedforward pode ser utilizada justamente para aproximar a função $h$ do modelo $N A R(p)$ através de um treinamento supervisionado. Tal aproximação não linear pode ser realizada através da arquitetura da Figura 3.2 , resultando na representação matemática apresentada pela Equação 3.3.

$$
\hat{z}_{t}=h\left(z_{t-1}, z_{t-2}, \ldots, z_{t-p}\right) \approx \sum_{t=1}^{m} W_{t} f\left(\sum_{j=1}^{p} w_{\jmath t} z_{t-j}+\theta_{t}\right)
$$

onde $f$ é uma função não linear suave, limitada e monotômica como, por exemplo, a função logistica ou tangente hiperbólica. 
As entradas da rede são as observações passadas da série $z_{t-1}, z_{1-2}, \ldots, z_{t-p}$ as quais são

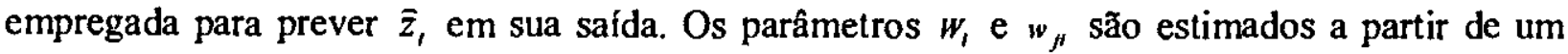
conjunto de dados de treinamento, produzindo uma estimativa $\hat{h}$ da função $h$.

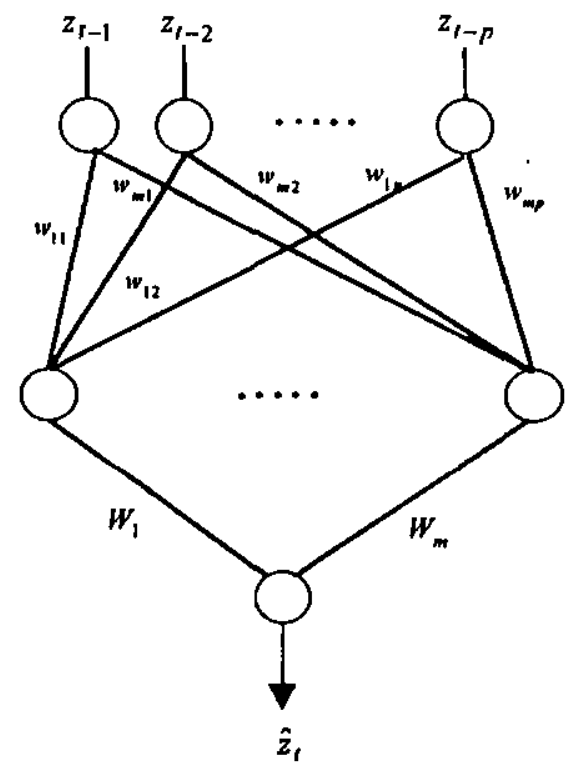

Figura 3.2: RNA feedforward para aproximação do modelo $N A R(p)$.

\subsubsection{Redes Recorrentes}

Uma generalização natural do modelo $\operatorname{ARMA}(p, q)$ para os casos não lineares é o modelo $\operatorname{NARMA}(p, q)$ (Drossu e Obradovic, 1996; Connor e Martin, 1994), cuja descrição é dada pela Equação 3.4:

$$
z_{t}=h\left(z_{t-1}, z_{t-2}, \ldots, z_{t-p}, a_{t-1}, a_{t-2}, \ldots, a_{t-q}\right)+a_{t}
$$

em que $h$ é uma função desconhecida não linear e suave e $a_{1}$ é um ruído branco. Se este modelo for inversível, a previsão da série $z_{l}$ é calculada como o valor esperado condicional da Equação 3.5 com um erro médio quadrático igual $\mathbf{a} \sigma_{a}^{2}$.

$$
\hat{z}_{1}=E\left(z_{1} \mid z_{i-1}, z_{t-2}, \ldots, z_{t-p}, a_{t-1}, a_{t-2}, \ldots, a_{t-q}\right)=h\left(z_{t-1}, z_{t-2}, \ldots, z_{t-p}, a_{t-1}, a_{t-2}, \ldots, a_{t-q}\right)
$$


A previsão realizada através do modelo $\operatorname{NARMA}(p, q)$ pode então ser aproximada através da Equação 3.6, que corresponde a arquitetura da RNA ilustrada pela Figura 3.3 (Drossu e Obradovic, 1996; Connor e Martin,.1994):

$$
\hat{z}_{t}=h\left(z_{t-1}, z_{t-2}, \ldots, z_{t-p}, a_{t-1}, a_{t-2}, \ldots, a_{t-q}\right) \approx \sum_{t=1}^{m} W_{t} f\left(\sum_{j=1}^{p} w_{j i} z_{t-j}+\sum_{j=1}^{q} w^{\prime}{ }_{j l}\left(z_{t-j}-\hat{z}_{t-j}\right)+\theta_{t}\right)
$$

em que $f$ é uma função suave e não linear semelhante a função logística ou tangente hiperbólica e a diferença $z_{t-j}-\hat{z}_{t-j}$ é o ruído branco $a_{t-j}$. Esta arquitetura recorrente memorizaria ruídos passados que seriam utilizados como futuras entradas da camada intermediária.

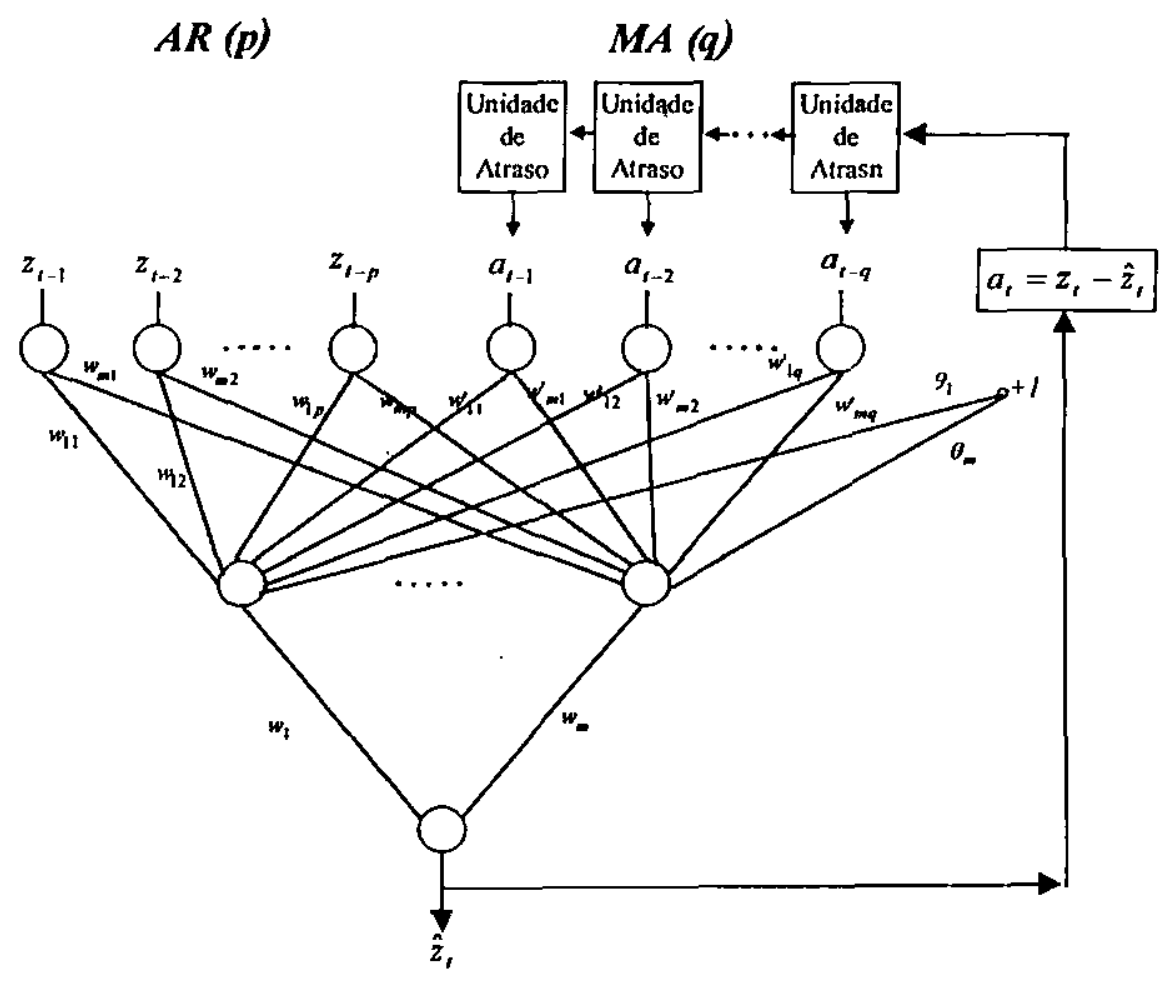

Figura 3.3: RNA recorrente para aproximação do modelo $N A R M A(p, q)$.

\subsubsection{FAC E FACP}

Devido à habilidade das RNAs em produzir aproximações dos modelos Box \& Jenkins, a análise das estimativas das funções de auto-correlação e auto-correlação parcial tem sido utilizada para acrescentar informação a priori no projeto da arquitetura neural. 
Estas funções poderiam indicar o tipo de arquitetura e dimensionar o número de neurônios na camada de entrada. Por exemplo, se a FAC e a FACp revelam um modelo $A R(p)$ para modelar o comportamento de uma série temporal, isto pode sugerir o uso de uma rede MLP com $p$ neurônios na camada de entrada. Cada um destes neurônios representa uma observação passada da série em questão.

\subsubsection{Validação do modelo}

O passo de validação verifica a adequação do modelo através da análise de resíduos dos erros de previsão de um conjunto de teste. Este conjunto é geralmente formado pelas últimas observações amostradas da série temporal. Esta checagem também pode ser realizada pela análise do critério de erro de previsão final de Akaike (Akaike, 1970) e pelo critério de informação (Drossu e Obradovic, 1996).

\subsubsection{Previsão}

Após ser treinada e validada, a rede pode ser utilizada para realizar basicamente dois tipos de previsão: 1-passo-a-frente (single-step) ou vários-passos-a-frente (multi-step).

A previsão 1-passo-a-frente ocorre quando a rede é utilizada para prever uma única observação futura ( $k=1$ passos a frente) de uma dada série temporal. Em aplicações práticas de longo prazo, este tipo de previsão tem pouca utilidade.

Assim, é necessário expandir o horizonte de previsão para $k>l$ passos a frente constituindo a chamada previsão vários-passos-a-frente (multi-step). A previsão do tipo váriospassos-a-frente pode ser realizada seguindo um modelo incremental, onde a rede prevê todos os valores intermediários da série $\left(\hat{z}_{t}, \hat{z}_{t+1}, \ldots, \hat{z}_{t+k}\right)$ até $k$ passos a frente, usando os valores previstos anteriormente para prever os próximos valores.

\subsection{Seleção de Variáveis por Métodos de Poda}

A determinação de quais entradas deveriam ser empregadas para obtenção de uma previsão otimizada pode também ser encarada como um problema de seleção de variáveis.

As técnicas tradicionais de seleção de variáveis partem da suposição de que existe inicialmente um conjunto compreendendo todas as variáveis candidatas necessárias para a resolução do problema.

As variáveis que efetivamente participariam da modelagem do problema são selecionadas a partir deste conjunto inicial. Uma vez que uma busca exaustiva aplicada sobre todos os 
subconjuntos possíveis de variáveis é computacionalmente inviável, algumas técnicas alternativas têm sido desenvolvidas. Um exemplo dessas técnicas são os métodos stepwise mencionados por Goutte (Goutte, 1996) que podem ser subdivididos em duas categorias: métodos forward selection e métodos backward elimination.

Os métodos forward selection adicionam variáveis, que são escolhidas uma após a outra, de acordo com um dado critério de seleção, a um conjunto de variáveis de entrada. Este conjunto é inicialmente vazio e o processo de adição se repete até que a condição de parada prédeterminada seja satisfeita.

Os métodos backward elimination eliminam as variáveis, uma após a outra, de acordo com um dado critério de seleção, a partir de um conjunto de variáveis de entrada, que inicialmente compreende todas as variáveis candidatas. Esta eliminação prossegue até que a condição de parada seja satisfeita.

No contexto de Redes Neurais, os métodos de poda podem ser considerados como métodos backward elimination. Neste caso, o critério de seleção pode ser a heurística de poda e o critério de parada é baseado na estimativa do erro de generalização.

Se apenas as informações sobre uma série temporal forem consideradas, as variáveis candidatas poderiam, por exemplo, representar valores passados da mesma. Desta forma, os métodos de poda selecionariam quantas observações passadas deveriam ser utilizadas para realizar a previsão.

Contudo, diversos autores (White, 1988; Mostafa, 1996) acreditam que as séries temporais também podem ser influenciadas por informações externas e que a capacidade de mapeamento das RNAs poderiam facilmente captar tais relacionamentos. Assim, as RNA possuiriam maiores subsídios para executarem uma previsão mais precisa. Os métodos de seleção de variáveis baseados em poda também seriam ferramentas úteis para evidenciar quais destes relacionamentos são mais importantes e reduzir a complexidade do modelo.

\subsection{Processamento Temporal}

Uma outra característica das Redes Neurais que pode ser utilizada em previsão de séries temporais é a capacidade que alguns de seus modelos possuem de representar o tempo. A incorporação do fator tempo na operação de uma Rede Neural lhe permite acompanhar variações estatísticas de processos não estacionários presentes em vários tipos de série temporais. Esta incorporação pode ser realizada de duas maneiras distintas: 
1. Representação Explícita: A aiternativa mais comum é uma representação espacial desta sequência, em que o fator tempo é determinado pela ordem serial das observaçðes dentro do vetor padrão. Por exemplo, se uma rede MLP fosse treinada para prever a observação $z$, de uma dada série temporal a partir de alguns de seus valores pasșaḍos $z_{t-1}, z_{t-2}, \ldots, z_{t-p}$, o padrão seria formado da seguinte maneira: o primeiro elemento representaria o valor da série no instante $t-1$, o segundo elemento representaria o instante $t-2$, e assim sucessivamente. Este tipo de abordagem possui sérias desvantagens (Elman, 1990). Inicialmente, é necessário que haja alguma interface com o mundo externo, que armazene entradas, de forma que elas possam ser apresentadas todas ao mesmo tempo. Em segundo lugar, o registrador de intervalos impõe um limite rígido na duração dos padrões devido ao fato de que a camada de entrada deve fornecer o maior padrão possível. Além disso, este registrador sugere que todos os vetores de entrada sejam do mesmo tamanho. Finalmente, o problema mais sério é que tal abordagem não distingue entre posições temporais relativa e absoluta (Eiman,1990).

2. Representação Implícita: $O$ tempo é representado pelo efeito que ele possui no processamento de sinal de uma forma implícita. Em outras palavras, isto significa dar à rede propriedades de sistemas dinâmicos que lhes permitam extrair relacionamentos temporais. Para que a rede seja dinâmica, ela deve possuir memória. Esta memória pode ser divididas em duas classes, de acordo com o tempo de retenção: memória de curto prazo e memória de longo prazo. A memória de curto prazo pode atribuir a uma RNA propriedades dinâmicas em situações que a dimensão temporal está definida. Uma maneira de realizar isto é através da utilização de defasagens de tempo (time delays) no nível de sinapse ou camada de entrada da rede em questão. A memória de longo prazo é incorporada à rede através de um processamento temporal, onde o conteúdo da informação do conjunto de treinamento é em parte ou completamente armazenado nos pesos sinápticos da rede. Isto é feito através do uso de re-alimentação (feedback) dentro da estrutura da RNA. Existe dois tipos de re-alimentação: local e global. A re-alimentação local ocorre à nível de neurônio, enquanto a re-alimentação global compreende toda a rede. Redes Neurais Artificiais com re-aliamentação são conhecidas como redes recorrentes.

Esta subseção tratará apenas de modelos de Redes Neurais que representam o tempo implicitamente com memórias de curto e longo prazo. Para memória de curto período, o modelo Time Delay Neural Network (TDNN) será aplicado para previsão. As redes recorrentes de Elman e Jordan ilustrarão a utilização de memória de longo prazo para previsão de séries temporais. 


\subsubsection{Time Delay Neural Network}

O modelo TDNN foi inicialmente projetada para reconhecimento de linguagem natural (Waibel, 1989). Entretanto, a rede TDNN tem sido também empregada para previsão de séries temporais. A rede TDNN é uma rede feedforward cujos neurônios das camadas intermediárias e de saída são replicados através do tempo. Esta replicação ocorre pela adição de um filtro de Reposta de Impulso Finito (FIR) em cada sinapse destes neurônios.

Em muitos modelos de RNAs, a unidade básica de processamento (neurônio) realiza uma soma ponderada de suas entradas e então aplica à esta soma uma função geralmente não linear (função sigmóide) para gerar sua saída. A arquitetura TDNN modificou esta unidade básica pela introdução de defasagens no tempo $\left(D_{l}\right.$ até $\left.D_{N}\right)$, como é mostrado na Figura 2.10. As $J$ entradas de cada unidade são agora multiplicadas pelos pesos do instante atual e dos instantes defasados no tempo. Desta maneira, uma unidade TDNN tem a habilidade de relatar e comparar entradas atuais com a história passada dos eventos. A função logística foi escolhida como a função de ativação $f$ da Figura 3.4 devido às suas propriedades matemáticas convenientes.

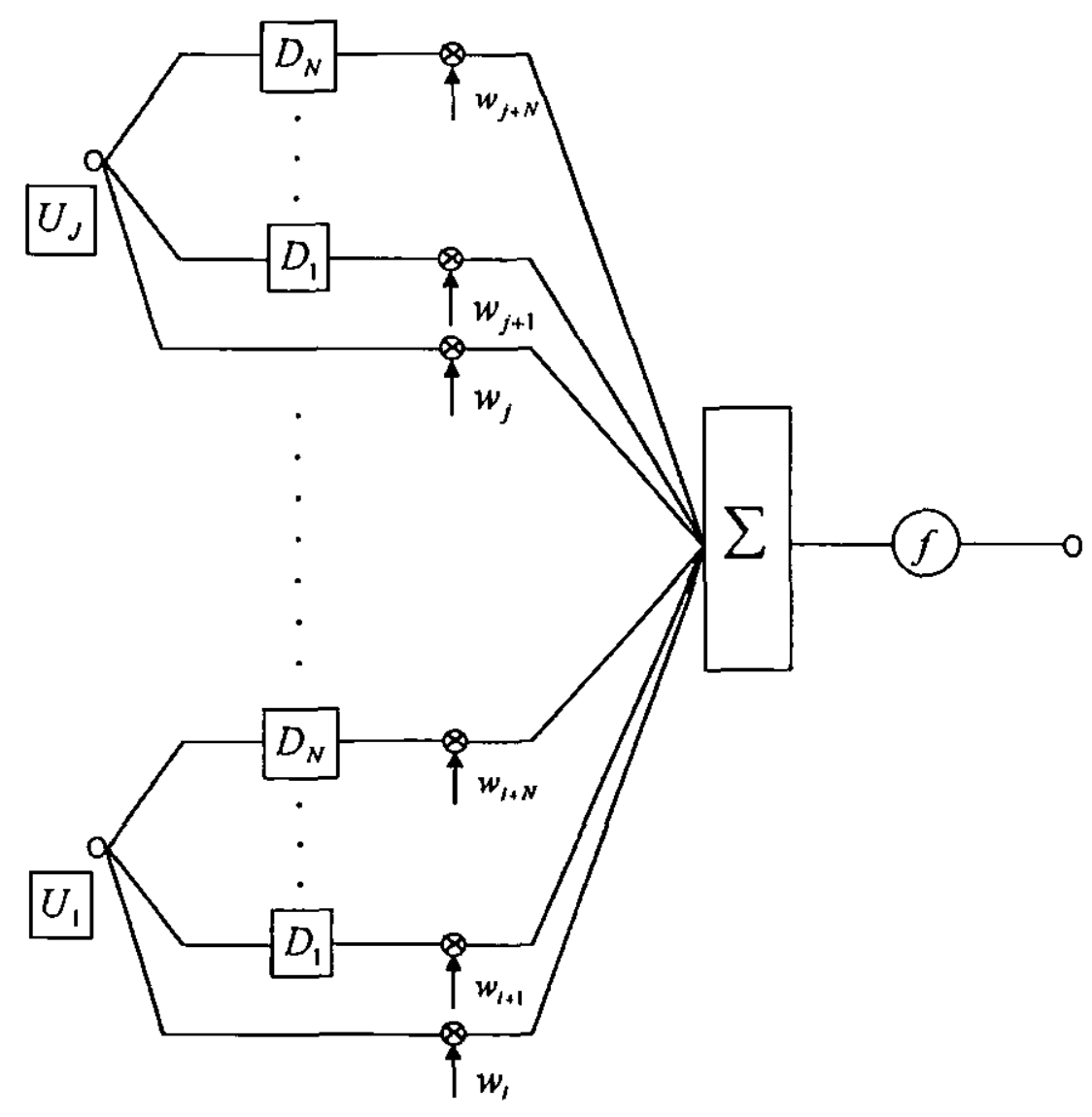

Figura 3.4: Neurônio TDNN. 
Uma arquitetura TDNN pode ser treinada com algoritmos de gradiente descendente, como, por exemplo, o Backpropagation. Contudo, algumas modificações precisam ser realizadas para que o modelo TDNN possa expressar estruturas temporais. Para obter este procedimento de aprendizagem desejado, é necessário garantir que a rede seja exposta a seqüências de padrões desejados, além de ser encorajada a aprender os mais poderosos relacionamentos temporais existentes entre tais padrões.

Conceitualmente, o algoritmo Backpropagation pode ser aplicado aos padrões deslocados ao longo do tempo. Contudo, isto é um tanto dispendioso. Um meio equivalente de obter este mesmo resultado é utilizar padrões de entradas expandidos espacialmente. Cada coleção de unidades descritas anteriormente é duplicada para cada atraso no tempo. Desta maneira, a história completa das atividades da rede fica completamente disponivel ao mesmo tempo.

Uma vez que as cópias defasadas da unidades TDNN são meramente duplicações, os pesos das conexões correspondentes de cada uma destas cópias podem ser restringidos ao mesmo valor. Isto é implementado aplicando os passos de ida e volta do algoritmo Backpropagation comum a todas as cópias defasadas no tempo, como se elas fossem eventos separados. Desta forma, são geradas diferentes derivadas de erro para cada defasagem no tempo da conexão correspondente. Ao invés de alterar os pesos de cada defasagem separadamente, cada peso é atualizado por um mesmo valor, conhecido como a média de todas as alterações dos pesos defasados no tempo de uma dada conexão.

\subsubsection{Redes Recorrentes}

A seguir são brevemente descritas as redes recorrentes de Elman e de Jordan que memorizam estados de ativação internos e externos da rede a longo prazo.

\subsubsection{Rede de EIman}

A rede Elman (Elman, 1990), ilustrada pela Figura 3.5, modifica uma arquitetura MLP através da adição de unidades extras à camada de entrada, que são chamadas de Unidades de Contexto. Estas unidades podem ser consideradas como pertencentes à camada intermediária, uma vez que interagem exclusivamente com os outros neurônios internos à rede, e não com o mundo exterior.

Desta forma, o processamento temporal consiste da seguinte seqüência de eventos. No tempo $t$, as unidades de entrada rccebem a primeira entrada da seqüência temporal. As unidades de contexto são inicialmente ativadas com o valor 0.5. Ambas as unidades de entradas e de 
contexto ativam as unidades intermediárias. Por sua vez, as unidade intermediárias propagam seus sinais para ativarem as unidades de saida. $\Lambda s$ unidades intermediárias também retropropagam seus sinais para ativarem as unidades de contexto. Dependendo da tarefa, pode ou não haver uma fase de treinamento neste ciclo. Se houver, a saída é comparada com a entrada desejada, e a retropropragação do erro é usada para ajustar os pesos das conexões incrementalmente. Os pesos das conexões recorrentes são fixados em 1.0 e não sofrem ajustes. No próximo passo, $t+l$, esta sequêencia é repetida, mas as unidades de contexto contêm valores que são exatamente as ativações das unidades intermediárias no tempo 1 . Assim, estas unidades de contexto fornecem memória à rede.

Em redes MLPs, a função das unidades intermediárias é desenvolver representações internas para os padrões de entrada, recodificando-os de modo que a rede possa produzir a saída correta para uma dada entrada. Na rede de Elman, as unidades de contexto lembram os estados internos anteriores. Assim, as unidades intermcdiárias são responsáveis pelo mapeamento tanto de uma entrada externa quanto dos estados internos anteriores. Dado que padrões nas unidades intermediárias são armazenados como contexto, as unidades intermediárias podem realizar este mapeamento e, ao mesmo tempo, desenvolver representações que são codificações úteis das propriedades temporais das entradas seqüenciais. Assim, as representações internas que se desenvolvem são sensíveis ao contexto temporal e o efeito do tempo torna-se implícito nestes estados internos. 


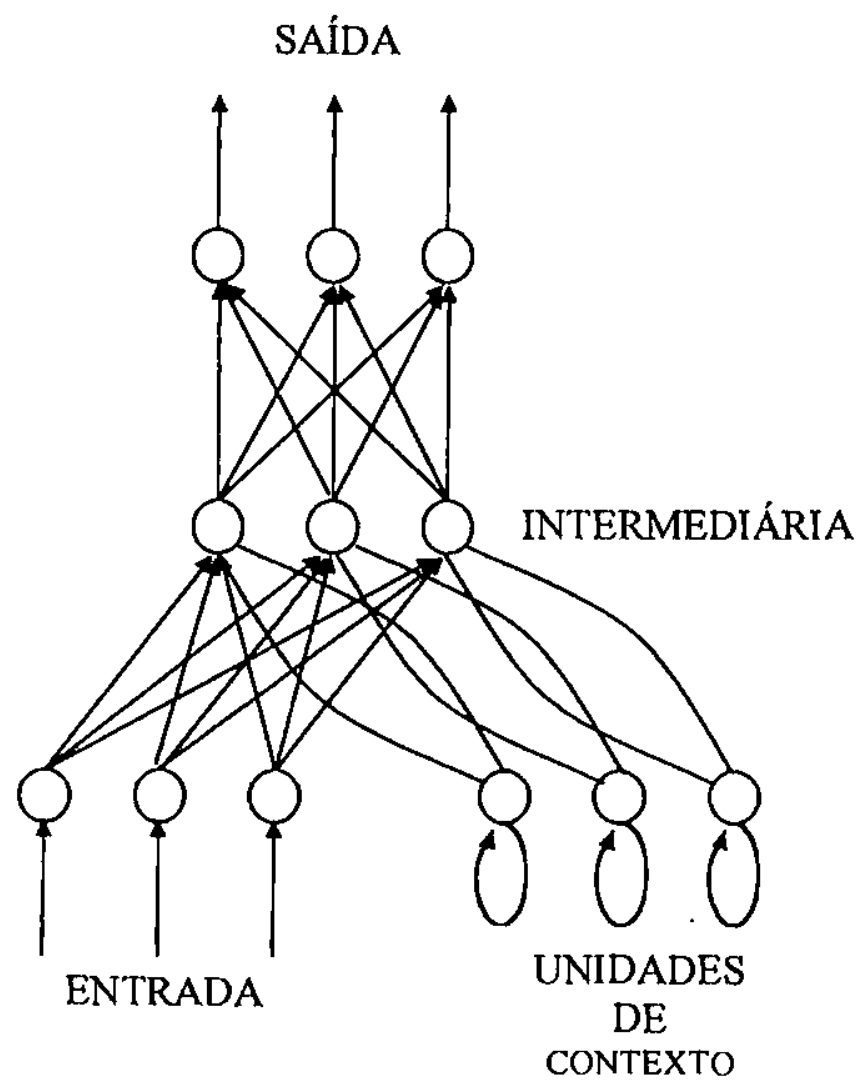

Figura 3.5: Rede de Elman.

\subsubsection{Rede de Jordan}

A rede de Jordan (Jordan, 1986), mostrada pela Figura 3.6, contém conexões recorrentes que são usadas para associar um padrão estático de entrada a um padrão de saída seqüencialmente ordenado no tempo.

As conexões recorrentes permitem que as unidades da camada intermediária considerem as saídas anteriores da rede no momento em que são ajustadas pelo algoritmo de treinamento. Assim, os procedimentos subsequentes podem ser moldados pelas respostas anteriormente produzidas pela rede. Estas saídas são armazenadas em unidades especiais que representam os estados imediatamente passados em que rede se encontrava. Tais conexões recorrentes são responsáveis por atribuir à rede uma memória.

$\mathrm{O}$ algoritmo de treinamento da rede de Jordan é bastante similar ao da rede de Elman. $\mathrm{O}$ que realmente muda são apenas as informações extras que as unidades da camada intermediária possuem. 


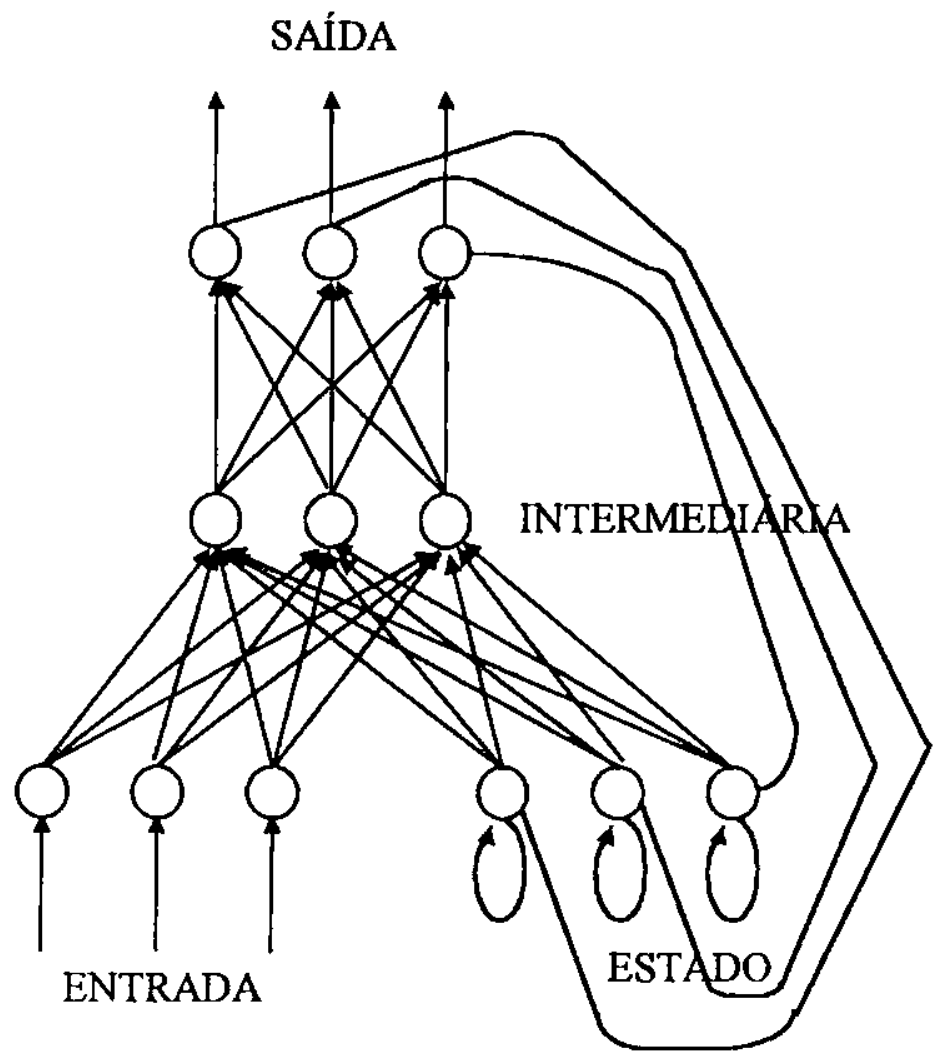

Figura 3.6: Rede de Jordan.

\subsection{Combinadores de Previsão}

Devido à grande quantidade de ruídos presente em aplicações práticas de séries temporais, o controle da variância da previsão é extremamente requisitado. Uma das abordagens para reduzir esta variância é a utilização de combinadores ou comitê de previsores.

Os combinadores de previsão buscam explorar as vantagens e capacidades individuais de cada um de seus membros com a finalidade de promover a realização de uma previsão mais estável e confiável.

A prática de utilização de comitês em previsões financeiras é bastante divulgada no meio estatístico. Em um vasto relatório, Clemen apresentou mais de 200 referências sobre o assunto (Clemen, 1989). A média das previsões dos membros do comitê é uma maneira bastante simples de combiná-los.

Um exemplo da utilização de combinadores de previsão no contexto de RNAs consiste da combinação dos resultados das melhores arquiteturas treinadas para um problema de previsão (Rehfuss et al., 1995). Essa combinação pode simplesmente ser a média das previsões realizadas por cada um dos membros do comitê. 
Uma RNA pode também ser treinada para ponderar a importância de cada um dos membros do comitê no resultado final. Em ambos casos, o modelo Box \& Jenkins ajustado também pode participar do comitê de previsores.

\subsection{Considerações Finais}

As RNAs apresentam soluções promissoras para problemas de previsão. Contudo, a busca pela sua capacidade de generalização deve ser favorecida quando se deseja obter desempenhos razoáveis. Uma forma de realizar isto é promover a utilização de modelos parcimoniosos de previsão. Cada uma das três abordagens discutidas neste capítulo possuem suas vantagens e desvantagens.

As operações de diferenciação e as ferramentas de identificação de modelos Box \& Jenkins podem ser usadas com sucessos na modelagem de dados 'e arquiteturas de RNAs. Entranto, as operações de diferenciação não são capazes de eliminar qualquer tipo de não estacionariedade e as funções de auto-correlação e auto-correlação parcial apenas revelam dependências lineares entres as informações passadas de uma série temporal. Além, disso existe uma necessidade de se possuir uma boa bagagem teórica para conseguir analisar os comportamentos das estimativas destas funções.

Os métodos de poda de RNAs permitem a visualização de dependências não lineares que possam eventualmente existir entre as entradas do modelo de previsão. Entretanto, estes métodos podem apenas ser aplicados com arquiteturas feedforwards e exigem claramente maneiras de se estimar o erro de generalização de forma precisa.

Os modelos de Redes Neurais com capacidade de extrair e representar características dinâmicas das séries temporais possuem recursos importantes que devem ser aplicados em previsão. Entretanto, nem todo comportamento não estacionário de algumas séries temporais pode ser extraido somente usando tais modelos. Assim, as operações de diferenciação podem ainda ser necessárias, cabendo às estas redes com memória a captação de outras não estacionariedades eliminadas por este recurso.

A combinação de previsores é uma técnica que vem sendo aplicada à muito tempo dentro da área de Estatística com a finalidade de reduzir a variância de previsão 1-passo-a-frente. Contudo, a complexidade do modelo é aumentada, dificultando o seu emprego principalmente quando se deseja prever vários passos à frente. 


\section{Experimentos}

Este capítulo apresenta os experimentos de utilização conjunta de Redes Neurais Artificiais e Método Box \& Jenkins para previsão de séries temporais. A seção 4.1 descreve alguns pontos genéricos referentes a utilização de RNAs nos experimentos. Os dados empregados sobre séries temporais financeiras de cotação de moedas e de valores de ações são descritos pela seção 4.2. A seção 4.3 apresenta os resultados dos experimentos realizados com o método Box \& Jenkins e as RNAs projetadas seguindo as três abordagem descritas no capítulo 3 . Finalmente, a seção 4.4 discute algumas consideraçðes sobre os resultados obtidos.

\subsection{Metodologia}

Os experimentos de previsão foram realizados com RNAs feedforward e recorrentes com aprendizado supervisionado. As RNAs feedforward utilizadas foram as redes MLP e ADALINE. As redes MLP possuem uma camáda de entrada, uma camada intermediária e uma de saída. Seus neurônios utilizam funções de ativação tangente hiperbólica e seus estados de ativação assumem valores reais compreendidos entre -1 e 1 . As arquiteturas do tipo ADALINE não possuem camadas intermediárias, utilizam a função de ativação identidade em seus neurônios. A rede TDNN e as redes recorrentes de Elman e Jordan apresentam uma única camada intermediária e seus neurônios empregam a função de ativação logística, que produz estados entre 0 e 1 .

Ao contrário dos modelos Box \& Jenkins, que trabalham diretamente com os valores da série para o ajuste de seus modelos, as RNAs exigiram a execução de uma etapa extra de normalização dos dados. Esta normalização restringiu os valores das séries temporais a intervalos reais cujos limitantes inferiores e superiores eram -0.90 e 0.90 para as redes MLP e ADALINE e 0.1 e 0.9 para as redes TDNN e recorrentes.

Os treinamentos destas diferentes redes foram executados através dos algoritmos RProp e Backpropagation. O algoritmo RProp foi empregado para as redes MLP, ADALINE e as redes recorrentes de Elman e Jordan por se tratar de uma das regras de convergência mais rápidas analisadas pelo relatório de Schiffmman (Schiffmman, 1992). As redes TDNN foram treinadas com uma variação do algoritmo Backpropagation que permite a representação das características temporais dos dados.

A função Mean Relative Error (MRE), ilustrada pela Equação 4.1, foi usada para avaliar a acurácia da previsão das séries temporais. 


$$
M R E=100 \times \frac{1}{N} \sum_{p} \sum_{j}\left|\frac{d_{n j}-y_{p j}}{d_{n j}}\right|
$$

em que $N$ é número de padrões do conjunto de treinamento, validação ou teste, $d_{p}$ é o vetor de saída desejada para o padrão $p$, e $y_{p}$ é a saida produzida pela RNA para o padrão $p$.

A técnica Random Sub-sampling foi aplicada para dividir os dados de treinamento em dois subconjuntos distintos de treinamento $(70 \%)$ e validação $(30 \%)$, e para estimar, consequentemente, o erro de generalização baseado no conjunto de validação. Apenas para as redes recorrentes, os dados não foram particionados aleatoriamente, devido às suas características de memórias de longo prazo. Assim, uma única partição foi formada, dividindo a série seqüencialmente em treinamento, validação e teste.

As três abordagens de previsores neurais foram então aplicadas para a previsão das séries temporais de moedas e de ações. A operação conjunta entre os métodos Box \& Jenkins e Redes Neurais e a seleção de variáveis por métodos de poda tiveram como objetivo a construção de um modelo de previsão otimizado. O objetivo inicial do uso do modelo TDNN e de redes recorrentes era verificar sua capacidade de aprender a não estacionariedade das séries de moedas e ações sem a nescessidade de pré-processamento. Contudo, estes modelos não conseguiram extrair e generalizar diretamente os comportamentos não estacionários das séries financeiras. Mesmo assim, estes modelos podem também ser usados para aprender as séries temporais préprocessadas uma vez que as operações de diferenciação não foram capazes de eliminar completamente a não estacionariedade nas séries estudadas.

\subsection{Dados}

As RNAs foram treinadas para realizar a previsões do tipo 1-passo-a-frente e váriospassos-a-frente com duas bases distintas de séries temporais: cotação de moedas e preço de ações.

Os dados sobre cotação de moedas consistem de cinco séries temporais de 3510 valores amostrados diariamente entre o periodo de 01/06/73 a 21/05/87. Esses dados foram investigados no artigo "Predicting Sunspots and Exchange Rates with Connectionist Networks" (Weigend et al., 1992). Cada uma das séries diz respeito a cotação em Dólar Americano das seguintes moedas: Libra Esterlina, Dólar Canadense, Marco Alemão, Franco Suíço e o Iene Japonês. As 
séries da Libra Esterlina e do Marco Alemão, ilustradas através da Figura 4.1, foram escolhidas para serem mais detalhadamente estudadas.

Os experimentos de previsão de valores de ações da TELEBRAS foram realizados com uma base de dados compostas de oito séries temporais com valores amostrados diariamente durante o período de 01/08/94 a 13/03/97. Tais séries representam a quantidade de negócios, quantidade de títulos negociados, volume e os preços de abertura, fechamento, mínimo, máximo e médio das ações. Apenas os preços mínimo e máximo, cujas curvas são apresentadas na Figura 4.2, foram usados como saída dos previsores. As outras séries serviram somente como fonte adicional de informações de entrada.

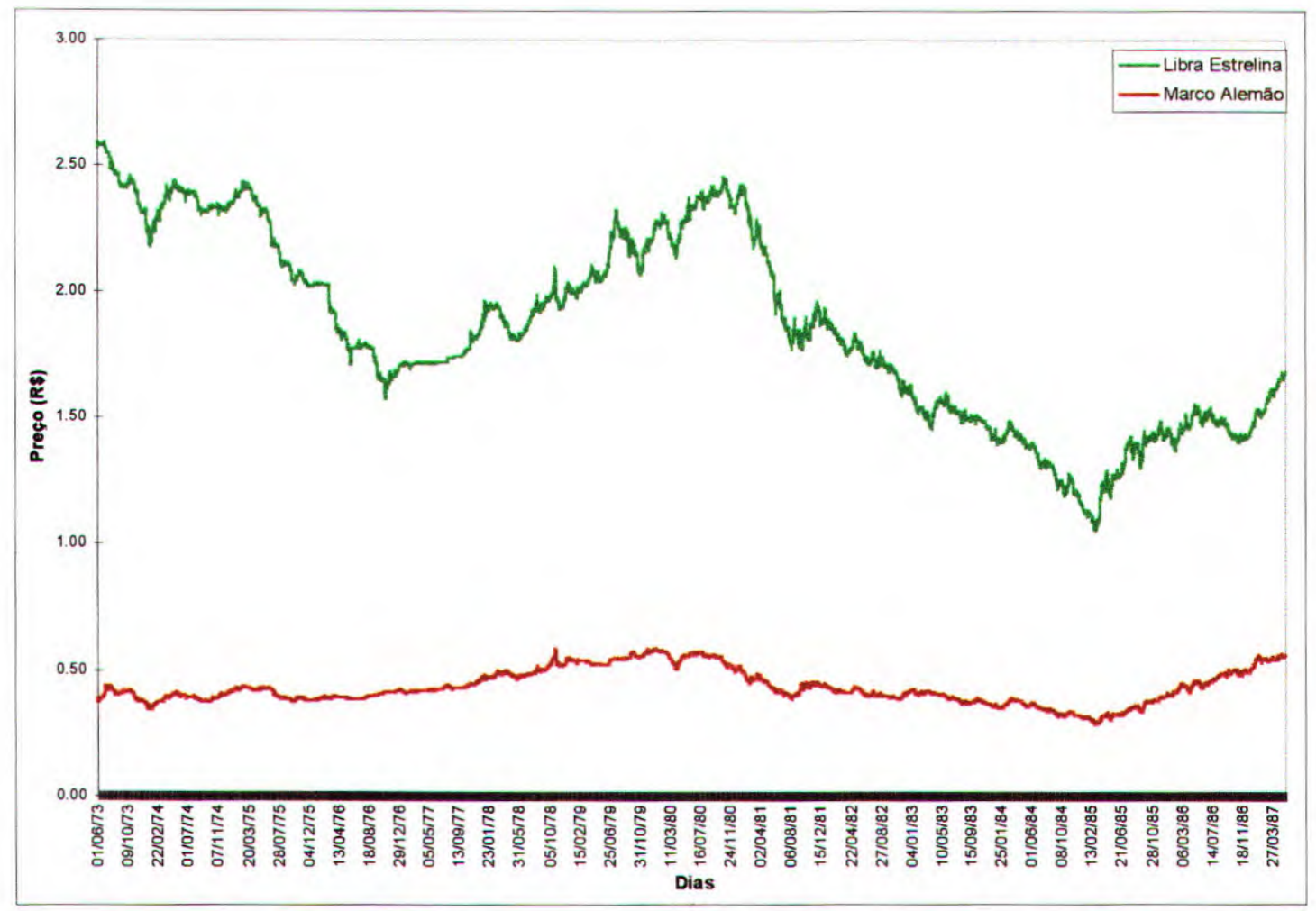

Figura 4.1: Séries Temporais da Libra Esterlina e Marco Alemão. 


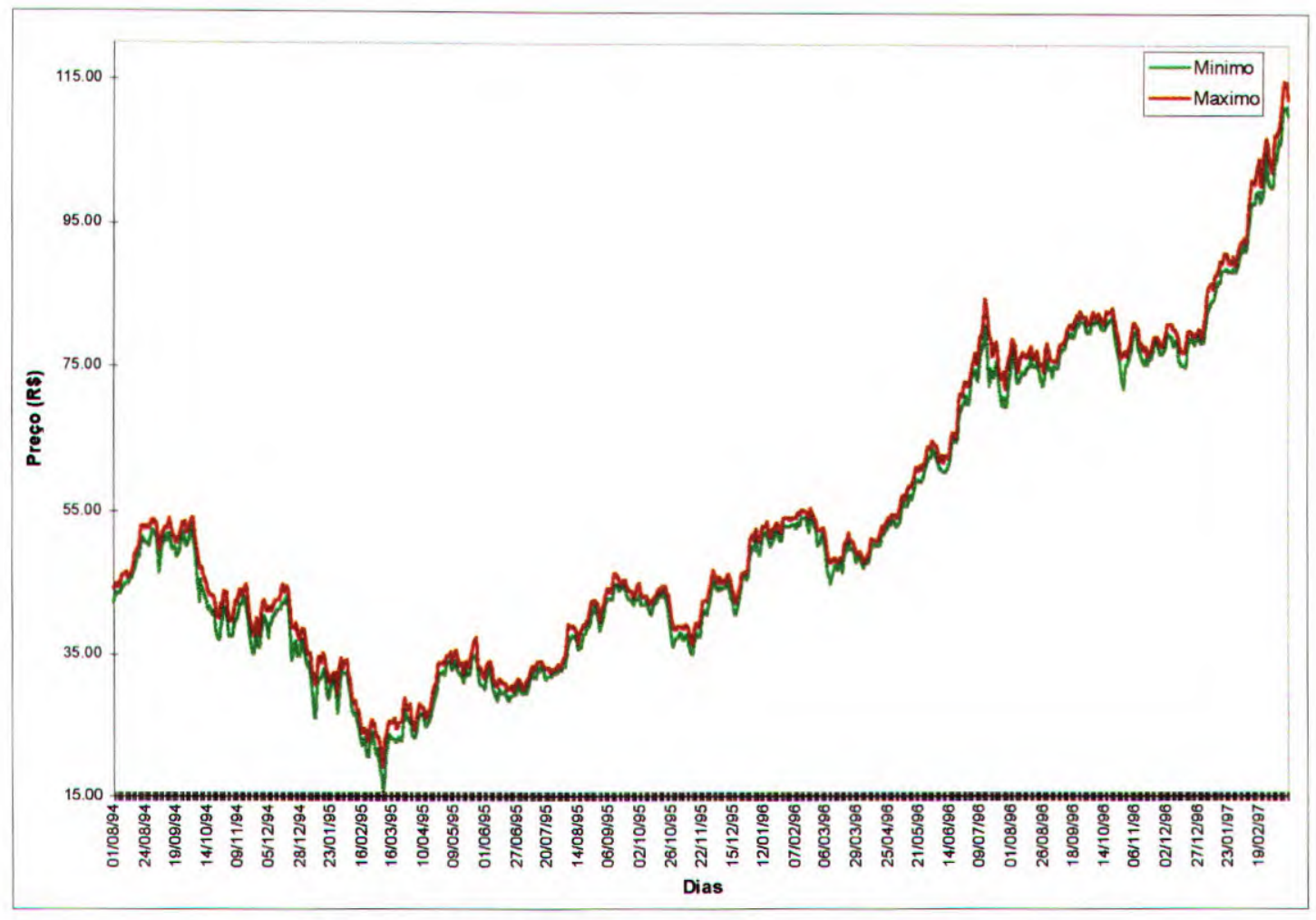

Figura 4.2: Séries temporais de preço mínimo e máximo.

\subsection{Resultados}

A seguir são apresentados os resultados obtidos dos experimentos que utilizaram as três abordagens de previsores neurais.

\subsubsection{Sistema Híbrido}

O sistema híbrido descrito na seção 3.2 foi aplicado para a modelagem de Redes Neurais na previsão de cotação de moedas e preço de ações. Em ambos os casos foi verificado o efeito do pré-processamento para tornar as séries estacionárias.

\subsubsection{Moedas}

O comportamento não estacionário das séries temporais da Libra Esterlina e Marco Alemão pode ser facilmente verificado a partir de uma inspeção visual de suas curvas, ilustradas pela Figura 4.1.

Os valores da FAC para a Libra Esterlina foram praticamente constantes e iguais a 1, como ilustra a Figura 4.3. Isto sugeriu uma possível representação deste processo através do modelo random walk descrito pela Equação 4.2. A Figura 4.4 mostra a FACp da Libra Esterlina que reforça esta análise. Já no caso da série temporal do Marco Alemão, foi necessário aplicar 
uma operação de diferenciação antes de cstimar a $F \wedge C$ c a $F \wedge C p$. () comportamento da $F \wedge C$ pode ser visto como uma queda exponencial rápida com oscilações em torno do cixo das abcissas, conforme ilustra a lïigura 4.5. Fiste fato, aliado às estimativas da FACp, dada pela Figura 4.6, sugeriram um modelo $A R I(I, I)$, descrito pela Fquação 4.3. A região delimitada pelas linhas pontilhadas em azul e verde nos gráficos das Figuras 4.3 à 4.6 representam os intervalos de confianca. Os valores da FAC e FACp dentro destes intervalos podem ser considerados nulos.

$$
\begin{gathered}
z_{t}=z_{t-1}+a_{t} \\
\left(1-\phi_{1} B\right)(1-B) z_{t}=a,
\end{gathered}
$$

A Equação 4.3 pode ainda ser desenvolvida para expressar $z$, em função dos valores passados da série, como se segue:

$$
z_{t}=\left(1+\phi_{1}\right) z_{t-1}-\phi_{1} z_{t-2}+a_{1}
$$

Desta forma, as previsões da Libra Esterlina e do Marco Alemão podem então ser realizada efetuando o cálculo do valor esperado condicional, representado pelas Equaçóes $4.5 \mathrm{e}$ 4.6:

$$
\begin{gathered}
E\left(z_{t} \mid z_{t-1}\right)=z_{t-1} \\
E\left(z_{1} \mid z_{t-1}, z_{t-2}\right)=\left(1+\phi_{1}\right) z_{t-1}-\phi_{1} z_{t-2}
\end{gathered}
$$

Os desempenhos nas fase de ajuste e teste dos modelos random walk e $\operatorname{ARI}(1,1)$ são finalmente apresentados pela Tabela 4.1 .

\begin{tabular}{|c|c|c|c|}
\hline Série & Parametros & $\begin{array}{c}\text { Ajuste } \\
\text { MRE }(\%)\end{array}$ & $\begin{array}{c}\text { Teste } \\
M R E(\%)\end{array}$ \\
\hline Libra Esterlina & - & 0.4399 & 0.4008 \\
\hline Marco Alemão & $\phi_{1}=-0.0521$ & 0.4990 & 0.4346 \\
\hline
\end{tabular}

Tabela 4.I: Parametros e desempenhos dos modelos Box \& Jenkins ajustados. 
FAC (k)

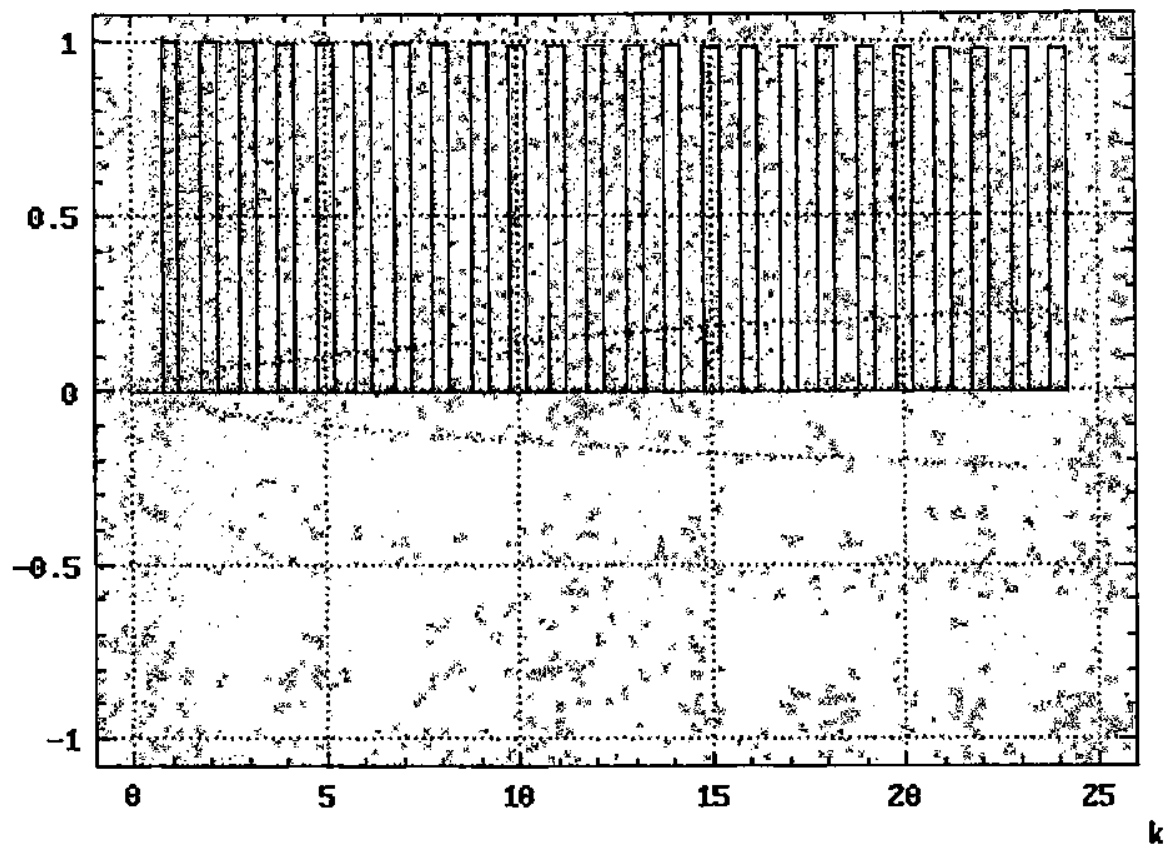

Figura 4.3: FAC da série da Libra Esterlina.

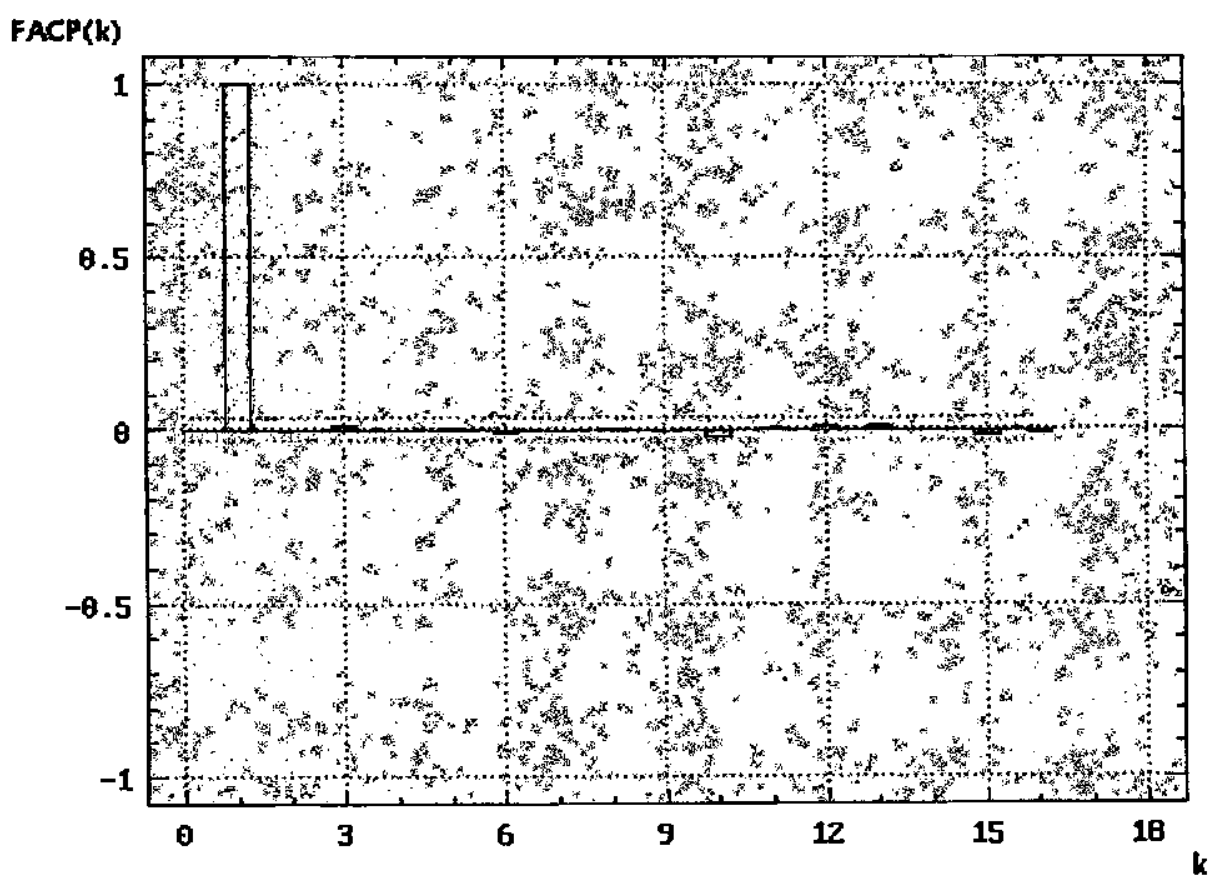

Figura 4.4: FACp da série da Libra Esterlina. 


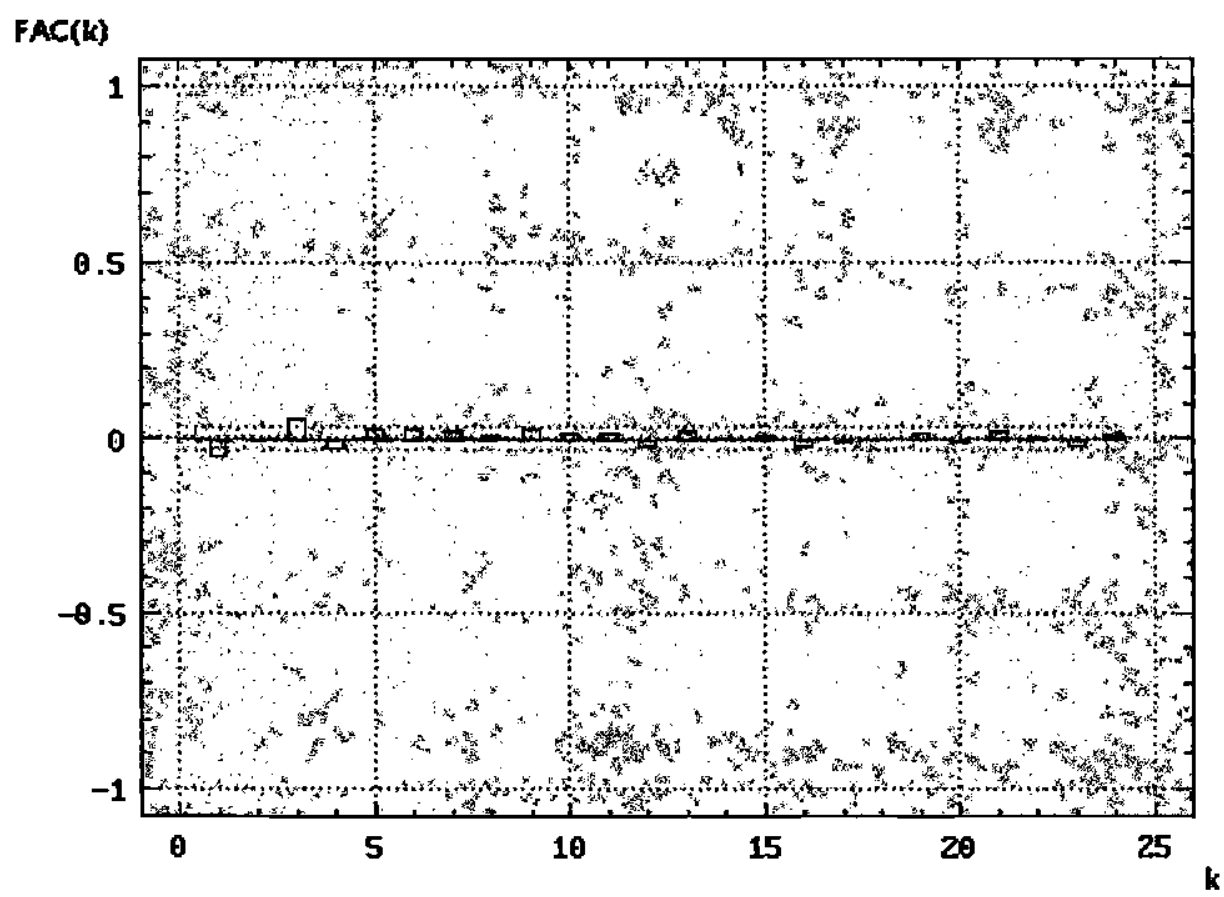

Figura 4.5: FAC da série do Marco Alemão.

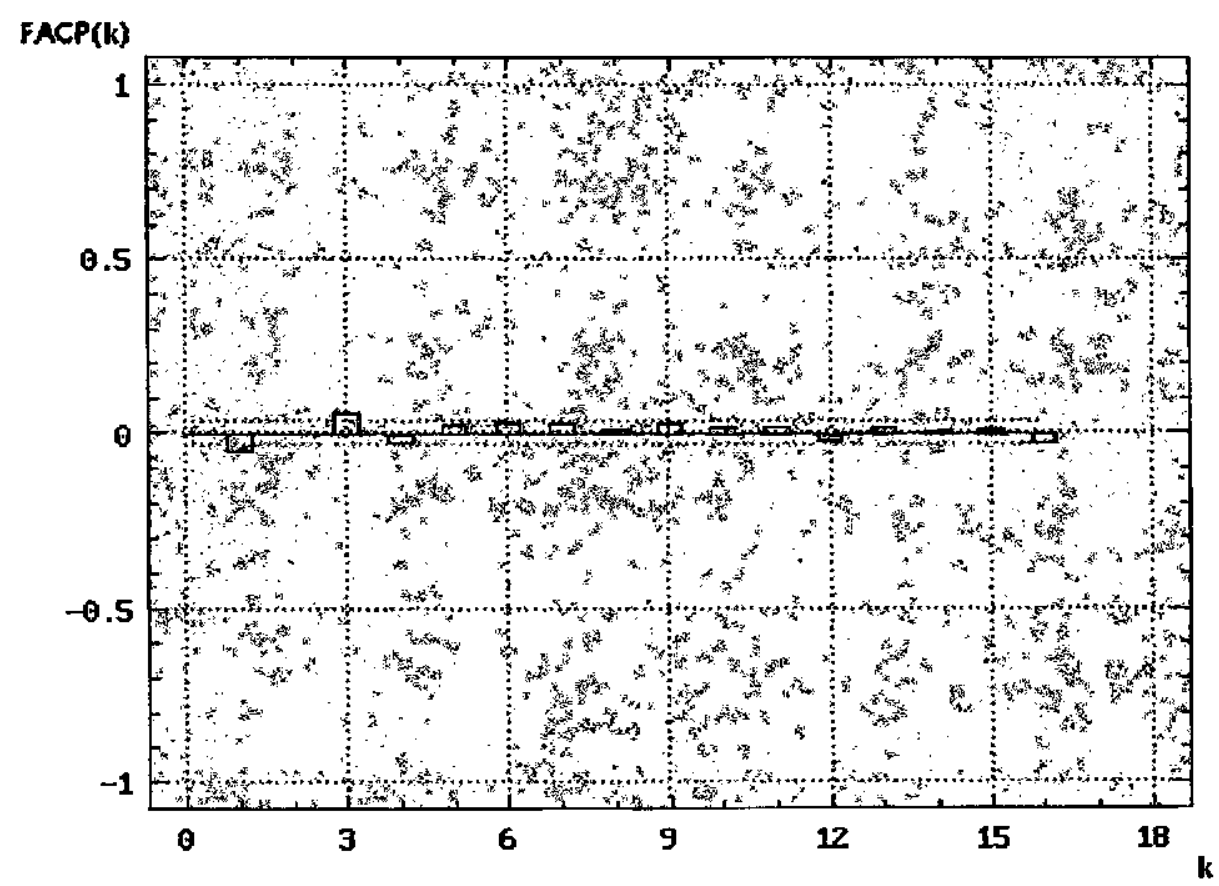

Figura 4.6: FACp da série do Marco Alemão.

A identificação e o ajuste dos modelos da seção anterior contribuíram diretamente para a modelagem de 10 diferentes arquiteturas para previsão dos valores de moedas. Em todas as tabelas de resultados, a notação $i{ }_{-} h_{l_{-}} h_{2}$ oAct foi utilizada para distinguir as arquiteturas. Nesta notação $i, h_{1}, h_{2}$ e $o$ representam o número de neurôniossnas camadas de entrada, intermediárias 
e de saída, respectivamente. Act é uma função de ativação: Identidade (I), Logística (L) ou Tangente Hiperbólica (T). Os termos $h_{1}$ e $h_{2}$ podem estar ausentes, o que representaria a falta de uma ou duas camadas intermediárias na arquitetura. Os melhores resultados são sempre apresentados em negrito.

O modelo random walk sugeriu a utilização de um neurônio na camada de entrada $\left(z_{t-1}\right)$ para a previsão de $z_{t}$ na saída da rede. $\Lambda$ Tabela 4.2 ilustra a média por partição dos erros em MRE de treinamento, validação e tcste para a Libra Esterlina. De acordo com o critério da melhor validação, a arquitetura linear seria escolhida como a melhor solução. Entretanto, algumas arquiteturas não lineares obtiveram desempenhos semelhantes.

Para o Marco Alemão, dois grupos de arquiteturas foram estudadas para verificar o comportamento das RNAs em relação à não estacionariedade da série. $O$ primeiro grupo era formado por arquitcturas com apenas um neurônio na camada de entrada. Este neurônio representava uma observação $w_{t-1}$ da séric temporal $w$ obtida a partir da aplicação de uma operação de diferenciação sobre a série original $z$. O segundo grupo possuía arquiteturas com dois neurônios na camada de entrada $\left(z_{t-1}\right.$ e $\left.z_{t-2}\right)$, que foram treinadas com as observações da série do Marco Alemão sem pré-processamento. As Tabelas 4.3 e 4.4 ilustram os resultados para ambos os grupos. Genericamente, a maioria das arquileturas conseguiu gerar previsð̃es com desempenho similar aos modelos Box \& Jenkins ajustados. Apesar do comportamento não estacionário, o segundo grupo de arquitetura apresentou um desempenho apenas um pouco inferior.

\begin{tabular}{|l|c|c|c|}
\hline Arquitetura & $\begin{array}{c}\text { Treinamento } \\
M R E(\%)\end{array}$ & $\begin{array}{c}\text { Validação } \\
M R E(\%)\end{array}$ & $\begin{array}{c}\text { Teste } \\
M R E(\%)\end{array}$ \\
\hline 1_1I & 0.440164 & $\mathbf{0 . 4 4 1 5 1 9}$ & $\mathbf{0 . 3 9 9 1 0 2}$ \\
\hline 1_1T & 1.253306 & 1.244907 & 1.385057 \\
\hline 1_1_1T & 1.262660 & 1.255317 & 1.390325 \\
\hline 1_3_1T & 0.463578 & 0.467761 & 0.398674 \\
\hline 1_5_1T & 0.457197 & 0.459988 & 0.418290 \\
\hline 1_7_1T & 0.522366 & 0.517359 & 0.429648 \\
\hline 1_9_1T & 0.456827 & 0.459576 & 0.417408 \\
\hline 111_1T & 0.460695 & 0.462893 & 0.418445 \\
\hline 1_13_1T & 0.456025 & 0.458361 & 0.412662 \\
\hline 1_15_1T & 0.458653 & 0.462095 & 0.423345 \\
\hline
\end{tabular}

Tabela 4.2: Desempenho de previsão (MRE) das RNAs para a Libra Esterlina. 


\begin{tabular}{|l|c|c|c|}
\hline Arquitetura & $\begin{array}{c}\text { Treinamento } \\
M R E(\%)\end{array}$ & $\begin{array}{c}\text { Validação } \\
M R E(\%)\end{array}$ & $\begin{array}{c}\text { Teste } \\
M R E(\%)\end{array}$ \\
\hline 1_1I & 0.7438 & 0.7515 & 0.6184 \\
\hline 1_1T & 0.5024 & 0.5065 & 0.4348 \\
\hline 1_1_1T & 0.5023 & 0.5065 & 0.4348 \\
\hline 1_3_1T & 0.5025 & 0.5067 & 0.4352 \\
\hline 1_5_1T & 0.5025 & 0.5068 & 0.4352 \\
\hline 1_7_1T & 0.5025 & 0.5067 & 0.4352 \\
\hline 1_9_1T & 0.5024 & 0.5072 & 0.4353 \\
\hline 1_11_1T & 0.5025 & 0.5067 & 0.4351 \\
\hline 1_13_1T & 0.5024 & 0.5071 & 0.4351 \\
\hline 1_15_1T & 0.5023 & 0.5071 & 0.4351 \\
\hline
\end{tabular}

Tahela 4.3:Desempenho de previsão (MRE) das RNAs para a séric do Marco Alemão com diferenciação.

\begin{tabular}{|l|c|c|c|}
\hline Arquitelura & $\begin{array}{c}\text { Treinamento } \\
\text { MRE (\%) }\end{array}$ & $\begin{array}{c}\text { Validaçåo } \\
\text { MRE (\%) }\end{array}$ & $\begin{array}{c}\text { Teste } \\
M R E(\%)\end{array}$ \\
\hline 2_1I & $\mathbf{0 . 4 9 7 5 0 4}$ & $\mathbf{0 . 5 0 4 2 3 9}$ & $\mathbf{0 . 4 3 5 0 8 7}$ \\
\hline 2_1T & 1.047055 & 1.042605 & 1.061107 \\
\hline 2_1_1T & 1.057759 & 1.054205 & 1.047452 \\
\hline 2_3_1T & 0.507113 & 0.517111 & 0.452320 \\
\hline $\mathbf{2}$ 5_1T & 0.503439 & 0.513210 & 0.448180 \\
\hline 2_7_1T & 0.504051 & 0.513631 & 0.447352 \\
\hline 2_8_1T & 0.504217 & 0.514730 & 0.449870 \\
\hline 2_10_1T & 0.504428 & 0.514289 & 0.448316 \\
\hline 2_13_1T & 0.513434 & 0.524144 & 0.457967 \\
\hline 2_15_1T & 0.506922 & 0.519288 & 0.454831 \\
\hline
\end{tabular}

Tabela 4.4:Desempenho de previsão (MRE) das RNAs para a série do Marco Alemão sem diferenciação.

\subsubsection{Ações}

A observação das séries temporais de valores mínimos e máximos de ações revelou um comportamento não estacionário, envolvendo uma combinação de tendência linear e mudança de niveis, conforme ilustra a Figura 4.2.

Após ser executada uma diferenciação, as estimativas das funçóes de auto-correlação e auto-correlação parcial foram calculadas, resultando nos gráficos expressos pelas Figuras 4.7, 4.8, 4.9 e 4.10. Em ambas as séries, a FAC pode ser interpretada como uma queda exponencial que prossegue até o infinito. Os valores da FACp podem ser considerados nulos a partir de $k>2$, por estarem dentro do intervalo de confiança delimitado pelas linhas pontilhadas nos gráficos.

A análise destas funções conduziu a interpretação das séries temporais de valores mínimo e máximo das ações como uma possível realização dos processos descritos pelos modelos $A R I(1,1)$ e $A R I(2,1)$ ilustrados pelas Equações 4.7 e 4.8, respectivamente. Apesar da FACp da série de mínimo sugerir uma ordem $p=2$, um modelo $A R I(1,1)$ obteve um desempenho melhor, 
sendo portanto escolhido. Isso provavelmente é explicado pelo fato de se trabalhar com estimativas destas funções.

$$
\begin{gathered}
\left(1-\phi_{1} B\right)(1-B) z_{1}=a_{1} \\
\left(1-\phi_{1} B-\phi_{2} B^{2}\right)(1-B) z_{1}=a_{1}
\end{gathered}
$$

As Equação 4.7 e 4.8 podem ainda ser desenvolvidas para expressar $z$, em função dos valores passados da série, o que resultaria em:

$$
\begin{gathered}
z_{t}=\left(1+\phi_{1}\right) z_{t-1}-\phi_{1} z_{t-2}+a_{t} \\
z_{t}=\left(1+\phi_{1}\right) z_{t-1}+\left(\phi_{2}-\phi_{1}\right) z_{t-2}-\phi_{2} z_{t-3}+a_{t}
\end{gathered}
$$

$\Lambda$ ssim, as previsões 1 -passo-a-frente do preço mínimo e máximo das ações podem então ser efetuada através dos cálculos do valor esperado condicional, representado pelas Equações 4.11 e 4.12 :

$$
\begin{gathered}
E\left(z_{t} \mid z_{t-1}, z_{t-2}\right)=\left(1+\phi_{1}\right) z_{t-1}-\phi_{1} z_{t-2} \\
E\left(z_{1} \mid z_{t-1}, z_{t-2}, z_{t-3}\right)=\left(1+\phi_{1}\right) z_{t-1}+\left(\phi_{2}-\phi\right)_{1} z_{t-2}-\phi_{2} z_{t-3}
\end{gathered}
$$

Os parâmetros ajustados para os modelos e as suas avaliações de desempenho em previsão 1-passo-a-frente são apresentados pela Tabela 4.5 .

\begin{tabular}{|c|c|c|c|}
\hline Série & Parâmetros & $\begin{array}{c}\text { Ajuste } \\
\text { MRE }(\%)\end{array}$ & $\begin{array}{c}\text { Teste } \\
M R E(\%)\end{array}$ \\
\hline Mínimo & $\phi_{1}=0.16735$ & 2.2945 & 1.0956 \\
\hline Máximo & $\begin{array}{c}\phi_{1}=0.13687 \\
\phi_{2}=-0.08455\end{array}$ & 1.9706 & 1.2260 \\
\hline
\end{tabular}

Tabela 4.5: Parâmetros e desempenhos dos modelos Box \& Jenkins ajustados.

Dados os modelos ajustados anteriormente, diversas arquiteturas de RNAs foram construídas e treinadas para também realizar a previsão 1-passo-a-frente das séries temporais de preço mínimo e máximo das ações. Em ambas as séries, foram construídos dois grupos de arquiteturas para serem treinadas com os dados antes e após a eliminação da não estacionariedade. 
O primeiro grupo era formado por arquiteturas que foram treinadas com observações da série $w$ obtidas a partir da aplicação de uma operação de diferenciação sobre a série original $z$. Neste caso, as arquiteturas consideravam um $\left(w_{t-1}\right)$ e dois ( $w_{t-1}$ e $\left.w_{t-2}\right)$ neurônios na camada de entrada para a previsão das séries de preço mínimo e máximo, respectivamente. As Tabelas $4.6 \mathrm{e}$ 4.8 ilustram os erros de previsão das arquiteturas deste grupo. As RNAs se aproximaram dos modelos Box \& Jenkins, produzindo, em alguns casos, previsões com taxas de erros menores.

O segundo grupo possuía arquiteturas treinadas com observações das séries originalmente não estacionárias. Neste grupo, havia dois $\left(z_{t-1}\right.$ e $\left.z_{t-2}\right)$ e três $\left(z_{t-1}, z_{t-2}\right.$ e $\left.z_{t-3}\right)$ neurônios na camada de entrada das arquiteturas que realizavam a previsão das séries de preço mínimo e máximo das ações, respectivamente. As Tabelas 4.7 e 4.9 ilustram os erros de previsão destas redes para as séries de preço mínimo e máximo s. Ao contrário da série do Marco Alemão, a retirada da não estacionariedade destas séries levou a uma sensível melhora dos resultados obtidos.

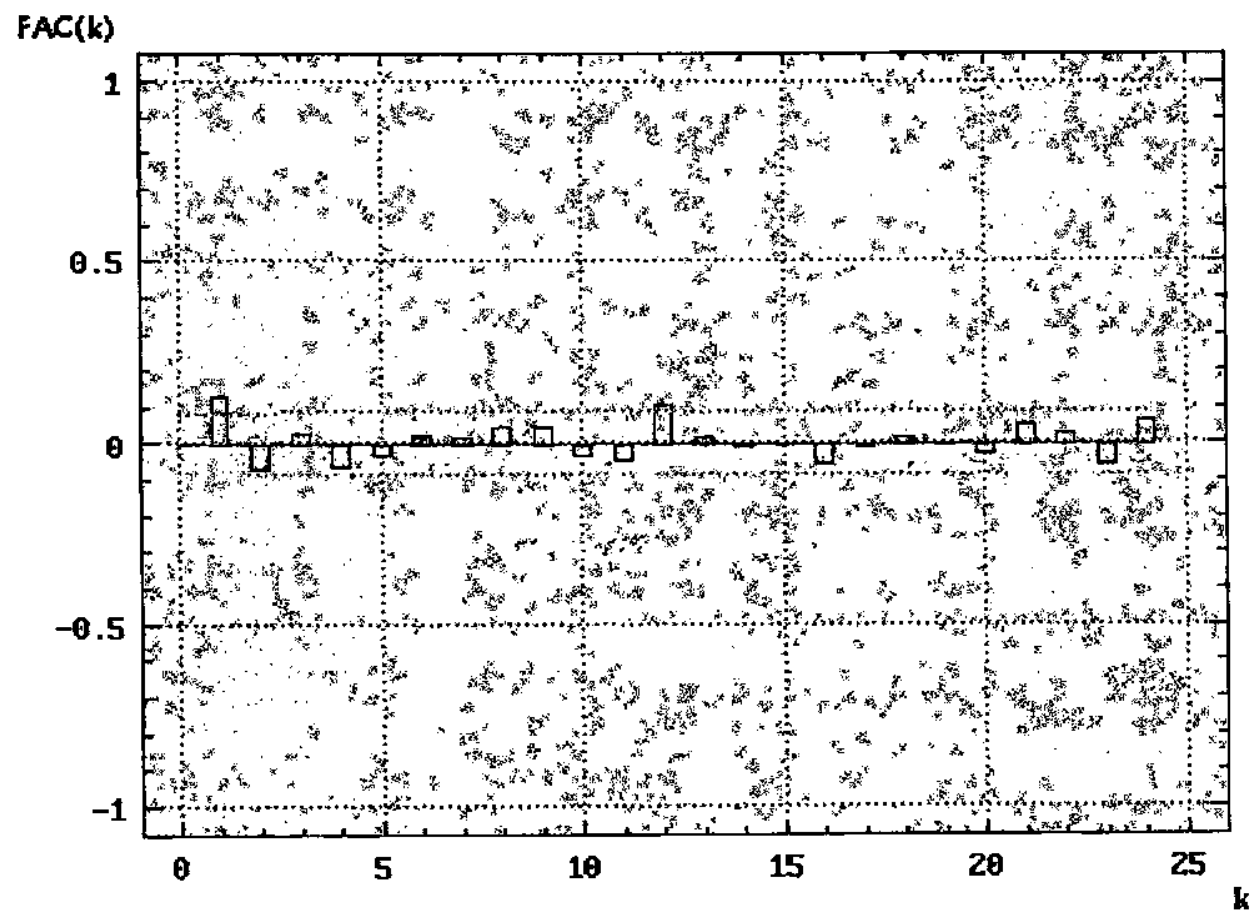

Figura 4.7: FAC da série de preço mínimo. 


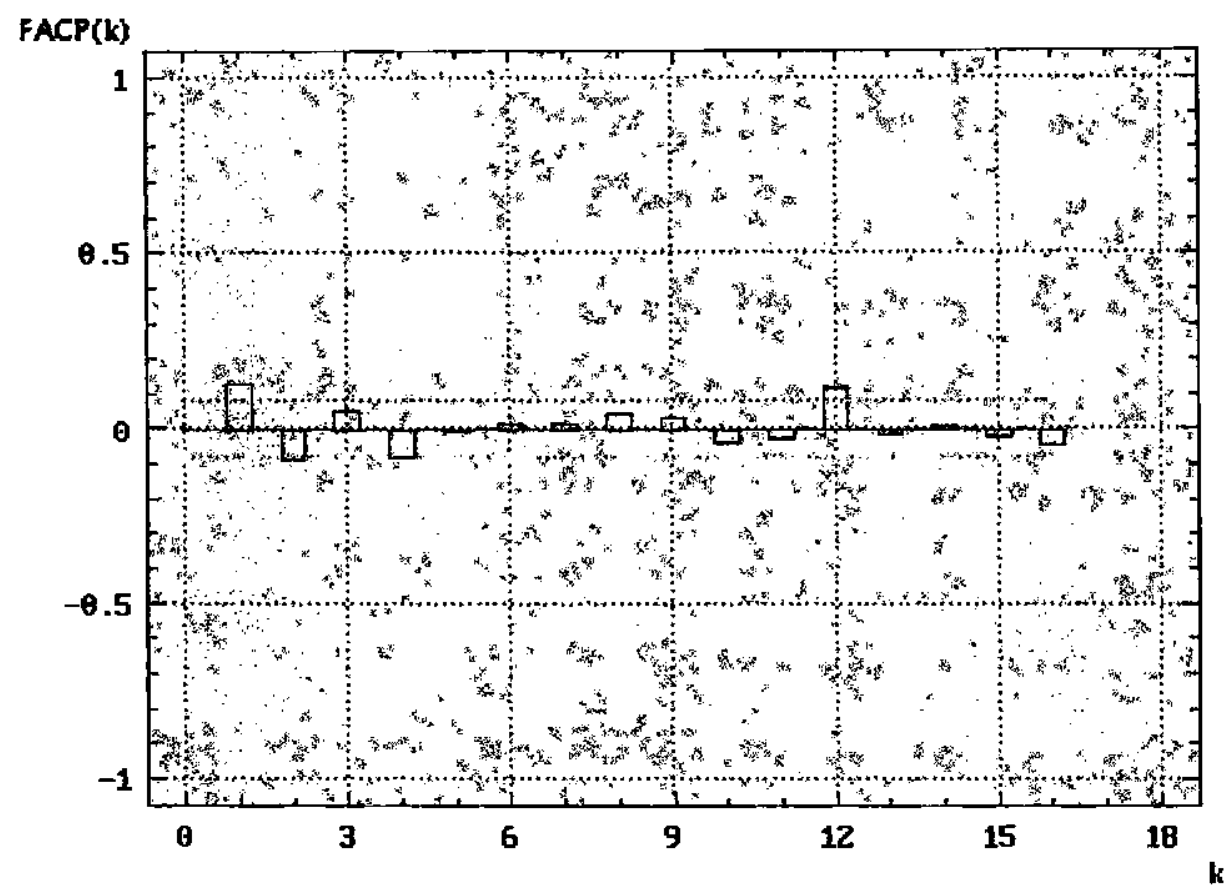

Figura 4.8: FACp da série de preço minimo.

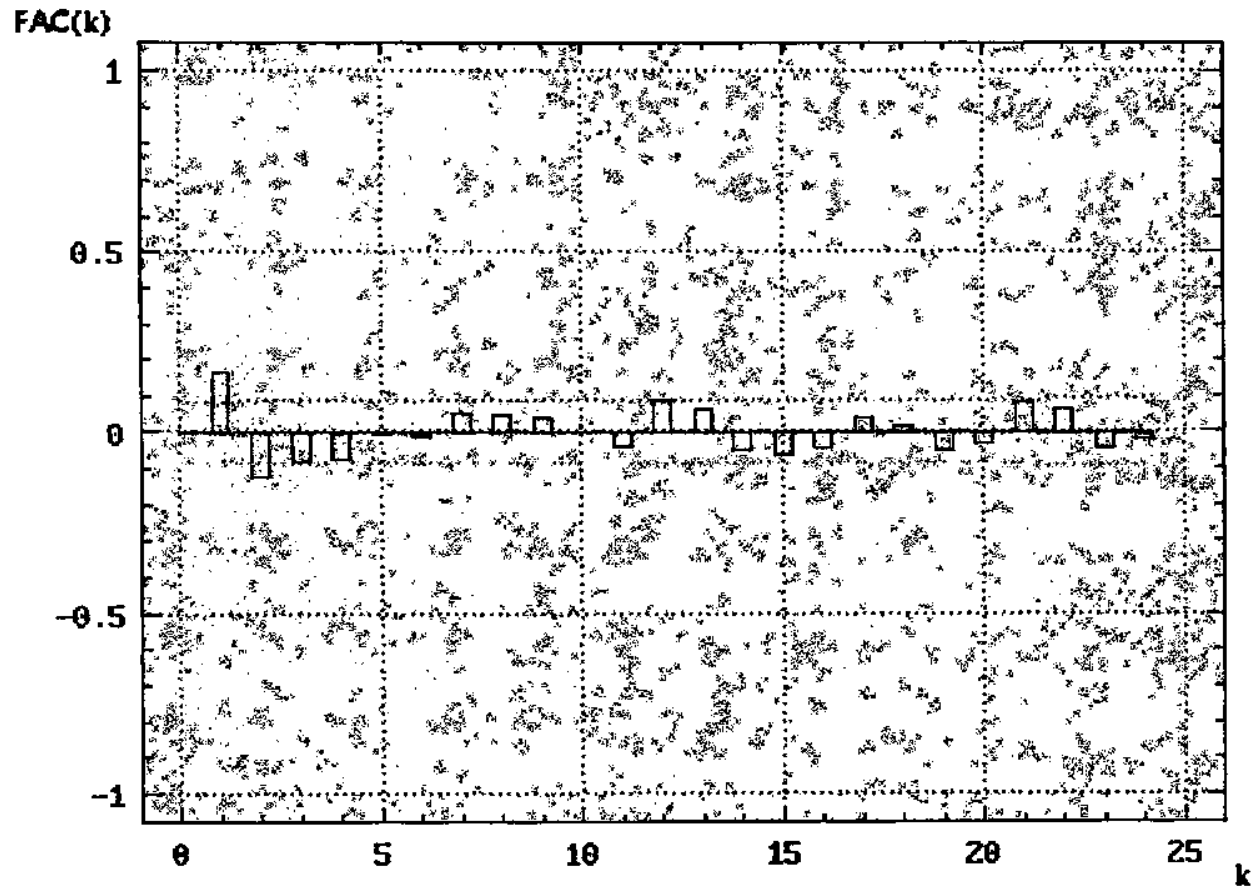

Figura 4.9: FAC da série de prę̧o móximo. 


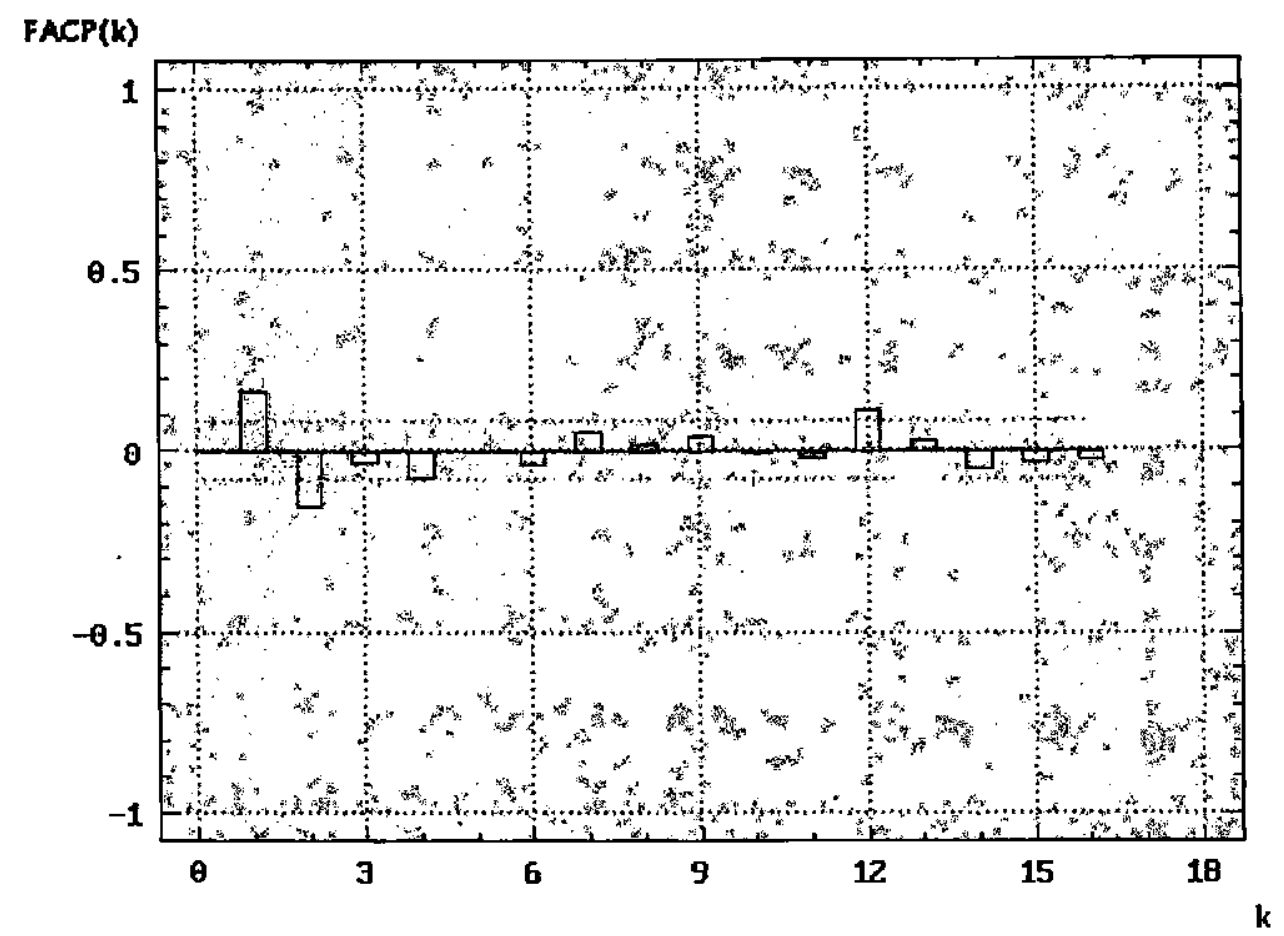

Figura 4.10: FACp da série de preço máximo.

\begin{tabular}{|c|c|c|c|}
\hline Arquitetura & $\begin{array}{c}\text { Treinamento } \\
M R E(\%)\end{array}$ & $\begin{array}{l}\text { Validação } \\
M R E(\%)\end{array}$ & $\begin{array}{c}\text { Teste } \\
\text { MRE (\%) }\end{array}$ \\
\hline 1_1L & 2.3863 & 2.3160 & 1.1767 \\
\hline 1_1T & 2.3057 & 2.2633 & 1.0824 \\
\hline 1.1.1T & 2.2996 & 2.2361 & 1.0633 \\
\hline $131 \mathrm{~T}$ & 2.2485 & 2.2234 & 1.0886 \\
\hline $151 \mathrm{~T}$ & 2.2466 & 2.2282 & 1.0996 \\
\hline 1.71T & 2.2470 & 2.2273 & 1.0923 \\
\hline $191 \mathrm{~T}$ & 2.2468 & 2.2270 & 1.0971 \\
\hline 111 1T & 2.2464 & 2.2276 & 1.0973 \\
\hline $1131 \mathrm{~T}$ & 2.2456 & 2.2282 & 1.0967 \\
\hline $\begin{array}{lll}115 & 1 T\end{array}$ & 2.2455 & 2.2289 & 1.0984 \\
\hline
\end{tabular}

Tabela 4.6: Desempenho de previsão (MRE) das RNAs para o preço minimo com diferenciação.

\begin{tabular}{|l|c|c|c|}
\hline Arquitetura & $\begin{array}{c}\text { Treinamento } \\
\text { MRE (\%) }\end{array}$ & $\begin{array}{c}\text { Validação } \\
\text { MRE (\%) }\end{array}$ & $\begin{array}{c}\text { Teste } \\
M R E(\%)\end{array}$ \\
\hline 2_1I & 2.2977 & 2.2938 & 1.1068 \\
\hline 2_1T & 3.9074 & 3.7552 & 1.9827 \\
\hline 2_1_1T & 2.7343 & 2.4827 & 5.9408 \\
\hline 2_3_1T & 2.3983 & 2.2555 & 1.8300 \\
\hline 2_5_1T & 2.2804 & 2.2942 & 4.3183 \\
\hline 2_7_1T & 2.2682 & 2.2950 & 4.7274 \\
\hline 2_9_1T & 2.2813 & 2.3196 & 3.9802 \\
\hline 2_11_1T & 2.2985 & 2.3045 & 2.6876 \\
\hline 2_12_1T & 2.2922 & 2.2769 & 5.7061 \\
\hline 2_15_1T & 2.3010 & 2.3101 & 3.4536 \\
\hline
\end{tabular}

Tabela 4.7: Desempenho de previsão (MRE) das RNAs para o preço mínimo sem diferenciação. 


\begin{tabular}{|c|c|c|c|}
\hline Arquitetura & $\begin{array}{c}\text { Treinamento } \\
M R E(\%)\end{array}$ & $\begin{array}{c}\text { Validação } \\
M R E(\%)\end{array}$ & $\begin{array}{c}\text { Teste } \\
M R E(\%)\end{array}$ \\
\hline $21 \mathrm{~L}$ & 2.0339 & 1.8762 & 1.2701 \\
\hline $21 \mathrm{~T}$ & 2.0076 & 1.8506 & 1.2196 \\
\hline $211 T$ & 2.0048 & 1.8443 & 1.2129 \\
\hline $231 T$ & 1.9708 & 1.8748 & 1.2042 \\
\hline $251 \mathrm{~T}$ & 1.9234 & 1.9192 & 1.2565 \\
\hline $271 \mathrm{~T}$ & 1.9071 & 1.9408 & 1.2534 \\
\hline $291 \mathrm{~T}$ & 1.8820 & 1.9532 & 1.2560 \\
\hline $2111 \mathrm{~T}$ & 1.8691 & 1.9531 & 1.2683 \\
\hline $2131 \mathrm{~T}$ & 1.8818 & 1.9485 & 1.2654 \\
\hline $2151 T$ & 1.8841 & 1.9744 & 1.2879 \\
\hline
\end{tabular}

Tabela 4.8:Desempenho de previsão (MRE) das RNAs para o preço máximo com diferenciação.

\begin{tabular}{|c|c|c|c|}
\hline Arquitetura & $\begin{array}{c}\text { Treinamento } \\
M R E(\%) \\
\end{array}$ & $\begin{array}{c}\text { Validação } \\
M R E(\%)\end{array}$ & $\begin{array}{c}\text { Teste } \\
M R E(\%)\end{array}$ \\
\hline 311 & 1.9934 & 1.9418 & 1.2419 \\
\hline $31 \mathrm{~T}$ & 3.8193 & 3.6266 & 2.0187 \\
\hline $311 \mathrm{~T}$ & 2.2989 & 2.3070 & 6.3099 \\
\hline $331 \mathrm{~T}$ & 1.9723 & 1.9728 & 4.8214 \\
\hline $351 \mathrm{~T}$ & 1.9637 & 1.9858 & 4.4314 \\
\hline $371 \mathrm{~T}$ & 1.9778 & 2.0128 & 1.9721 \\
\hline $391 \mathrm{~T}$ & 1.9526 & 1.9993 & 3.3623 \\
\hline $3111 \mathrm{~T}$ & 1.9744 & 1.9926 & 3.0476 \\
\hline $313-1 \mathrm{~T}$ & 1.9750 & 1.9960 & 2.2955 \\
\hline $3151 \mathrm{~T}$ & 1.9490 & 2.0302 & 3.0987 \\
\hline
\end{tabular}

Tabela 4.9: Desempenho de previsão (MRE) das RNAs para o preço máximo sem diferenciação.

\subsubsection{Seleção de Variáveis}

Os objetivos deste grupo de experimentos foram a avaliação da contribuição de variáveis adicionais à previsão e a simplificação dos modelos de previsão através de técnicas de seleção de variáveis baseadas em métodos de poda de RNAs .

Algumas variáveis adicionais foram utilizadas para explorar melhor a capacidade de mapeamento não linear oferecida pelas RNAs. Tais variáveis constituíam-se de observações passadas de outras série temporais que poderiam ter alguma influência no desempenho de previsão.

O primeiro passo foi verificar se a influência destas variáveis realmente existia. Para tanto, diversas redes MLPs foram inicialmente treinadas com informações à respeito de todas as variáveis disponiveis. É importante ressaltar que estes treinamentos foram interrompidos quando houve aumento exacerbado do erro de validação. Assim, as arquiteturas que melhor validaram foram selecionadas para sofrer podas. Apesar de terem sido utilizados três partições de dados distintas, somente a que gerou o melhor desempenho foi empregada. Isto decorre do fato de que 
difcrentes conjuntos de treinamento podem provocar diferentes conjuntos de variáveis selecionadas. Se a poda funcionar para a partição de melhor validação, ela provavelmente funcionará para as demais partições.

Em seguida, um método de poda de RNAs foi aplicado como técnica de seleção de variáveis para tornar o modclo de previsão mais parcimonioso c facilitar a sua utilização futura. A heurística Skeletonization (Mozer e Smolensky, 1991) foi empregada para selecionar os neurônios da camada de entrada a serem eliminados. A não ser pela primeira arquitetura que havia sido treinada e validada, cada seleção sempre ocorria após o término de 5000 ciclos de treinamento. Entretanto, somente o conjunto de pesos da arquitetura que produzia a menor validação era considerado dentre estes ciclos. Assim, para cada nova arquiletura era gerada com uma outra entrada a menos e com uma possível menor validação.

Este algoritmo de seleção de variáveis foi aplicado para as séries temporais de cotação de moedas e preço de ações.

\subsubsection{Moedas}

O primeiro passo deste experimento foi verificar quantitativamente a importância de outras variáveis externas na previsão da Libra Esterlina e do Marco Alemão. Isto foi realizado construindo Redes Neurais que consideravam quatro valores passados de quatros séries temporais (Libra Esterlina ou Marco Alemão mais Dolar Canadense, Franco Súç̧o e Iene) como entradas em dois experimentos distintos. Isto significa que para a previsão da Libra Esterlina não era considerada nenhuma informação sobre o Marco Alemão e vice-versa. Esta decisão foi tomada pois as duas séries foram previamente escolhidas para serem previstas. As Redes Neurais não foram treinadas com os dados originais destas séries adicionais. Algumas operações de difercnciação foram antes aplicadas, quando necessárias, para a eliminação da nãoestacionariedade.

As informações utilizadas nas entradas da Rede Neural constituída para prever a Libra Esterlina e o Marco Alemão são esquematizadas através das Tabelas $4.10 \mathrm{a}$ e $4.10 \mathrm{~b}$, respectivamente. Em ambas as tabelas, as colunas representam as cinco séries temporais de moedas e as linhas as suas quatro observações passadàs. Cada campo da tabelas coloridos em azul ilustra a presença de uma observação passada de uma dada moeda na entrada do previsor. Por outro lado, campos em branco representam a ausência de informação. 


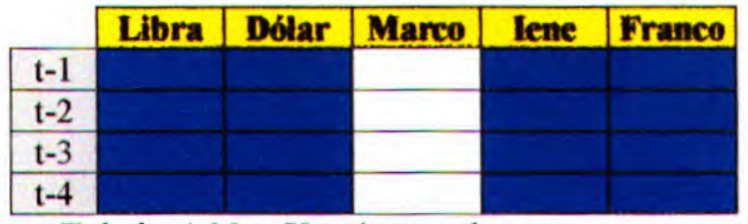

Tabela 4.10a: Variáveis adicionais para a Libra Esterlina.

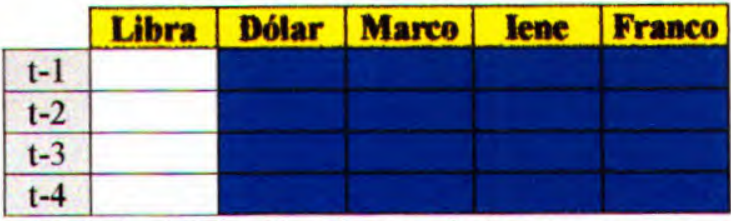

Tabela 4.10b: Variáveis adicionais para o Marco Alemão.

Estas configurações de entrada foram integralmente submetidas ao treinamento de algumas Redes Neurais para a previsão 1-passo-a-frente de cotação de moedas. Tais redes possuíam 16 neurônios na camada de entrada para prever a observação atual da série desejada, representada através de um neurônio na camada de saída. Os resultados iniciais destas previsões da Libra Esterlina e Marco Alemão são apresentados nas Tabelas 4.11 e 4.12, respectivamente. Conforme pode ser observado nestes resultados, o acréscimo de variáveis não provocou uma queda considerável da taxa de erro de previsão para ambas as moedas. Além disso, seus desempenhos nem mesmo conseguiram se aproximar das redes treinadas apenas com informações sobre as próprias séries, como pode ser visto nas Tabelas 4.2 e 4.3 . Isto provavelmente ocorreu devido ao fato de que estas novas variáveis não ofereceram qualquer contribuição extra e ainda dificultaram o treinamento das redes. Mesmo assim, o algoritmo de poda será aplicado em ambas as séries.

\begin{tabular}{|l|c|c|c|}
\hline Arquitetura & $\begin{array}{c}\text { Treinamento } \\
\text { MRE (\%) }\end{array}$ & $\begin{array}{c}\text { Validação } \\
\text { MRE (\%) }\end{array}$ & $\begin{array}{c}\text { Teste } \\
\text { MRE (\%) }\end{array}$ \\
\hline 16_1I & 0.4407 & 0.4421 & 0.4055 \\
\hline 16_1T & 1.1338 & 1.1266 & 1.1724 \\
\hline 16_1_1T & 1.1396 & 1.1317 & 1.1911 \\
\hline 16_3_1T & $\mathbf{0 . 4 4 8 1}$ & $\mathbf{0 . 4 5 3 4}$ & $\mathbf{0 . 4 3 1 4}$ \\
\hline 16_5_1T & 0.4438 & 0.4592 & 0.4614 \\
\hline 16_7_1T & 0.4428 & 0.4679 & 0.4574 \\
\hline 16_9_1T & 0.4341 & 0.4698 & 0.4462 \\
\hline 16_11_1T & 0.4400 & 0.4716 & 0.4670 \\
\hline 16_13_1T & 0.4282 & 0.4944 & 0.6190 \\
\hline 16_15_1T & 0.4407 & 0.4890 & 0.5068 \\
\hline 16_30_1T & 0.4378 & 0.5287 & 0.6829 \\
\hline
\end{tabular}

Tabela 4.11: Desempenho de redes MLP para a Libra Esterlina considerando variáveis adicionais. 


\begin{tabular}{|c|c|c|c|}
\hline Arquitetura & $\begin{array}{c}\text { Treinamento } \\
M R E(\%)\end{array}$ & $\begin{array}{c}\text { Validaçåo } \\
M R E(\%)\end{array}$ & $\begin{array}{c}\text { Teste } \\
M R E(\%)\end{array}$ \\
\hline 1611 & 0.5497 & 0.5508 & 0.4898 \\
\hline $161 \mathrm{~T}$ & 0.5032 & 0.5027 & 0.4332 \\
\hline $16 \quad 11 \mathrm{~T}$ & 0.4979 & 0.5162 & 0.4626 \\
\hline $1631 T$ & 0.4929 & 0.5202 & 0.4511 \\
\hline $1651 \mathrm{~T}$ & $0 . \overline{4943}$ & 0.5323 & 0.4612 \\
\hline $1671 \mathrm{~T}$ & 0.4925 & 0.5276 & 0.4998 \\
\hline $1691 \mathrm{~T}$ & 0.4863 & 0.5358 & 0.5177 \\
\hline 16_11 $1 \mathrm{~T}$ & 0.4836 & 0.5473 & 0.4983 \\
\hline $16131 \mathrm{~T}$ & 0.4910 & 0.5374 & 0.5093 \\
\hline $16151 \mathrm{~T}$ & 0.4811 & 0.5496 & 0.5112 \\
\hline $16301 \mathrm{~T}$ & 0.4758 & 0.5674 & 0.5205 \\
\hline
\end{tabular}

Tabela 4.12: Desempenho de redes MLP para o Marco Alemão considerando variáveis adicionais.

Para a utilização dos métodos de poda, foram selecionadas as melhores arquiteturas obtidas e as melhores partições de dados (treinamento, validação e teste) usạdas para treiná-las e testá-las. Da mesma forma que nos experimentos anteriores, o erro de validação foi usado como critério de seleção. O aumento máximo permitido do erro de validação foi de $10 \%$ comparado com a melhor validação da melhor arquitetura treinada com a melhor partição. Infelizmente, como diferentes partições de dados podem provocar as escolhas de conjuntos distintos de variáveis, somente a partição que gerou o melhor resultado de previsão foi empregada . Como pode-se observar nas Tabelas 4.11 e 4.12 , as melhores arquiteturas para a Libra Esterlina e Marco Alemão são 16_3_1T e 16_1T, respectivamente.

Em seguida, o método Skeletonization foi sucessivamente aplicado apenas à camada de entrada das redes, com intuito de selecionar as variáveis mais relevantes. $O$ aumento brusco da taxa de erro de validação foi empregado para determinar a parada da seleção. As Figuras $4.11 \mathrm{e}$ 4.12 mostram a avaliação do desempenho de treinamento, validação e teste das arquiteturas geradas a partir da atuação desta técnica. As curvas em preto, vermelho, e azul representam, respectivamente, os erros de treinamento, validação e teste ao longo da poda. A região em cinza representa o intervalo máximo de validação permitido. 
Seleção de Váriaveis

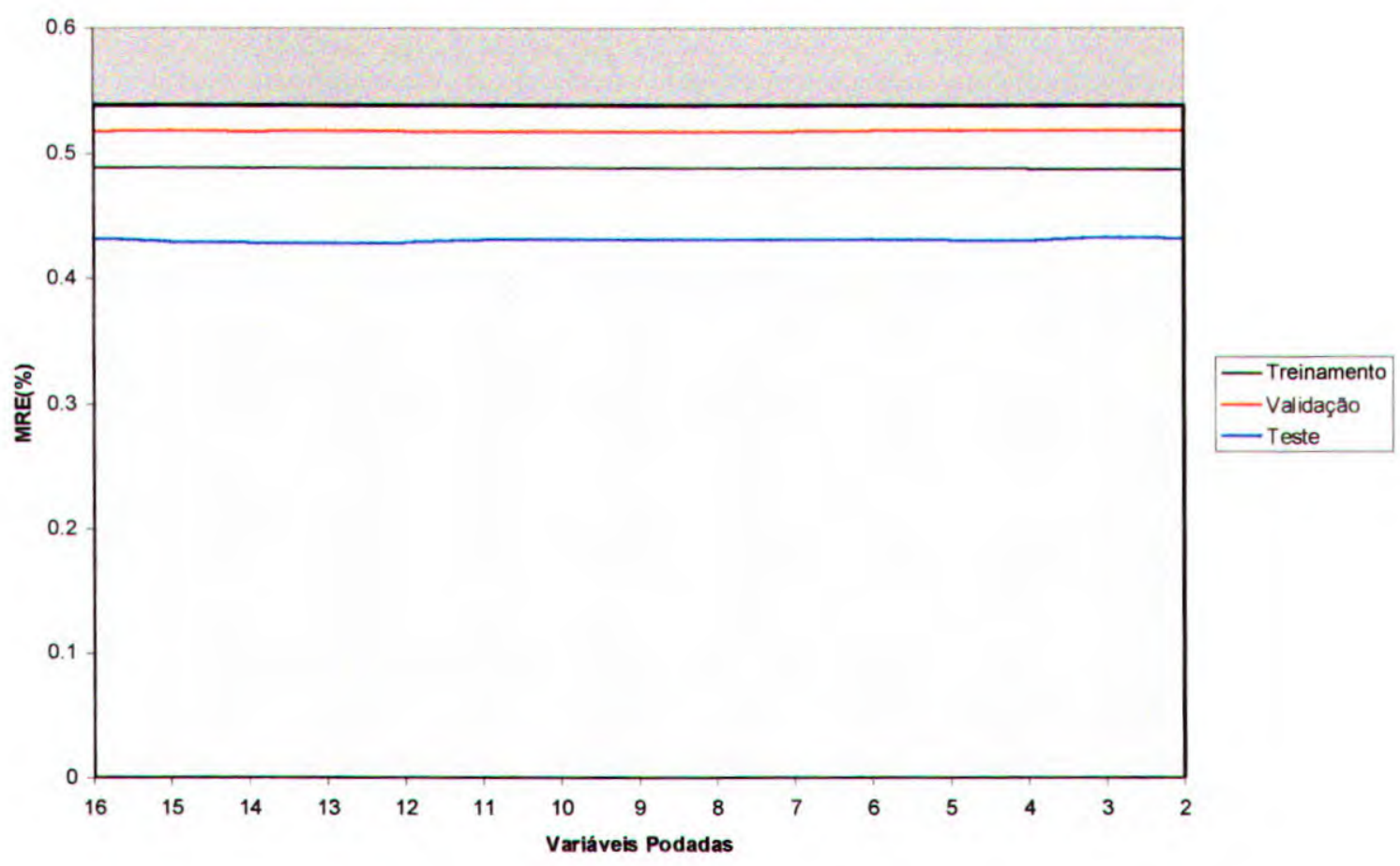

Figura 4.11: Seleção de variáveis para a série da Libra Esterlina

Seleção de Váriaveis

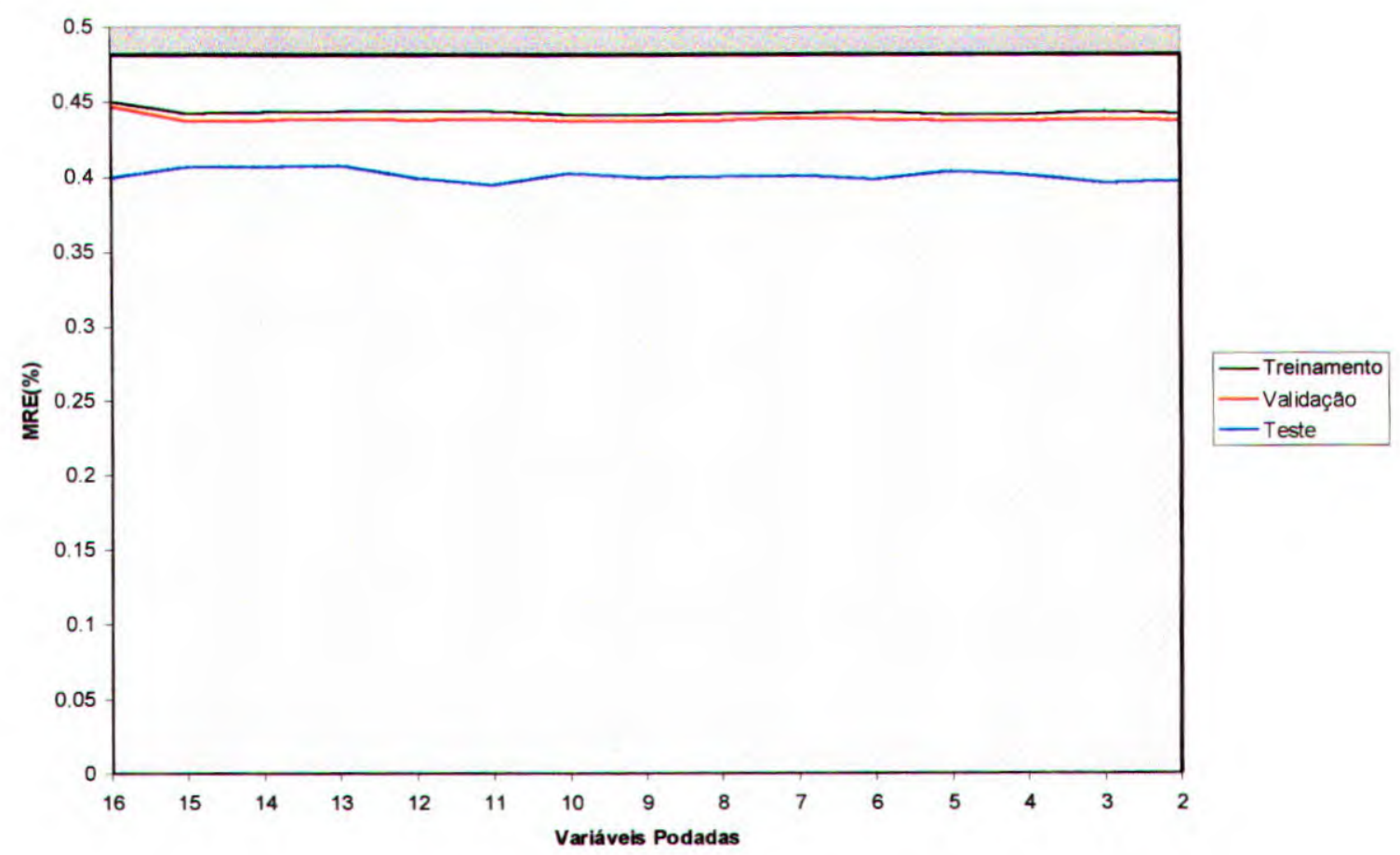

Figura 4.12: Seleção de variáveis para a série da Marco Alemão. 
Em ambos os casos, a poda das arquiteturas das RNAs não provocou melhoras significativa do desempenho de previsão tanto para o treinamento quanto para a validação. Isto reforçou o que havia sido percebido anteriormente no treinamento com todas as váriaveis. Tanto para a Libra Esterlina quanto para o Marco, todas as entradas foram eliminadas a não ser aquelas que representavam os próprios valores das séries. As Tabelas 4.13a e 4.13b apresentam as variáveis selecionadas através de podas das arquiteturas para ambos os casos.

\begin{tabular}{|c|c|c|c|c|c|}
\cline { 2 - 5 } \multicolumn{1}{c|}{} & Libra & Dólar & Marce & Iene & France \\
\hline$t-1$ & & & & & \\
\hline$t-2$ & & & & & \\
\hline$t-3$ & & & & & \\
\hline$t-4$ & & & & & \\
\hline
\end{tabular}

Tabela 4.13a: Variáveis selecionadas para a Libra Esterlina.

\begin{tabular}{|c|c|c|c|c|c|}
\cline { 2 - 5 } \multicolumn{1}{c|}{} & Libra & Dólar & Marco & Iene & Franco \\
\hline$t-1$ & & & & & \\
\hline$t-2$ & & & & & \\
\hline$t-3$ & & & & & \\
\hline$t-4$ & & & & & \\
\hline
\end{tabular}

Tabela 4.13b: Variáveis selecionadas para o Marco Alemão.

É interessante observar que os resultados obtidos reforçam a necessidade da eliminação da não estacionariedade das séries e coincidem, de certa forma, com as sugestões oferecidas pela abordagem que combinavam o método Box \& Jenkins e as Redes Neurais.

\subsubsection{Ações}

Assim como para as séries temporais da cotações de moedas, variáveis adicionais foram também consideradas como entradas da rede para as séries de preço de ações. Porém, estas variáveis representavam quatro valores passados de sete séries temporais distintas: preço mínimo ou máximo mais a quantidade de negócios, quantidade de títulos, volume, e preços de abertura, fechamento e médio. Na previsão do preço mínimo, informações sobre o preço máximo não são utilizadas e vice-versa. Estas outras séries temporais foram também diferenciadas para remover comportamentos não-estacionários.

As entradas das Redes Neurais treinadas para prever os preços mínimo e máximo das ações são esquematizadas através das Tabelas 4.14a e 4.14b respectivamente.

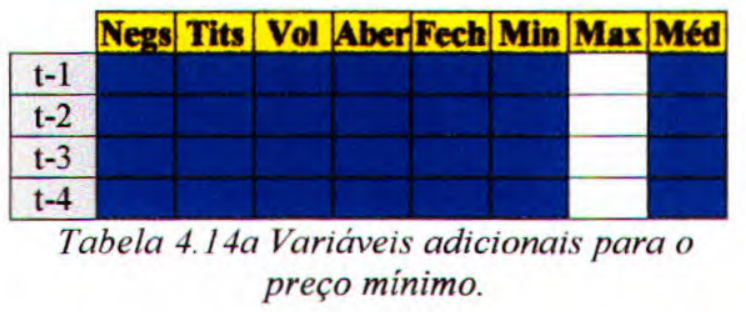

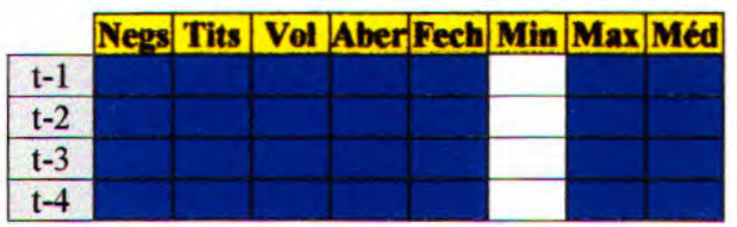

Tabela $4.14 b$ Variáveis adicionais para o preço máximo. 
Estas duas combinações de variávcis foram então submetidas integralmente ao treinamento de algumas Redes Neurais com 28 neurônios na camada de entrada e 1 neurônio na camada de saída. Os erros de treinamento, validação e teste desta redes treinadas com as séries de preço mínimo e máximo são apresentados pelas Tabelas 4.15 e 4.16, respectivamente. Tanto para o preço mínimo, quanto para o máximo, aconteceram boas reduções dos erros de previsão do conjunto de testes comparados com as Tabelas 4.5 e 4.7. Isto incentivou ainda mais a busca das variáveis mais importantes.

\begin{tabular}{|c|c|c|c|}
\hline Arquitetura & $\begin{array}{c}\text { Treinamento } \\
M R E(\%)\end{array}$ & $\begin{array}{l}\text { Validação } \\
M R E(\%)\end{array}$ & $\begin{array}{c}\text { Teste } \\
M R E(\%)\end{array}$ \\
\hline 2811 & 1.7926 & 2.0540 & 0.9781 \\
\hline $28 \quad 1 T$ & 1.7222 & 1.9350 & 0.9448 \\
\hline $2811 \mathrm{~T}$ & 1.7141 & 1.9343 & 0.9066 \\
\hline $2831 \mathrm{~T}$ & 1.4303 & 2.1748 & 1.2638 \\
\hline $2851 \mathrm{~T}$ & 1.4406 & 2.2923 & 1.2843 \\
\hline $2871 \mathrm{~T}$ & 1.3501 & 2.2346 & 1.1567 \\
\hline $2891 \mathrm{~T}$ & 1.2625 & 2.3647 & 1.2151 \\
\hline $28111 \mathrm{TT}$ & 1.2251 & 2.4945 & 1.3082 \\
\hline $28 \quad 13 \quad 1 T$ & 1.2114 & 2.5176 & 1.4662 \\
\hline $28 \_15 \quad 1 T$ & 1.1824 & 2.4186 & 1.4040 \\
\hline $28 \quad 301 T$ & 0.9503 & 2.9132 & 1.5694 \\
\hline
\end{tabular}

Tabela 4. 15: Desempenho de redes MLP para a série do mínimo considerando variáveis adicionais.

\begin{tabular}{|c|c|c|c|}
\hline Arquitetura & $\begin{array}{c}\text { Treinamento } \\
M R E(\%)\end{array}$ & $\begin{array}{l}\text { Validação } \\
M R E(\%) \\
\end{array}$ & $\begin{array}{c}\text { Teste } \\
M R E(\%)\end{array}$ \\
\hline $28 \_11$ & 1.5691 & 1.6920 & 1.1204 \\
\hline $281 \mathrm{~T}$ & 1.5344 & 1.6308 & 1.0714 \\
\hline $2811 \mathrm{~T}$ & 1.6284 & 1.8757 & 1.1828 \\
\hline $2831 \mathrm{~T}$ & 1.3513 & 1.9125 & 1.3492 \\
\hline $2851 \mathrm{~T}$ & 1.2835 & 1.8759 & 1.3084 \\
\hline $2871 \mathrm{~T}$ & 1.2632 & 1.8457 & 1.2417 \\
\hline $28 \_9 \_1 T$ & 1.3472 & 1.9044 & 1.2851 \\
\hline 2811 1T & 1.2414 & 2.0719 & 1.4893 \\
\hline $2813 \quad 1 \mathrm{~T}$ & 1.1559 & 2.0984 & 1.3977 \\
\hline $28151 T$ & 1.2953 & 1.9350 & 1.3612 \\
\hline $28 \quad 30 \quad 1 T$ & 1.2862 & 1.6773 & 1.2438 \\
\hline
\end{tabular}

Tabela 4.16: Desempenho de redes MLP para a série do máximo considerando variáveis adicionais.

Os mesmos critérios usados para podar as Redes Neurais treinadas com dados sobre moedas foram aplicados no caso das séries de ações. As arquiteturas 28_l_IT e 28_IT foram selecionadas para os preços mínimo e máximo, respectivamente. O mesmo algoritmo de seleção de variáveis, usando o método de poda Skeletonization e o critério de parada que permitia somente um aumento de $10 \%$ do erro de validação, foi aplicado para a eliminação de variáveis sem relevância. 
As Figura 4.13 e 4.14 mostram a avaliação do desempenho durante o treinamento, validação e teste das arquiteturas resultantes da atuação desta técnica de seleção de variáveis. É interessante observar que a medida que a curva de erros de validação crescia ou decrescia, este comportamento se refletia no erro de teste. Isto indica que o conjunto de validação foi uma boa estimativa do erro de generalização neste dois casos específicos.

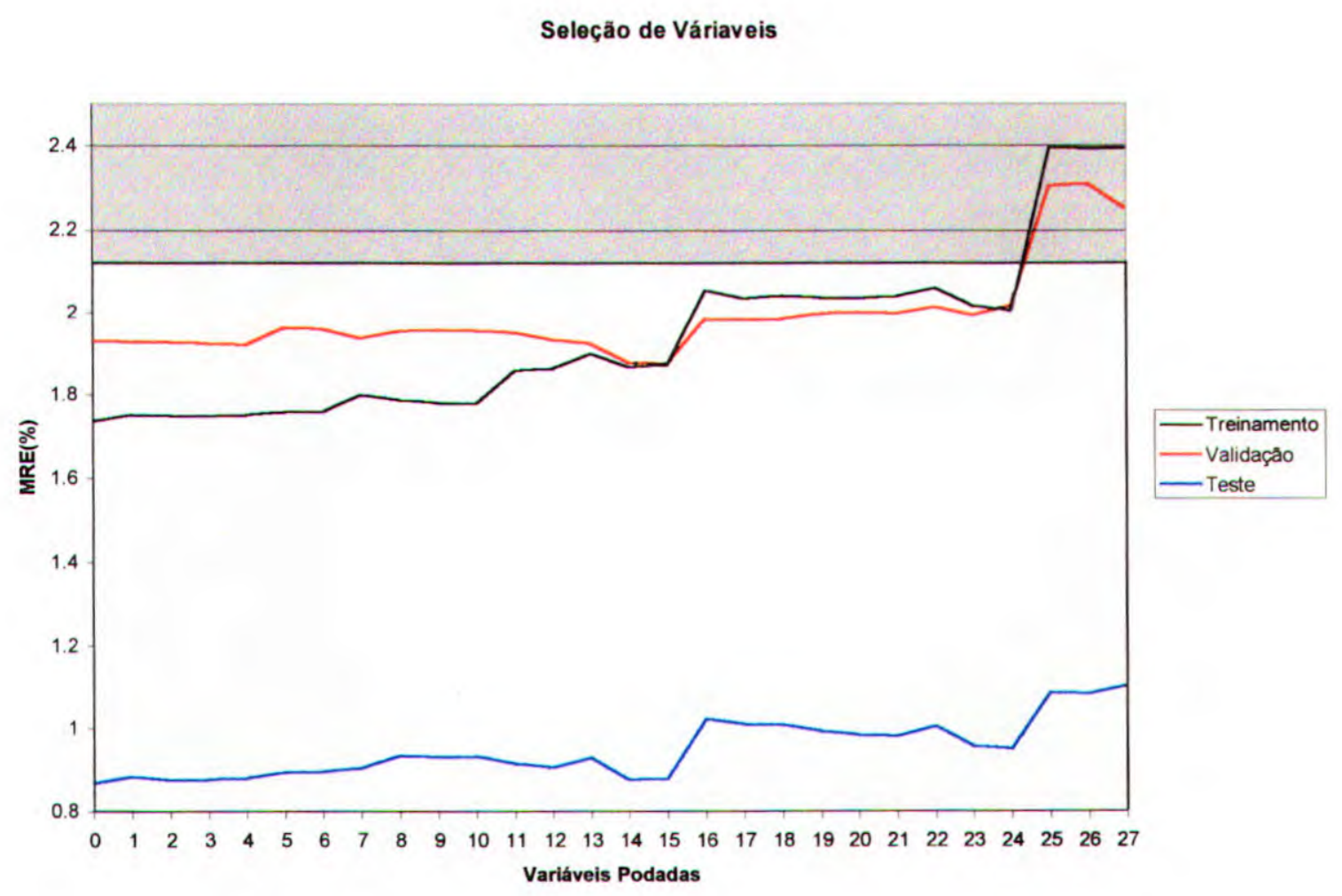

Figura 4.13: Seleção de variáveis para a série do mínimo. 


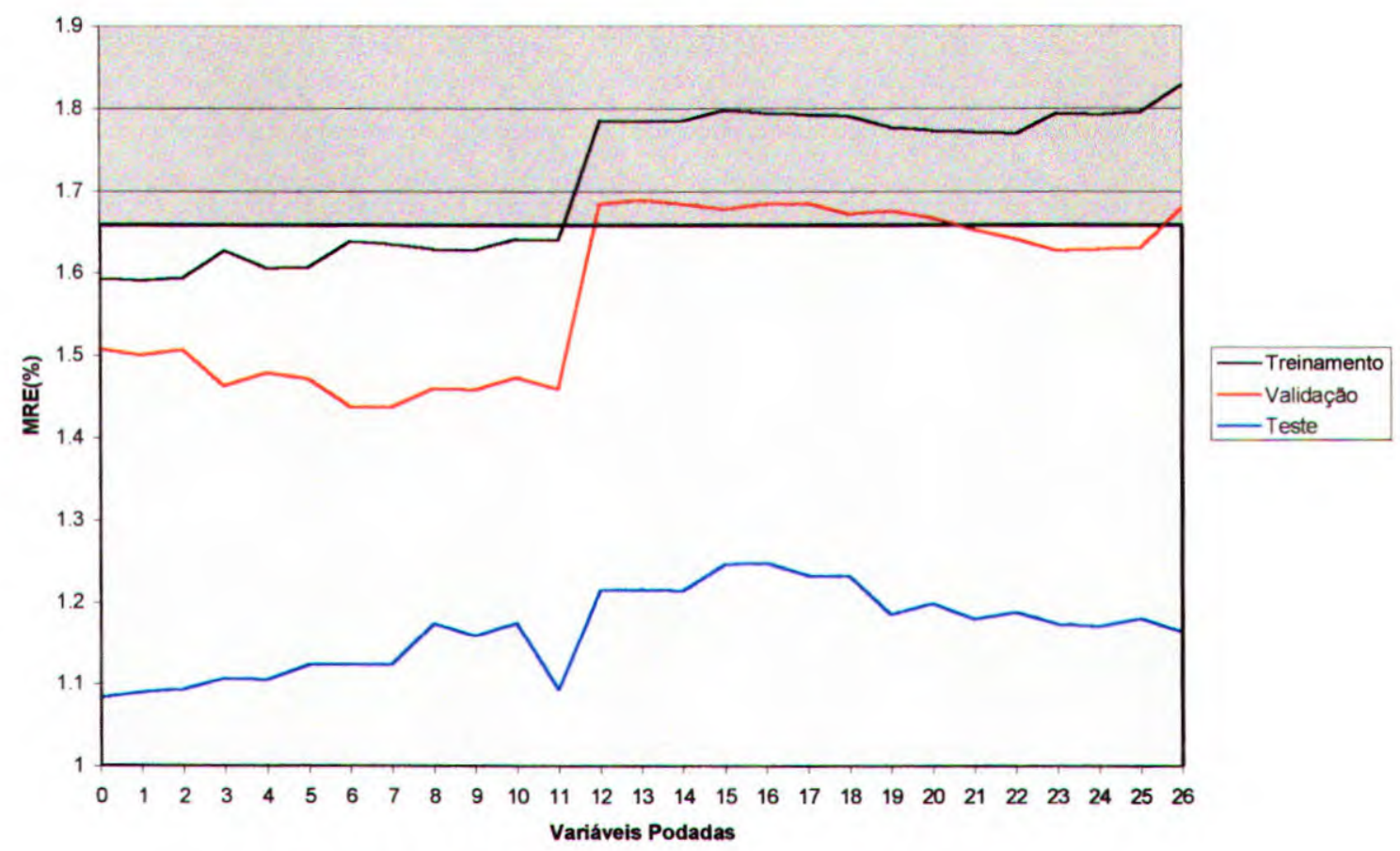

Figura 4.14: Seleção de variáveis para a série do máximo.

Além disso, como pode-se observar na Figura 4.13, apenas houve um aumento brusco do erro de validação para a série do mínimo, selecionando as quatro entradas mostrada pela Tabela 4.17a. Isto já não ocorreu para o preço máximo. Para esta série, ocorreu uma recuperação após o erro de validação ultrapassar pela primeira vez o limite pré-especificado, provocando a seleção das três variáveis ilustradas pela Tabela $4.17 \mathrm{~b}$.

Em ambos os casos, houve um pequeno prejuízo no erro de teste. Contudo, este é o preço que se paga pela obtenção de um modelo menor de previsão. Outro fato importante a ser notado é que as entradas que continham informações sobre o preço mínimo ou máximo foram eliminadas no final poda, criando um modelo alternativo, baseado principalmente nos valores de abertura e fechamento das ações. Este modelo ainda apresentou erros menores de previsão do que as redes treinadas somente com os valores das séries individuais.

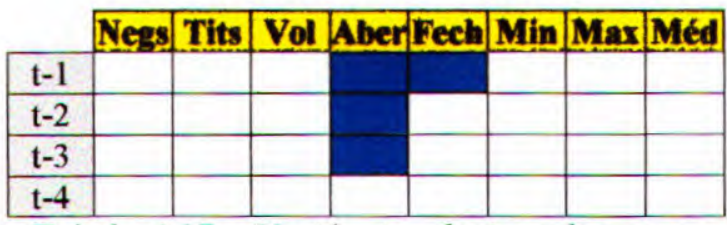

Tabela 4.17a: Variáveis selecionadas para o preço mínimo.

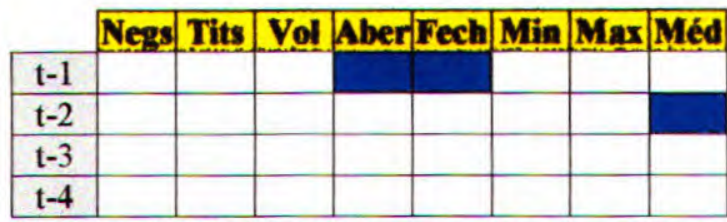

Tabela 4.17b: Variáveis selecionadas parao preço máximo. 


\subsubsection{Processamento Temporal}

Os experimentos cnvolvendo Redes Neurais com memórias de curto e longo prazos foram também realizados para as séries temporais de ações e moedas. Anteriormente, os modelos TDNN e de Elman e Jordan foram diretamente treinados com as séries não estacionárias com o objetivo de extrair comportamentos como tendências lineares e mudanças de níveis. Entretanto, os resultados não foram satisfatórios e novas melhorias foram aplicadas. Ao invés de se trabalhar com os valores originais da série, foram executadas as operações de diferenciação que obtiveram sucesso nos experimentos com as redes MLP. Isto foi realizado em virtude da observação de que nem todo comportamento não estacionário é eliminado através deste recurso. Assim sendo, torna-se plausivel a exploração das características temporais destes modelos em tal contexto. Os resultados obtidos são apresentados a seguir.

\subsubsection{Moedas}

As séries temporais da Libra Esterlinas e Marco Alemão foram algumas das fontes de dados utilizadas para treinar alguns modelos de Redes Neurais com memória de curto e longo prazos. A série da Libra Esterlina não foi diferenciada, uma vcz que sua análise estocástica identificou um modelo random walk que melhor a representava. Por outro lado, a série temporal do Marco Alemão exigiu pré-processamento através da execução de uma operação de diferenciação.

\subsection{TDNN}

Neste trabalho, o desempenho do modelo TDNN foi analisado através dos efeitos provocados por diferentes atrasos na càmada intermediária e de saída das melhores redes MLP treinadas na seção 4.3.1.1. Para a Libra Esterlina, estes atrasos foram submetidos a uma arquitetura com um neurônio na camada de entrada, dez neurônios na camada intermediária e urn neurônio na camada de saida, conforme ilustra a Tabela 4.18 . No caso do Marco Alemão, os atrasos foram adicionados a uma arquitetura MLP com um, três e um neurônios nas camadas de entrada, intermediária e de saida, respectivamente, de acordo com o que é apresentado pela Tabela 4.19.

Os atrasos da camada de entrada foram determinados através das funções de autocorrelação e auto-correlação parcial. Em seguida, diversas possibilidades de atrasos da camada intermediária e da camada de saída foram avaliadas. Estes atrasos são representados seguindo a notação $D_{k} D_{o}$, em que $D_{h}$ é o número de atrasos na camada intermediária e $D_{o}$ é o número de 
atrasos na camada de saída. A Figura 4.15 ilustra o exemplo de uma arquitetura TDNN espacialmente expandida para $D_{h}=0$ e $D_{o}=3$. Os círculos preenchidos em preto representam os verdadeiros neurônios da rede. Os círculos sem preenchimento ilustram as cópias destes neurônios que estão defasadas temporalmente.

$\mathrm{O}$ acréscimo de atrasos provocou uma suave melhora tanto para a sćrie da I,ibra Esterlina quanto para a série do Marco Alemão.

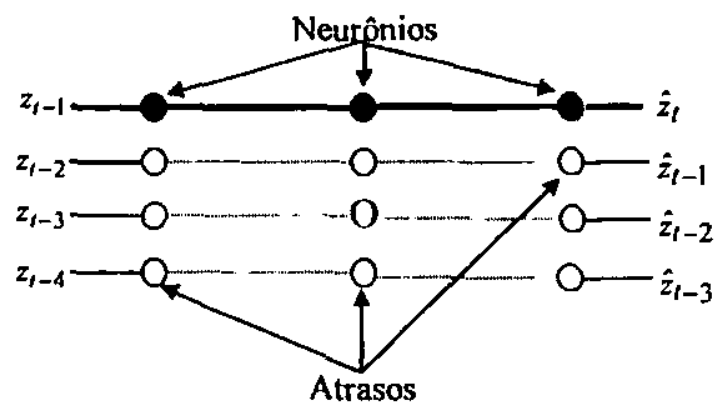

Figura 4.15: TDNN expandida para $D_{h}=0$ e $D_{n}=3$.

\begin{tabular}{|l|c|c|c|}
\hline Atrasos & $\begin{array}{c}\text { Treinamento } \\
M R E(\%)\end{array}$ & $\begin{array}{c}\text { Validação } \\
M R E(\%)\end{array}$ & $\begin{array}{c}\text { Teste } \\
M R E(\%)\end{array}$ \\
\hline $\mathbf{0 \_ 1}$ & 0.4436 & 0.4505 & 0.4042 \\
\hline $\mathbf{0 \_ 3}$ & 0.4507 & 0.4449 & 0.4125 \\
\hline $\mathbf{0 \_ 6}$ & 0.4564 & 0.4448 & $\mathbf{0 . 3 9 6 9}$ \\
\hline 1_0 & 0.4650 & 0.4531 & 0.4043 \\
\hline 3_0 & 0.4662 & 0.4670 & 0.4176 \\
\hline 6_0 & 0.4701 & 0.4644 & 0.4192 \\
\hline
\end{tabular}

Tabela 4.18: Desempenho das redes TDNN para a série da Libra.

\begin{tabular}{|c|c|c|c|}
\hline Atrasos & $\begin{array}{c}\text { Treinamento } \\
M R E(\%)\end{array}$ & $\begin{array}{c}\text { Validação } \\
\text { MRE (\%) }\end{array}$ & $\begin{array}{c}\text { Teste } \\
\text { MRE (\%) }\end{array}$ \\
\hline$\overline{01}$ & 0.5102 & 0.5111 & 0.4386 \\
\hline 0,3 & 0.5106 & 0.4971 & 0.4373 \\
\hline $0 \_6$ & 0.5060 & 0.5032 & 0.4361 \\
\hline $1 \_0$ & 0.5047 & 0.5100 & $0 . \overline{4365}$ \\
\hline 30 & 0.5080 & 0.5158 & 0.4344 \\
\hline $6 \_0$ & 0.5131 & $0 . \overline{5149}$ & 0.4381 \\
\hline
\end{tabular}

Tabela 4.19: Desempenho das redes TDNN para a série do Marco diferenciada.

\subsection{Redes Recorrentes}

As redes recorrentes de Elman e Jordan também foram treinadas com os valores das séries de cotações de moedas pré-processadas por operações de diferenciação. Ao contrário das redes MLP e TDNN, as redes com memória de longo prazo possuiam um neurônio na camada de entrada, diversos neurônios na intermediária e um neurônio na camada de saida. O neurônio de 
entrada representava uma observação passada da série, $z_{t-1}$, enquanto o neurônio da camada de saida ilustrava o valor atual a ser previsto, $z_{\imath}$. As Tabelas 4.20 e 4.21 apresentam as taxas de erro em MRE dos conjuntos de treinamento, validação e teste para a Libra Esterlina. Para a série do Marco Alemão, os resultados obtidos são ilustrados pelas Tabelas 4.22 e 4.23. É importante ressaltar novamente que essas taxas não são médias por partições devido ds características de memória destas redes.

\begin{tabular}{|c|c|c|c|}
\hline Arquitetura & $\begin{array}{c}\text { Treinamento } \\
M R E(\%)\end{array}$ & $\begin{array}{c}\text { Validaçāo } \\
M R E(\%)\end{array}$ & $\begin{array}{c}\text { Teste } \\
M R E(\%)\end{array}$ \\
\hline $111 \mathrm{~L}$ & 0.3773 & 4.4367 & 0.6492 \\
\hline $131 \mathrm{~L}$ & 0.3191 & 1.8072 & 0.2904 \\
\hline $151 \mathrm{~L}$ & 0.3410 & 1.2496 & 0.4170 \\
\hline $171 \mathrm{~L}$ & 0.9503 & 1.6711 & 1.1344 \\
\hline $191 \mathrm{~L}$ & 0.6947 & 1.2757 & 0.9432 \\
\hline $1111 \mathrm{~L}$ & 0.3379 & 1.8426 & 0.2894 \\
\hline $1131 \mathrm{~L}$ & 0.3664 & 1.4309 & 0.3029 \\
\hline $1151 \mathrm{~L}$ & 0.3313 & 1.0146 & 0.3250 \\
\hline $1201 \mathrm{~L}$ & 0.3263 & 1.8101 & 0.3167 \\
\hline $1251 \mathrm{~L}$ & 0.4128 & 1.0307 & 0.3359 \\
\hline $1301 \mathrm{~L}$ & 0.5801 & 0.8799 & 0.8383 \\
\hline
\end{tabular}

Tabela 4.20: Desempenho das redes Elman para a série da Libra Esterlina.

\begin{tabular}{|c|c|c|c|}
\hline Arquitetura & $\begin{array}{c}\text { Treinamento } \\
\text { MRE (\%) } \\
\end{array}$ & $\begin{array}{l}\text { Validação } \\
M R E(\%)\end{array}$ & $\begin{array}{c}\text { Teste } \\
M R E(\%)\end{array}$ \\
\hline $111 \mathrm{~L}$ & 0.3728 & 4.0801 & 0.5908 \\
\hline $131 \mathrm{~L}$ & 0.3154 & 0.6217 & 0.3344 \\
\hline $151 \mathrm{~L}$ & 0.3145 & 0.9897 & 0.3297 \\
\hline $171 \mathrm{~L}$ & 2.1982 & 0.8508 & 1.3983 \\
\hline $191 \mathrm{~L}$ & 1.9095 & 0.6316 & 1.0278 \\
\hline 1_11_1L & $0 . \overline{3449}$ & 0.8056 & $0.327 !$ \\
\hline $1131 \mathrm{~L}$ & 1.2738 & 0.6940 & 0.3997 \\
\hline $1151 \mathrm{~L}$ & 0.3194 & 0.9676 & 0.3830 \\
\hline $1201 \mathrm{~L}$ & 0.3584 & 1.4920 & 0.3408 \\
\hline $1251 \mathrm{~L}$ & 0.8933 & 0.7925 & 0.3998 \\
\hline $1301 \mathrm{~L}$ & 0.9744 & 0.8138 & 0.3574 \\
\hline
\end{tabular}

Tabela 4.21: Desempenho das redes Jordan para a série da Libra Esterlina. 


\begin{tabular}{|l|c|c|c|}
\hline Arquitetura & $\begin{array}{c}\text { Treinamento } \\
M R E(\%)\end{array}$ & $\begin{array}{c}\text { Validação } \\
M R E(\%)\end{array}$ & $\begin{array}{c}\text { Teste } \\
M R E(\%)\end{array}$ \\
\hline 1_1_1L & 0.4515 & 0.6110 & 0.4351 \\
\hline 1 3_1L & 0.4496 & 0.6093 & 0.4423 \\
\hline 1 5_1L & 0.4504 & 0.6131 & 0.4390 \\
\hline 1 7_1L & 0.4529 & 0.6114 & 0.4344 \\
\hline 1 9_1L & 0.4518 & 0.6126 & 0.4318 \\
\hline 1 11_1L & 0.4498 & 0.6127 & 0.4343 \\
\hline 1 13_1L & 0.4493 & 0.6167 & 0.4414 \\
\hline 1 15_1L & 0.4486 & 0.6133 & 0.4327 \\
\hline 1 20_1L & 0.4484 & 0.6158 & 0.4372 \\
\hline 1 25_1L & 0.4508 & 0.6134 & 0.4320 \\
\hline 1 30_1L & 0.4507 & 0.6084 & 0.4342 \\
\hline
\end{tabular}

Tabela 4.22: Desempenho das redes Elman para a série do Marco diferenciada.

\begin{tabular}{|l|c|c|c|}
\hline Arquitetura & $\begin{array}{c}\text { Treinamen to } \\
M R E(\%)\end{array}$ & $\begin{array}{c}\text { Validação } \\
M R E(\%)\end{array}$ & $\begin{array}{c}\text { Teste } \\
M R E(\%)\end{array}$ \\
\hline 1_1_1L & 0.4495 & 0.6150 & 0.4355 \\
\hline 1_3_1L & 0.4515 & 0.6118 & 0.4349 \\
\hline 1_5_1L & 0.4516 & 0.6115 & 0.4392 \\
\hline 1_7_1L & 0.4516 & 0.6115 & 0.4398 \\
\hline 191L & 0.4516 & 0.6116 & 0.4383 \\
\hline 1_11_1L & 0.4516 & 0.6114 & 0.4377 \\
\hline 1_13_1L & 0.4517 & 0.6116 & 0.4388 \\
\hline 1_15_1L & 0.4516 & 0.6113 & 0.4368 \\
\hline 1_20_1L & 0.4516 & 0.6115 & 0.4369 \\
\hline 1_25_1L & 0.4516 & 0.6113 & 0.4368 \\
\hline 130_1L & 0.4515 & 0.6113 & 0.4361 \\
\hline
\end{tabular}

Tabela 4.23: Desempenho das redes Jordan para a série do Marco diferenciada.

Ao contrário das arquiteturas TDNN, as redes de Elman e Jordan foram capazes de extrair melhor o comportamento global da série e generalizar o conjunto de treinamento. Houve uma melhora significativa no erro de previsão especialmente para a série da Libra Esterlina. Para o Marco Alemão, as redes com memória de longo prazo se comportaram similarmente às redes MLP. Um resultado interessante é o tamanho da arquiteturas destas redes. Na maioria dos casos, os melhores resultados só foram obtidos com um número relativamente grande de neurônios na camada intermediária.

\subsubsection{Ações}

Da mesma forma que as séries temporais de moedas, as redes TDNN e as redes recorrentes de Elman e Jordan também foram treinadas com dados sobre os preços mínimo e máximo das ações da TELEBRAS. Estes dados foram pré-porcessados através de operações de diferenciação. 


\subsection{TDNN}

O modelo TDNN também utilizou, em seu projeto, informações a priori adquiridas a partir da análise estocástica da série de preços diários de ações. As arquiteturas TDNN também foram projetadas com um neurônio na camada de entrada, um ou mais neurônios na camada intermediária e um neurônio na camada de saída.

Os atrasos da camada da entrada foram determinados em um dia e dois dias passados para as séries de preços mínimo e máximo, respectivamente. Eles foram definidos através das funções de auto-correlação e auto-correlação parcial. Em seguida, diversas combinações de atrasos das camadas intermediária e de saídas foram adicionadas às melhores redes MLP selecionadas anteriormente. Para o preço mínimo das ações, a melhor rede MLP apresentava um, três e um neurônio nas camadas de entrada, intermediária e de saída, respectivamente. A melhor rede MLP selecionada para o preço máximo possuía dois neurônios na camada de entrada e apenas um neurônio tanto na camada intermediária quanto na de saída. As Tabelas 4.24 e 4.25 apresentam os erros médios por partição das previsões de treinamento, validação e teste de algumas destas combinações para ambas as séries.

\begin{tabular}{|l|c|c|c|}
\hline Atrasos & $\begin{array}{c}\text { Treinamento } \\
M R E(\%)\end{array}$ & $\begin{array}{c}\text { Validação } \\
M R E(\%)\end{array}$ & $\begin{array}{c}\text { Teste } \\
M R E(\%)\end{array}$ \\
\hline $\mathbf{0 \_ 1}$ & 2.2567 & 2.2730 & 1.0734 \\
\hline $\mathbf{0} 3$ & 2.3085 & 2.3423 & 1.1202 \\
\hline $\mathbf{0} 6$ & 2.3261 & 2.2927 & 1.0944 \\
\hline $\mathbf{1}$ 0 & 2.2285 & 2.2997 & 1.1603 \\
\hline 3_0 & 2.2458 & 2.3483 & 1.1608 \\
\hline 6_0 & 2.2416 & 2.2745 & 1.1699 \\
\hline
\end{tabular}

Tabela 4.24: Desempenho das redes TDNN para a série do mínimo diferenciada.

\begin{tabular}{|l|c|c|c|}
\hline Atrasos & $\begin{array}{c}\text { Treinamento } \\
M R E(\%)\end{array}$ & $\begin{array}{c}\text { Validação } \\
M R E(\%)\end{array}$ & $\begin{array}{c}\text { Teste } \\
M R E(\%)\end{array}$ \\
\hline 0_1 & 2.0363 & 1.9116 & 1.2086 \\
\hline 0_3 & 1.9910 & 1.9637 & 1.2446 \\
\hline $0 \_6$ & 1.9873 & 1.9103 & 1.1956 \\
\hline 1_0 & 2.0216 & 2.0453 & 1.2408 \\
\hline 3_0 & 1.9910 & 1.9637 & 1.2446 \\
\hline 6_0 & 2.0963 & 2.0177 & 1.3355 \\
\hline
\end{tabular}

Tabela 4.25: Desempenho das redes TDNN para a série do máximo diferenciada.

O uso das redes TDNNs provocou suaves melhoras no desempenho das previsõs 1-passoa-frente das séries de ações. Em ambos os casos, os erros destas redes foram visivelmente 
menores quando atrasos foram adicionados na camada intermediária. Apenas os atrasos na camada de saída provocaram quedas nas taxas de erro.

\subsection{Redes Recorrentes}

Os comportamentos das redes recorrentes de Elman e Jordan também foram analisados para as séries temporais de preços mínimo e máximo de ações. As Tabelas 4.26 e 4.28 ilustram as taxas de erro em MRE das redes de Elman para os conjuntos de treinamento, validação e teste destas séries. As Tabelas 4.27 e 4.29 mostram os desempenhos de previsões das redes de Jordan. Estes erros não foram calculados como médias por partições devido às mesmas razões apresentadas anteriormente.

\begin{tabular}{|c|c|c|c|}
\hline Arquitetura & $\begin{array}{c}\text { Treinamento } \\
M R E(\%)\end{array}$ & $\begin{array}{c}\text { Validação } \\
M R E(\%)\end{array}$ & $\begin{array}{c}\text { Teste } \\
M R E(\%)\end{array}$ \\
\hline $111 \mathrm{~L}$ & 2.6755 & 1.3234 & 1.1159 \\
\hline $131 \mathrm{~L}$ & 2.6206 & 1.3203 & 1.1020 \\
\hline $151 \mathrm{~L}$ & 2.5473 & 1.3221 & 1.1525 \\
\hline $171 \mathrm{~L}$ & 2.5553 & 1.3028 & 1.2196 \\
\hline $19 \mathrm{tL}$ & 2.4357 & 1.3759 & 1.1535 \\
\hline $1111 \mathrm{~L}$ & 2.5675 & 1.3177 & 1.1802 \\
\hline $1131 \mathrm{~L}$ & 2.5963 & 1.3652 & 1.1329 \\
\hline $1151 \mathrm{~L}$ & 2.6850 & 1.3190 & 1.0989 \\
\hline $1201 \mathrm{~L}$ & $2 . \overline{5227}$ & 1.3094 & 1.1957 \\
\hline $1251 \mathrm{~L}$ & 2.5976 & 1.3226 & 1.1668 \\
\hline $130 \quad 1 \mathrm{~L}$ & 2.5762 & 1.3443 & 1.1111 \\
\hline
\end{tabular}

Tabela 4.26: Desempenho das redes Elman para a série do mínimo diferenciada.

\begin{tabular}{|c|c|c|c|}
\hline Arquitetura & $\begin{array}{l}\text { Treinamento } \\
M R E(\%)\end{array}$ & $\begin{array}{l}\text { Validação } \\
M R E(\%)\end{array}$ & $\begin{array}{c}\text { Teste } \\
M R E(\%)\end{array}$ \\
\hline $111 \mathrm{~L}$ & 2.6787 & 1.3326 & 1.1352 \\
\hline $131 \mathrm{~L}$ & 2.6186 & 1.2851 & 1.1160 \\
\hline $151 \mathrm{~L}$ & 2.6775 & 1.3282 & 1.1216 \\
\hline $171 \mathrm{~L}$ & 2.5629 & 1.4083 & 1.2092 \\
\hline 1912 & 2.6193 & 1.2990 & 1.1418 \\
\hline $1111 \mathrm{~L}$ & 2.5277 & 1.5141 & 1.0924 \\
\hline $1131 \mathrm{~L}$ & 2.5868 & 1.4152 & 2.4277 \\
\hline $1151 \mathrm{~L}$ & 2.5781 & 1.3407 & 1.1691 \\
\hline $1201 \mathrm{~L}$ & 2.6803 & 1.3274 & 1.1166 \\
\hline $1251 \mathrm{~L}$ & 2.4926 & 1.3491 & 1.2331 \\
\hline $1301 \mathrm{~L}$ & 2.5141 & 6.3061 & 1.5117 \\
\hline
\end{tabular}

Tabela 4.27: Desempenho das redes Jordan para a série do minimo diferenciada. 


\begin{tabular}{|c|c|c|c|}
\hline Arquitetura & $\begin{array}{c}\text { Treinamento } \\
M R E(\%)\end{array}$ & $\begin{array}{l}\text { Validação } \\
M R E(\%)\end{array}$ & $\begin{array}{c}\text { Teste } \\
M R E(\%)\end{array}$ \\
\hline $111 \mathrm{~L}$ & 2.2590 & 1.2416 & 1.2279 \\
\hline $131 \mathrm{~L}$ & 2.1888 & 1.2179 & 1.2374 \\
\hline $151 \mathrm{~L}$ & 2.1949 & 1.2556 & 1.2907 \\
\hline $171 \mathrm{~L}$ & 2.1829 & 1.2823 & 1.2283 \\
\hline $191 \mathrm{~L}$ & 2.1108 & 1.2553 & 1.3066 \\
\hline $1111 \mathrm{~L}$ & 2.1519 & . 1.2922 & 1.2622 \\
\hline $1131 \mathrm{~L}$ & 8.2443 & 4.2143 & 1.3048 \\
\hline $115 \mathrm{lL}$ & 2.1936 & 1.2714 & 1.2863 \\
\hline $1201 \mathrm{~L}$ & 2.1563 & 1.2919 & 1.2463 \\
\hline $1251 \mathrm{~L}$ & 2.1734 & 1.2736 & 1.2974 \\
\hline $1301 \mathrm{~L}$ & 2.2216 & 1.2427 & 1.2829 \\
\hline
\end{tabular}

Tabela 4.28: Desempenho das redes Elman para a série do máximo diferenciada.

\begin{tabular}{|c|c|c|c|}
\hline Arquitetura & $\begin{array}{c}\text { Treinamento } \\
M R E(\%)\end{array}$ & $\begin{array}{c}\text { Validação } \\
M R E(\%)\end{array}$ & $\begin{array}{c}\text { Teste } \\
M R E(\%)\end{array}$ \\
\hline $111 \mathrm{~L}$ & 2.2591 & 1.2386 & 1.2596 \\
\hline $131 \mathrm{~L}$ & 2.2799 & 1.2606 & 1.2453 \\
\hline $151 \mathrm{~L}$ & 2.2242 & 1.2379 & 1.2556 \\
\hline $171 \mathrm{~L}$ & 2.2196 & 1.2465 & 1.2599 \\
\hline $191 \mathrm{~L}$ & 2.1972 & 1.2238 & 1.1834 \\
\hline $1111 \mathrm{~L}$ & 2.2196 & 1.2414 & 1.1898 \\
\hline $1131 \mathrm{~L}$ & 2.2649 & 1.2604 & 1.2311 \\
\hline $1151 \mathrm{~L}$ & 2.1745 & 1.2476 & 1.2102 \\
\hline $1201 \mathrm{~L}$ & 2.2708 & 1.2518 & 1.2246 \\
\hline $1251 \mathrm{~L}$ & 2.2075 & 1.2124 & 1.2016 \\
\hline $1301 \mathrm{~L}$ & 2.2244 & 1.2287 & 1.2050 \\
\hline
\end{tabular}

Tabela 4.29: Desempenho das redes Jordan para a série do máximo diferenciada.

Da mesma forma que os modelos TDNN, as redes de Elman e Jordan não provocaram quedas significativas nos erros de previsão gerando resultados semelhantes àqueles das redes MLP. Entretanto, o esforço de projeto foi reduzido pelo fato de que a análise das funções de auto-correlação e auto-correlação parcial não foi necessária para se obter tais resultados similares.

\subsubsection{Combinadores de Previsão}

O objetivo principal destes experimentos é avaliar se a utilização de comitês ou combinadores de previsão pode provocar melhoras da previsão do tipo 1-passo-a-frente das séries temporais financeiras estudadas. 
O primeiro passo dado foi a seleção dos membros do comitĉ. Os melhores previsores de cada série temporal de moedas e ações foram combinados buscando uma redução de variabilidade dos erros individuais de seus membros. Os membros do comitê foram representados pelo modelo Box \& Jenkins ajustado e pelas melhores redes MLP, Elman, Jordan e TDNN treinadas somente com valores próprios de cada série. Nenhuma variável externa foi considerada na concepção destes membros.

Em seguida, foram realizadas as combinações destes previsores através da média das previsões e usando Redes Neurais do tipo MLP, Elman e Jordan. Todas estas redes recebiam como entrada as previsões dos cinco membros e tentavam explorar as suas características individuais.

\subsubsection{Moedas}

Os membros dos comitês da Libra Esterlina foram o modelo random walk ajustado, uma rede MLP com arquitetura 1_10_1T, uma rede Elman com arquitetura 1_25_1L, uma rede Jordan com arquitetura 1_3_1L e uma rede TDNN com arquitetura 1_10_1T sem atrasos na camada intermediária e com seis atrasos na camada de saída.

Já para a série do Marco Alemão, o modelo $A R I(1,1)$ ajustado, uma rede MLP com arquitetura 2_1_1T, uma rede Elman com arquitetura 1_25_1L, uma rede Jordan com arquitetura 1_3_1L e uma rede TDNN com arquitetura 2_1_1T sem atrasos na camada intermediária e com três atrasos na camada de saída participaram diretamente na formação dos comitês.

Apesar das Redes Neurais utilizarem diferentes tipos de funções de ativação, não houve nenhum problema durante a combinação das previsões uma vez que esta apenas foi realizada após a desnormalização ser executada.

Em seguida, as previsões foram combinadas usando uma média aritmética e alguns modelos de RNAs. Entre tais modelos, estavam presentes redes do tipo MLP, Elman e Jordan. As redes recorrentes foram também selecionadas devido às suas características temporais serem propícias para o tipo de mapeamento desejado.

As taxas de erros de teste em MRE da utilização da média aritmética como comitê para as séries da Libra Esterlina e Marco Alemão são ilustradas através da Tabela 4.30.

\begin{tabular}{|l|c|}
\hline \multicolumn{1}{|c|}{ Série } & $\begin{array}{c}\text { Teste } \\
M R E(\%)\end{array}$ \\
\hline Libra & 0.4061 \\
\hline Marco & 0.9805 \\
\hline
\end{tabular}

Tabela 4.30: Desempenho comitê por média para as séries da Libra Esterlina e Marco Alemão. 
Os desempenhos das RNAs do tipo MLPs, Elman e Jordan para combinação das melhores previsões da Libra Esterlina são apresentados através das Tabelas 4.31, 4.32 e 4.33, respectivamente. Para os três tipos de modelos neurais, houve uma grande diferença de desempenhos de acordo com a variação das dimensões das arquiteturas. Contudo, as redes MLP e de Elman obtiveram uma leve redução na taxa de erro do conjunto de teste. Esta redução proporcionou inclusive resultados melhores que aqueles obtidos pelos membros individuais do comitê.

\begin{tabular}{|c|c|c|c|}
\hline Arquitetura & $\begin{array}{c}\text { Treinamento } \\
M R E(\%)\end{array}$ & $\begin{array}{c}\text { Validação } \\
M R E(\%)\end{array}$ & $\begin{array}{c}\text { Teste } \\
M R E(\%)\end{array}$ \\
\hline 111 & 0.4439 & 0.4549 & 0.3973 \\
\hline $11 \mathrm{~L}$ & 0.8227 & 0.8223 & 0.7185 \\
\hline 1_1_1L & 0.8511 & 0.8515 & 0.7422 \\
\hline $131 \mathrm{~L}$ & 0.5660 & 0.5764 & $0 . \overline{4642}$ \\
\hline $151 \mathrm{~L}$ & 0.4931 & 0.5055 & 0.3874 \\
\hline $171 \mathrm{~L}$ & 0.4897 & 0.5014 & 0.3873 \\
\hline $191 \mathrm{~L}$ & $0.489 !$ & 0.5009 & 0.3869 \\
\hline $1111 \mathrm{~L}$ & 0.4882 & 0.4999 & 0.3863 \\
\hline $1131 \mathrm{~L}$ & 0.4884 & 0.5002 & $0 . \overline{3875}$ \\
\hline $1 \mathrm{t5} 1 \mathrm{~L}$ & 0.4885 & 0.5005 & $0 . \overline{3856}$ \\
\hline
\end{tabular}

Tabela 4.31: Desempenho das redes MLP usadas como comitês para a Libra Esterlina.

\begin{tabular}{|c|c|c|c|}
\hline Arquitetura & $\begin{array}{c}\text { Treinamento } \\
M R E(\%)\end{array}$ & $\begin{array}{c}\text { Validação } \\
M R E(\%)\end{array}$ & $\begin{array}{c}\text { Teste } \\
M R E(\%)\end{array}$ \\
\hline $1 \quad 1 \quad 1 L$ & 0.3991 & 4.6787 & 0.4269 \\
\hline $131 \mathrm{~L}$ & 0.4017 & 2.4546 & 0.3861 \\
\hline $151 \mathrm{~L}$ & 0.3871 & 2.2302 & 0.3931 \\
\hline $171 \mathrm{~L}$ & 0.9632 & 2.0750 & 1.2296 \\
\hline $191 \mathrm{~L}$ & 0.7727 & 2.2586 & 1.7444 \\
\hline $1111 \mathrm{~L}$ & 3.0987 & 1.4945 & 1.1056 \\
\hline $1131 \mathrm{~L}$ & 0.7009 & 2.9578 & 0.4958 \\
\hline $115 \_1 \mathrm{~L}$ & 0.4089 & 1.3563 & 0.3778 \\
\hline
\end{tabular}

Tabela 4.32: Desempenho das redes de Elman usadas como comilês para a Libra Esterlina.

\begin{tabular}{|l|c|c|c|}
\hline Arquitetura & $\begin{array}{c}\text { Treinamento } \\
M R E(\%)\end{array}$ & $\begin{array}{c}\text { Validação } \\
M R E(\%)\end{array}$ & $\begin{array}{c}\text { Teste } \\
M R E(\%)\end{array}$ \\
\hline 1 1_1L & 0.4039 & 5.0453 & 0.4743 \\
\hline 1 3_1L & 7.4074 & 1.6771 & 5.5103 \\
\hline 1 5_1L & 0.3898 & 0.9578 & 0.4405 \\
\hline 1 7_1L & 2.4592 & 0.8584 & 0.8554 \\
\hline 1 9_1L & 0.4257 & 0.7888 & 0.3993 \\
\hline 1 11_1L & 2.9355 & 1.2458 & 1.7812 \\
\hline 1 13_1L & 0.3979 & 0.9343 & 0.4258 \\
\hline 1 15_1L & 0.7430 & 1.3974 & 0.9795 \\
\hline
\end{tabular}

Tabela 4.33: Desempenho das redes de Jordan usadas como comitês para a Libra Esterlina. 
Os melhores previsores da sćric do Mareo Alemão também foram combinados por Redes Ncurais, cujos desempenhos são ilustrados pelas Tabelas 4.34, 4.35 e 4.36. Conforme pode ser observado, nenhuma das Redes Neurais propiciou melhoras significativas nos erros de previsão 1-passo-a-frente.

\begin{tabular}{|c|c|c|c|}
\hline Arquitetura & $\begin{array}{c}\text { Treinamen to } \\
M R E(\%)\end{array}$ & $\begin{array}{c}\text { Validação } \\
M R E(\%)\end{array}$ & $\begin{array}{c}\text { Teste } \\
M R E(\%)\end{array}$ \\
\hline 111 & 0.5075 & 0.4912 & 0.4352 \\
\hline $11 \mathrm{~L}$ & 0.5076 & 0.4913 & 0.4352 \\
\hline 1_1LL & 0.5079 & 0.4915 & 0.4354 \\
\hline $131 \mathrm{~L}$ & 0.5078 & 0.4913 & 0.4353 \\
\hline 15_1L & 0.5078 & 0.4913 & 0.4353 \\
\hline $17.1 \mathrm{~L}$ & 0.5078 & 0.4913 & 0.4353 \\
\hline $191 \mathrm{~L}$ & 0.5078 & 0.4913 & 0.4353 \\
\hline $1111 \mathrm{~L}$ & 0.5077 & 0.4913 & 0.4352 \\
\hline $1131 \mathrm{~L}$ & 0.5078 & 0.4913 & 0.4353 \\
\hline $1151 \mathrm{~L}$ & 0.5077 & 0.4913 & 0.4352 \\
\hline
\end{tabular}

Tabela 4.34: Desempenho das rede MLPs usadas como comitês para o Marco Alemão.

\begin{tabular}{|l|c|c|c|}
\hline Arquitetura & $\begin{array}{c}\text { Treinamento } \\
M R E(\%)\end{array}$ & $\begin{array}{c}\text { Validação } \\
M R E(\%)\end{array}$ & $\begin{array}{c}\text { Teste } \\
M R E(\%)\end{array}$ \\
\hline 1_1_1L & 0.4501 & 0.6104 & 0.4350 \\
\hline 1_3_1L & 0.4473 & 0.6220 & 0.4341 \\
\hline 1_5_1L & 0.4479 & 0.6147 & 0.4375 \\
\hline 1_7_1L & 0.4488 & 0.6166 & 0.4321 \\
\hline 1_9_1L & 0.4504 & 0.6111 & 0.4342 \\
\hline 1_11_1L & 0.4474 & 0.6217 & 0.4375 \\
\hline 1_13_1L & 0.4502 & 0.6238 & 0.4437 \\
\hline 1_15_1L & 0.4509 & 0.6100 & 0.4343 \\
\hline
\end{tabular}

Tabela 4.35: Desempenho das redes de Elman usadas como comitês para o Marco Alemão.

\begin{tabular}{|c|c|c|c|}
\hline Arquitetura & $\begin{array}{c}\text { Treinamento } \\
M R E(\%)\end{array}$ & $\begin{array}{c}\text { Validação } \\
M R E(\%)\end{array}$ & $\begin{array}{c}\text { Teste } \\
M R E(\%)\end{array}$ \\
\hline $111 \mathrm{~L}$ & 0.4506 & 0.6108 & 0.4408 \\
\hline $131 \mathrm{~L}$ & 0.0956 & 0.2248 & 0.4380 \\
\hline $151 \mathrm{~L}$ & 0.4505 & 0.6111 & 0.4372 \\
\hline $171 \mathrm{~L}$ & 0.4499 & 0.6113 & 0.4379 \\
\hline $191 \mathrm{~L}$ & 0.0933 & 0.1479 & 0.4378 \\
\hline $1111 \mathrm{~L}$ & 0.1091 & 0.1566 & 0.4370 \\
\hline $1131 \mathrm{~L}$ & 0.4508 & 0.6112 & 0.4362 \\
\hline $1151 \mathrm{~L}$ & 0.4508 & 0.6112 & 0.4383 \\
\hline
\end{tabular}

Tabela 4.36: Desempenho das redes de Jordan usadas como comitês para o Marco Alemão.

Tanto para Libra Esterlina quanto para o Marco Alemão, os beneficios da utilização de comitês não compensaram os custos envolvidos em sua construção. Esta séries são relativamente simples de prever o que não justifica a utilização de recursos tão sofisticados. 


\subsubsection{Ações}

Da mesma forma que para as séries de cotação de moedas, os experimentos envolvendo comitês foram repetidos os preços de ações. Os comitês de ações foram também constituídos pelos melhores previsores de cada uma das séries. Nlém da mćdia aritmética, também foram utilizados diferentes modelos de Redes Neurais para a combinação de previsð̃es.

Os membros sclecionados para os comitês de previsão da séric do preço mínimo de açĩes da TELEBRAS foram o modelo $A R I(I, 1)$ ajustado, uma rede MLP com arquitctura 1_3_IT, uma rede Elman com arquitetura 1_15_1L, uma rede Jordan com arquitetura 1_7_1L e uma rede TDNN com arquitetura 1_3_1L sem atrasos na camada intermediária c com um atraso na camada de saída.

Já para o caso do preço máximo, o modelo $A R I(2,1)$ ajustado, uma rede MLP com arquitetura 2_1_IT, uma rede Elman com arquiletura 1_25_11, uma rede Jordan com arquiletura 1_3_1L e uma rede TDNN com arquitetura 2_1_1T sem atraso na camada intermediária e com seis atrasos na camada de saída foram os membros que participaram diretamente na formação dos comitês.

As taxas de erros em MRE da utilização da média aritmética como comitê para os conjuntos de teste da séries do preço mínimo e máximo das ações são apresentadas através da Tabela 4.37.

\begin{tabular}{|l|c|}
\hline \multicolumn{1}{|c|}{ Série } & $\begin{array}{c}\text { Teste } \\
\text { MRE }(\%)\end{array}$ \\
\hline Mínimo & 1.0990 \\
\hline Máximo & 1.2039 \\
\hline
\end{tabular}

Tabela 4.37: Desempenho de comilês por média dos preços minimo e máximo.

Os erros de treinamento, validação e teste das Redes Neurais do tipo MLP, Elman e Jordan usadas como combinadores de previsão para a série do preço mínimo são ilustrados através das Tabelas 4.38, 4.39, e 4.40, respectivamente. Neste caso, não houve uma redução significativa do erro de previsão 1-passo-a-frente, o que talvez não compensaria o aumento de complexidade inerente do uso de comitês. Tanto as RNAs do tipo MLP quanto as recorrentes provavelmente se confundiram com os rúdos das previsões, buscando representá-los como possíveis relacionamentos. $O$ custo desta complexidade torna-se perceptivel principalmente quando se tenta realizar uma previsão do tipo vários-passos-a-frente com o comitê. Para tanto, antes de prever a série de interesse é necessário realizar a previsão vários-passos-a-frente de cada série adicional. 


\begin{tabular}{|c|c|c|c|}
\hline Arquitetura & $\begin{array}{c}\text { Treinamento } \\
M R E(\%)\end{array}$ & $\begin{array}{c}\text { Validação } \\
M R E(\%)\end{array}$ & $\begin{array}{c}\text { Teste } \\
M R E(\%)\end{array}$ \\
\hline 111 & 2.6105 & 2.4283 & 1.6925 \\
\hline $11 \mathrm{~L}$ & 2.2393 & 1.9781 & 1.2183 \\
\hline $111 \mathrm{~L}$ & 2.2376 & 1.9872 & 1.1958 \\
\hline $131 \mathrm{~L}$ & 2.2331 & 1.9820 & 1.2074 \\
\hline 1512 & 2.2330 & 1.9827 & 1.2086 \\
\hline $171 \mathrm{~L}$ & 2.2331 & 1.9827 & 1.2086 \\
\hline 1912 & 2.2331 & 1.9829 & $1.209 !$ \\
\hline $1111 \mathrm{~L}$ & 2.2330 & 1.9828 & 1.2092 \\
\hline $1131 \mathrm{~L}$ & 2.2351 & 1.9808 & 1.2070 \\
\hline $1151 \mathrm{~L}$ & 2.2330 & 1.9829 & 1.2093 \\
\hline
\end{tabular}

Tabela 4.38: Desempenho das redes MLP usadas como comitês para o preço minimo.

\begin{tabular}{|l|c|c|c|}
\hline Arquitetura & $\begin{array}{c}\text { Treinamento } \\
M R E(\%)\end{array}$ & $\begin{array}{c}\text { Validação } \\
M R E(\%)\end{array}$ & $\begin{array}{c}\text { Teste } \\
M R E(\%)\end{array}$ \\
\hline $\mathbf{1}$ 1_1L & 2.4968 & 1.3393 & 1.2403 \\
\hline $\mathbf{1}$ 3_1L & 2.4331 & 1.3636 & 1.4732 \\
\hline $\mathbf{1}$ 5_1L & 2.4001 & 1.3426 & 1.2858 \\
\hline $\mathbf{1}$ 7_1L & 2.3869 & 1.3433 & 1.3573 \\
\hline $\mathbf{1}$ 9_1L & 2.3906 & 1.3460 & 1.2622 \\
\hline $\mathbf{1}$ 11_1L & 2.4070 & 1.3484 & 1.2952 \\
\hline $\mathbf{1}$ 13_1L & $\mathbf{2 . 3 0 0 7}$ & $\mathbf{1 . 3 2 7 0}$ & $\mathbf{1 . 2 8 7 9}$ \\
\hline $\mathbf{1} \mathbf{1 5} \mathbf{1 L}$ & 2.3847 & 1.3512 & 1.3569 \\
\hline
\end{tabular}

Tabela 4.39: Desempenho das redes de Elman usadas como comitês para o preço mínimo.

\begin{tabular}{|c|c|c|c|}
\hline Arquitetura & $\begin{array}{c}\text { Treinamento } \\
M R E(\%)\end{array}$ & $\begin{array}{l}\text { Validação } \\
M R E(\%)\end{array}$ & $\begin{array}{c}\text { Teste } \\
M R E(\%)\end{array}$ \\
\hline $111 \mathrm{~L}$ & 2.4894 & 1.3533 & 1.2442 \\
\hline $131 \mathrm{~L}$ & 2.4773 & 1.3466 & 1.2447 \\
\hline $151 \mathrm{~L}$ & 2.4833 & 1.3583 & 1.2630 \\
\hline $171 \mathrm{~L}$ & 2.5024 & 1.3446 & 1.2194 \\
\hline $191 \mathrm{~L}$ & 2.4870 & 1.3553 & 1.2603 \\
\hline $1111 \mathrm{~L}$ & 2.4793 & 1.3564 & 1.2904 \\
\hline $1131 \mathrm{~L}$ & 2.4506 & 1.3557 & 1.2853 \\
\hline $1151 \mathrm{~L}$ & 2.4569 & 1.3605 & 1.2825 \\
\hline
\end{tabular}

Tabela 4.40: Desempenho das redes de Jordan usadas como comitês para o preço mínimo.

Para a série do preço máximo, os resultados obtidos por redes MLP, Elman e Jordan são ilustrados através das Tabelas 4.41, 4.42 e 4.43, respectivamente. As Redes Neurais se comportaram similarmente aos comitês neurais da Libra Esterlina proporcionado leves diminuições nos erros de previsão 1-passo-a-frente. 


\begin{tabular}{|c|c|c|c|}
\hline Arquitetura & $\begin{array}{c}\text { Treinamen to } \\
M R E(\%)\end{array}$ & $\begin{array}{c}\text { Validaçāo } \\
M R E(\%)\end{array}$ & $\begin{array}{c}\text { Teste } \\
M R E(\%)\end{array}$ \\
\hline 111 & 2.1586 & 2.0287 & 1.2821 \\
\hline $11 \mathrm{~L}$ & 1.9257 & 1.8367 & 1.1962 \\
\hline $111 \mathrm{~L}$ & 1.9259 & 1.8349 & 1.1966 \\
\hline $131 \mathrm{~L}$ & 1.9240 & 1.8378 & 1.1962 \\
\hline $151 \mathrm{~L}$ & 1.9238 & 1.8374 & 1.1963 \\
\hline $171 \mathrm{~L}$ & 1.9240 & 1.8379 & 1.1963 \\
\hline $191 \mathrm{~L}$ & 1.9240 & 1.8376 & 1.1962 \\
\hline 11112 & 1.9241 & 1.8378 & 1.1962 \\
\hline $1131 \mathrm{~L}$ & 1.9241 & 1.8363 & 1.1963 \\
\hline 115 1L & 1.9243 & 1.8378 & 1.1961 \\
\hline
\end{tabular}

Tabela 4.4I: Desempenho das redes MLP usadas como comitês para o preço máximo.

\begin{tabular}{|c|c|c|c|}
\hline Arquitetura & $\begin{array}{c}\text { Treinamento } \\
M R E(\%)\end{array}$ & $\begin{array}{c}\text { Validação } \\
M R E(\%)\end{array}$ & $\begin{array}{c}\text { Teste } \\
\text { MRE (\%) }\end{array}$ \\
\hline $111 \mathrm{~L}$ & 2.1820 & 1.2146 & 1.1901 \\
\hline $131 \mathrm{~L}$ & 2.1542 & 1.2222 & 1.2798 \\
\hline $151 \mathrm{~L}$ & 2.1376 & 1.2312 & 1.2094 \\
\hline $171 \mathrm{~L}$ & 2.1022 & 1.2682 & 1.1916 \\
\hline $191 \mathrm{~L}$ & 2.1394 & 1.2017 & 1.1773 \\
\hline 11111 & 2.1345 & 1.2868 & 1.1700 \\
\hline $113 \overline{1 L}$ & 2.1216 & 1.2521 & 1.1967 \\
\hline 115 IL & 2.2347 & 1.2763 & 1.2248 \\
\hline
\end{tabular}

Tabela 4.42: Desempenho das redes de Elman usadas como comitês para a o preço máximo.

\begin{tabular}{|c|c|c|c|}
\hline Arquitetura & $\begin{array}{c}\text { Treinamento } \\
M R E(\%)\end{array}$ & $\begin{array}{l}\text { Validação } \\
M R E(\%)\end{array}$ & $\begin{array}{c}\text { Teste } \\
M R E(\%)\end{array}$ \\
\hline $111 \mathrm{~L}$ & 2.1836 & 1.2109 & 1.1845 \\
\hline 13 1L & 2.1495 & 1.2548 & 1.1991 \\
\hline 1.5_1L & 2.1693 & 1.2266 & 1.2051 \\
\hline $171 \mathrm{~L}$ & 2.1678 & 1.2806 & 1.2436 \\
\hline $191 \mathrm{~L}$ & 2.1031 & 1.2728 & 1.4156 \\
\hline \begin{tabular}{|lll}
11 & $1 \mathrm{~L}$ \\
\end{tabular} & 2.1329 & 1.2581 & 1.2198 \\
\hline $1131 \mathrm{~L}$ & 2.1311 & 1.2759 & 1.2133 \\
\hline $1151 \mathrm{~L}$ & 2.0745 & 1.3253 & 1.3151 \\
\hline
\end{tabular}

Tabela 4.43: Desempenho das redes de Jordan usadas como comitês para o preço máximo.

\subsubsection{Comparação Final}

Esta subseção apresenta uma comparação final dos resultados obtidos através de alguns gráficos de previsão l-passo-a-frente e vários-passos-a-frente realizadas pelos modelos Box \& Jenkins e RNAs. 
Os gráficos das previsões 1-passo-a-frente são construídos para comparar os desempenhos dos modelos estocásticos e das Redes Neurais que foram ajustados e treinados apenas com dados referentes às próprias séries.

A previsão vários-passos-a-frente somente é analisada para os previsores que utilizaram a entradas de cada série individual em sua construção.

\subsubsection{Previsão I-passo-a-frente}

A seguir, são ilustrados os gráficos de previsões 1-passo-a-frente realizadas para as séries de cotações de moedas e preços diários de ações.

\subsection{Moedas}

Os resultados dos melhores previsores da Libra Esterlina e Marco Alemão são apresentados através das Figuras 4.16 e 4.17, respectivamente. A curva em preto representa as observações da série e as demais ilustram as previsões do modelo Box \& Jenkins ajustado e das melhores redes MLP, Elman, Jordan e TDNN. Em ambos os casos, a maioria dos previsores apresentou um desempenho semelhante, a não ser pela rede MLP treinada com dados sobre a série temporal do Marco Alemão. O comportamento não estacionário foi satisfatoriamente eliminado. Isto evitou grandes defasagens a medida que as observações da série vão se distanciando da amostragem usada no treinamento e ajuste dos modelos. 
Previsōes de 1-passo-a-frente

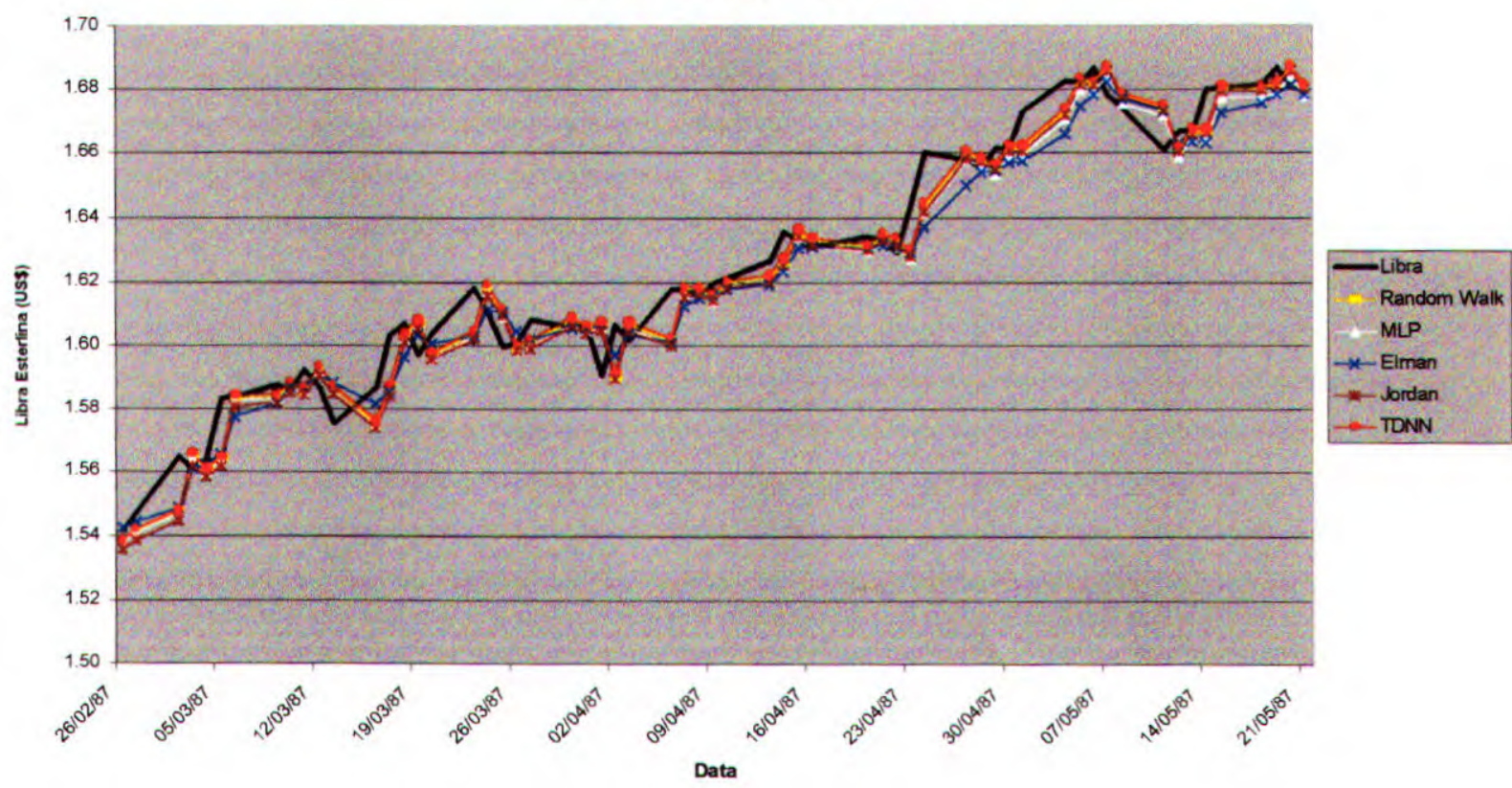

Figura 4.16: Previsões 1-passo-a-frente da Libra Esterlina.

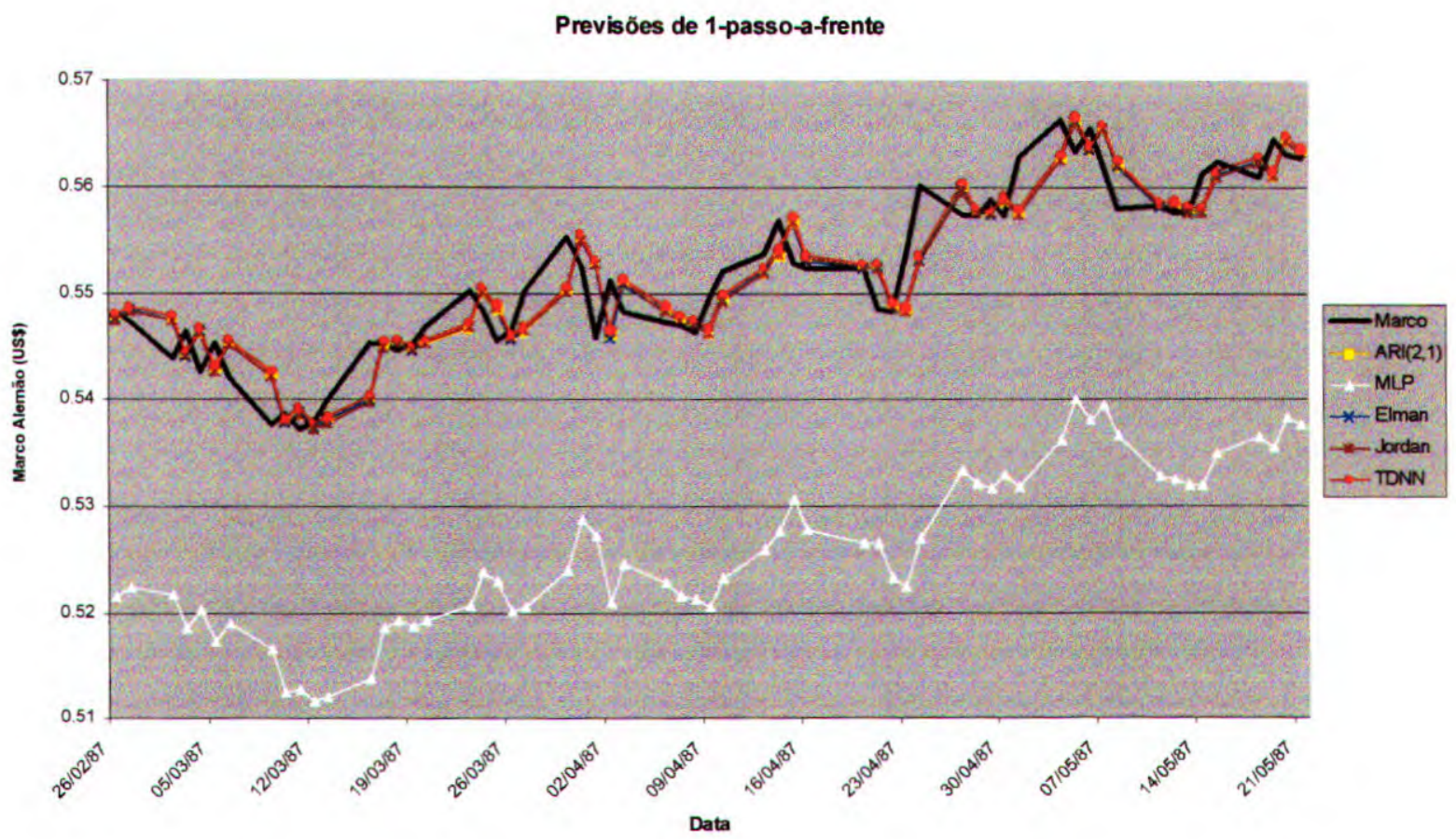

Figura 4.17: Previsões 1-passo-a-frente do Marco Alemão.

\subsection{Ações}

As previsões 1-passo-a-frente do conjunto de teste das séries de preço mínimo e máximo de ações realizadas pelo modelo $A R I(1,1)$ e pelas melhores Redes Neurais treinadas são 
comparadas através das Figuras 4.18 e 4.19, respectivamente. O comportamento não estacionário foi devidamente eliminado, o que contribuiu para a realização de boas previsões. Apesar da obtenção alguns erros menores com as redes recorrentes e TDNN, esta diferença não é perceptível apenas com a visualização das previsões 1-passo-a-frente. Isto ocorre provavelmente porque as redes prevêem as diferenças entre a observação atual e a observação passada e uma maior precisão não contribui tão efetivamente neste caso.

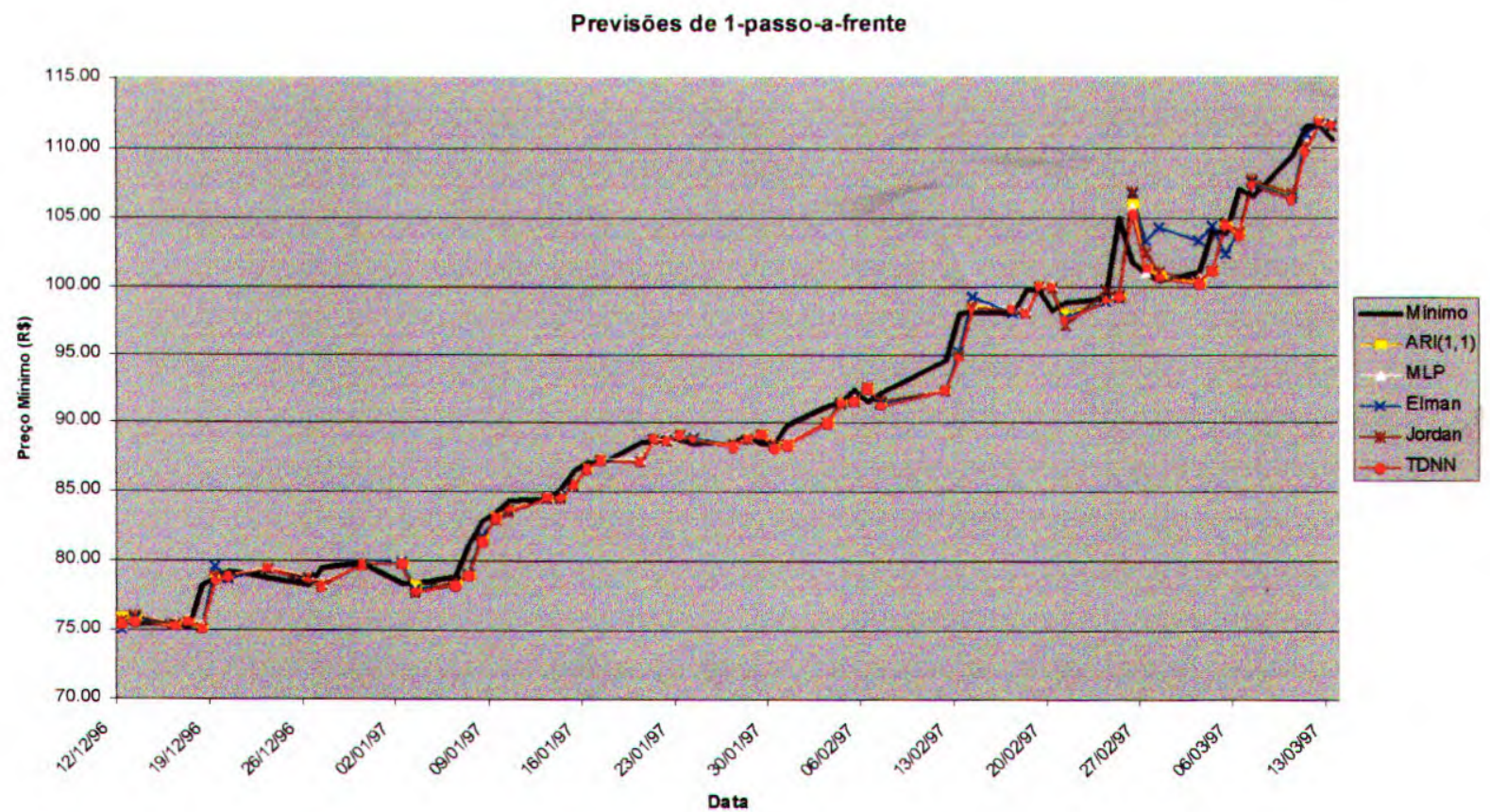

Figura 4.18: Previsões 1-passo-a-frente do preço mínimo de ações. 


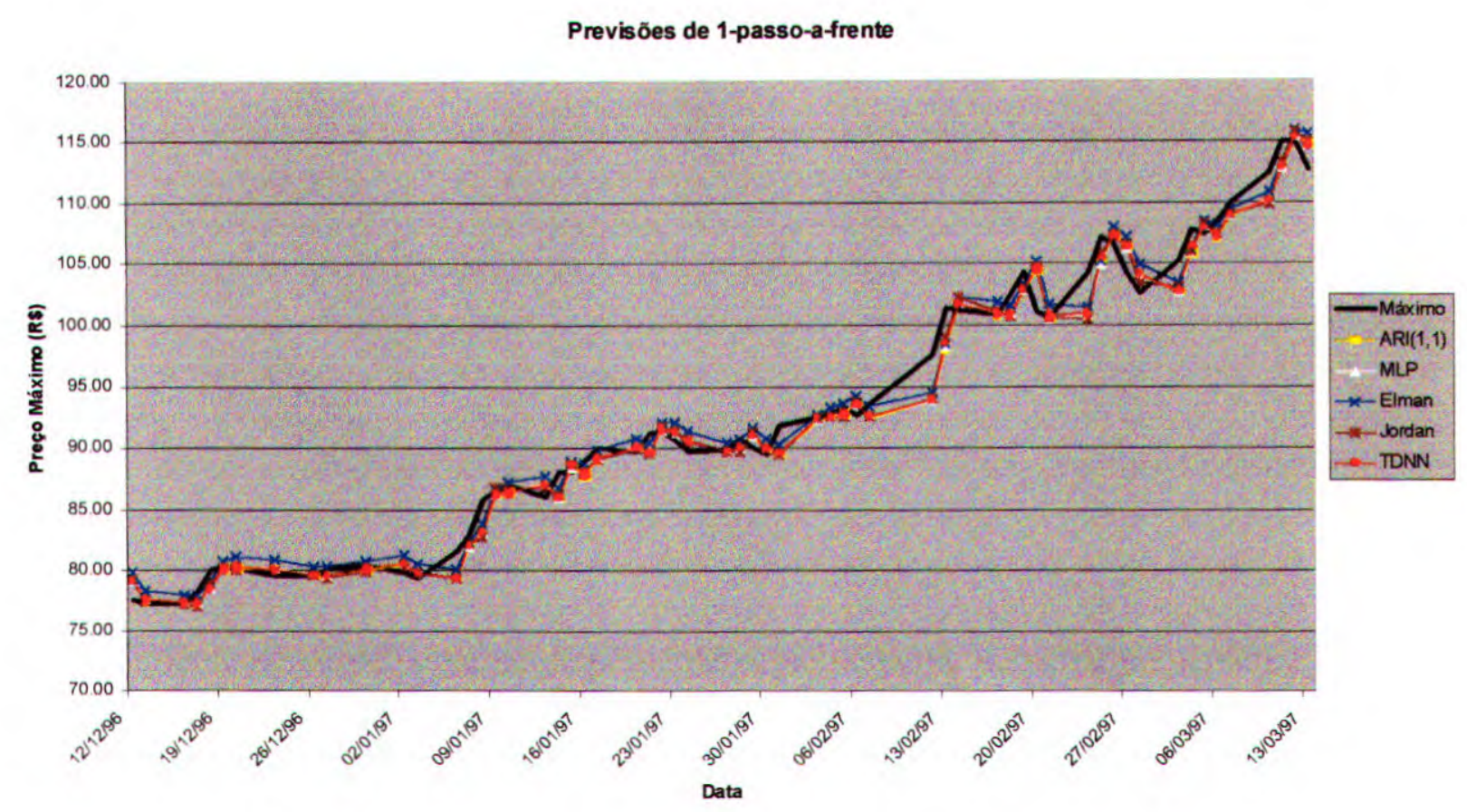

Figura 4.19: Previsões 1-passo-a-frente do preço máximo de ações.

\subsubsection{Previsão Vário-passos-a-frente}

Algumas previsões vários-passos-a-frente do tipo incremental foram realizadas tanto para as séries de cotações de moedas quanto para as de preços de ações, considerando 60 dias a frente. Os mesmos modelos Box \& Jenkins ajustados e as mesmas Redes Neurais treinadas foram também empregadas para esta finalidade. É importante ressaltar que o objetivo principal deste tipo de previsão é apenas verificar se o previsor consegue abstrair o comportamento genérico da série, como por exemplo, um tipo linear de crescimento. Os erros propriamente ditos não são tão importantes.

\subsection{Moedas}

As previsões vários-passos-a-frente para as séries de moedas não produziram resultados tão bons conforme ilustram as Figuras 4.20 e 4.21 .

A série da Libra Esterlina apresentou no conjunto de teste um leve crescimento que não foi percebido por nenhum dos previsores. A rede MLP e o modelo Box \& Jenkins produziram somente previsões constantes. O uso das redes recorrentes e TDNNs pareceu ser exagerado e desnecessário. Tais modelos provavelmente se confundiram, gerando super estimativas e sub estimativas. 
Já para a série do Marco Alemão, foram obtidas previsões vários-passos-a-frente um pouco melhores. O modelo $\mathrm{ARI}(1,1)$ e as redes Elman produziram previsões praticamente constantes. As redes MLP, Jordan e TDNN apontaram um crescimento levemente acentuado. Contudo, é importante enfatizar que houve pouca variação da cotação desta moeda no período, prejudicando a obtenção de resultados mais precisos.

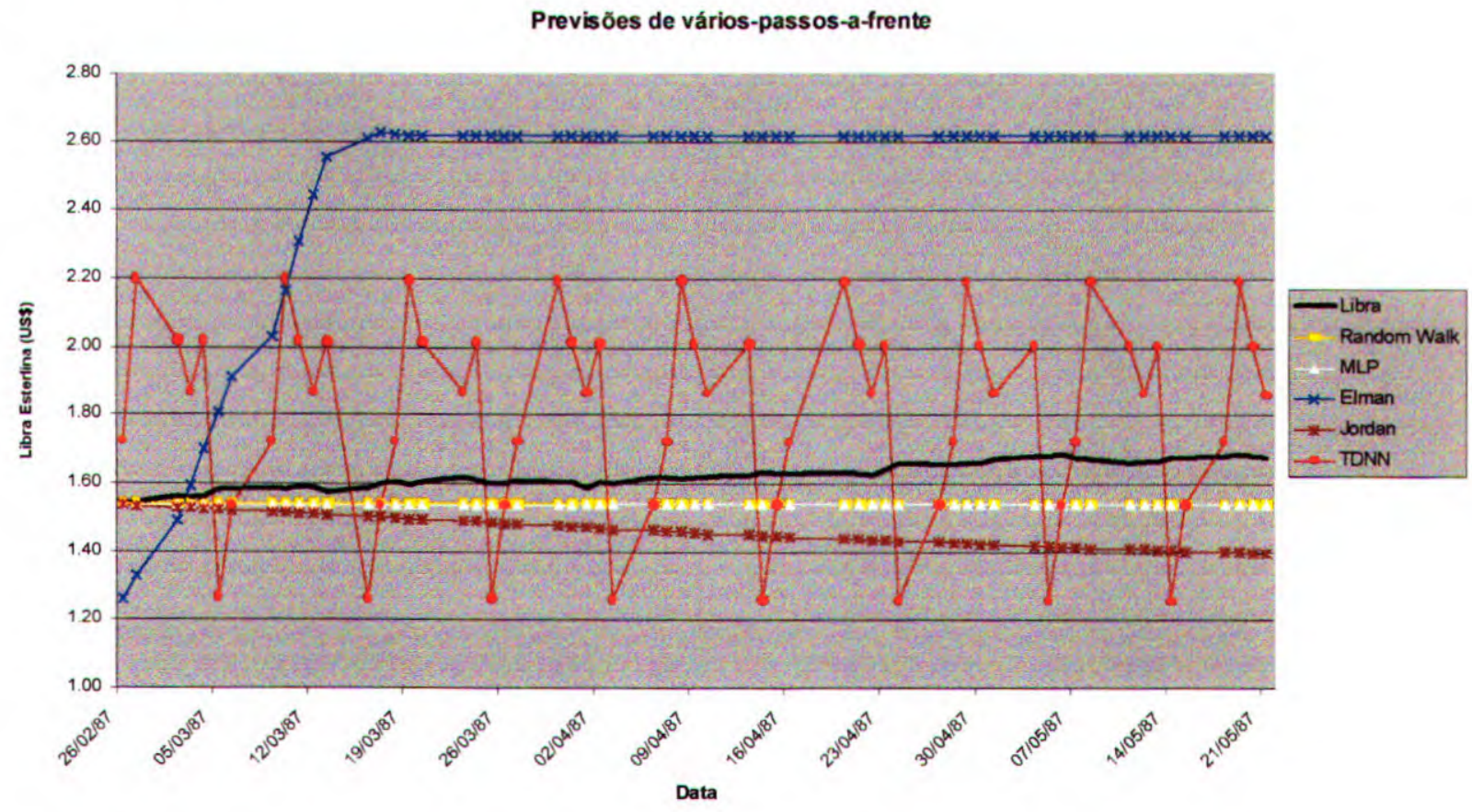

Figura 4.20: Previsões vários-passos-a-frente da Libra Esterlina.

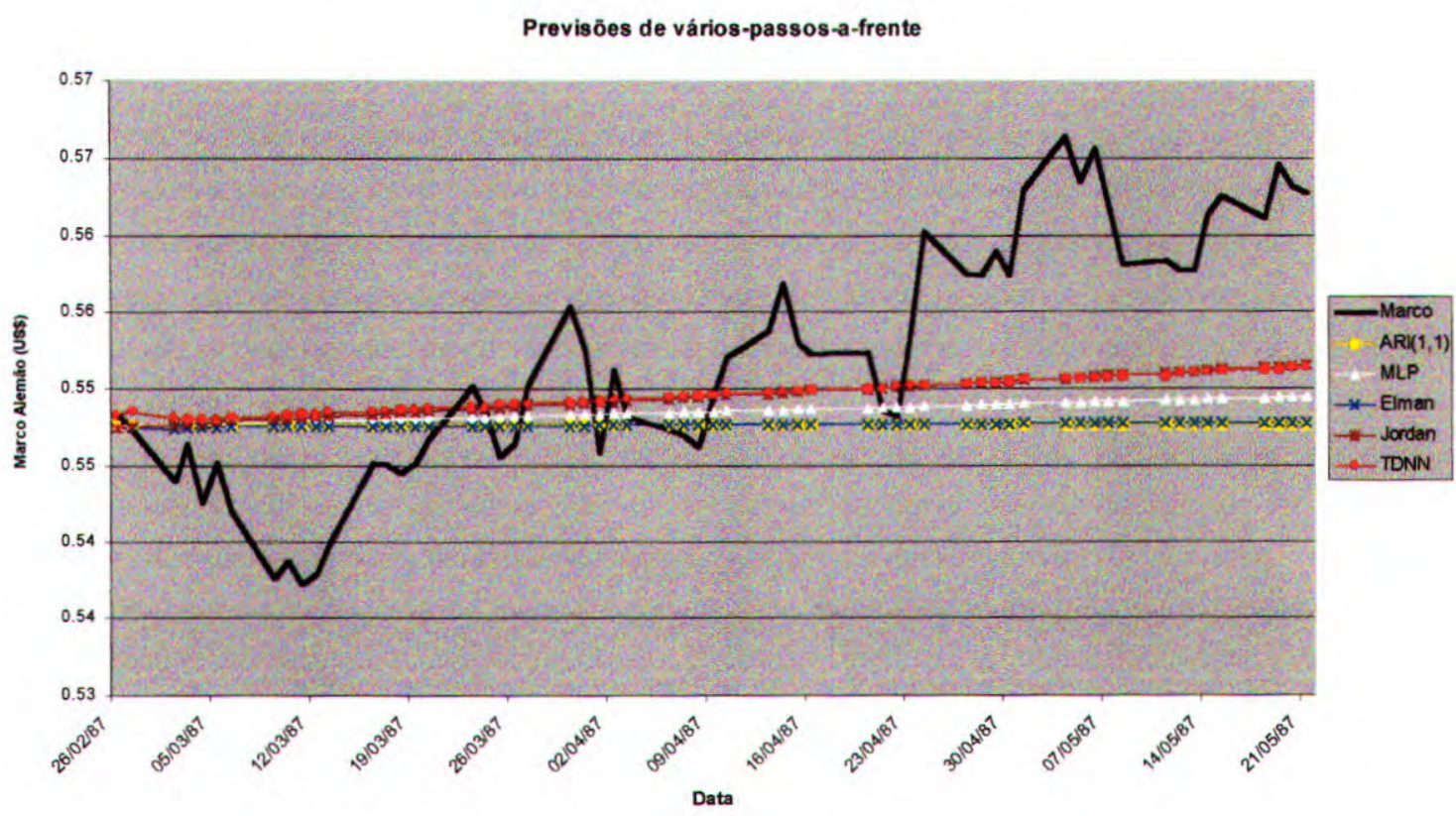

Figura 4.21: Previsões vários-passos-a-frente do Marco Alemão. 


\subsection{Ações}

As previsões vários-passos-a-frente das séries de preços de ações obtiveram muito mais sucesso do que no caso das séries de cotações de moedas, como se pode observar nas Figuras 4.22 e 4.23 .

Os modelos Box \& Jenkins ajustados não conseguiram produzir boas previsões do tipo vários-passos-a-frente para ambas as séries. Um resultado um tanto surpreendente foi a observação de que as redes MLP foram capazes de abstrair suaves crescimentos das séries de preço mínimo e máximo.

As redes recorrentes e TDNN obtiveram ótimo desempenho na representação do comportamento não estacionário das séries, especialmente para o preço mínimo. Na maioria dos casos, estes modelos neurais apontaram um aumento brusco do preço da ações dentro do período analisado. Contudo, a rede de Elman se confundiu e apontou uma desvalorização do preço máximo das ações da TELEBRAS. Isto ressalta a importância de se analisar o comportamento de vários previsores antes de se tomar uma decisão de mercado.

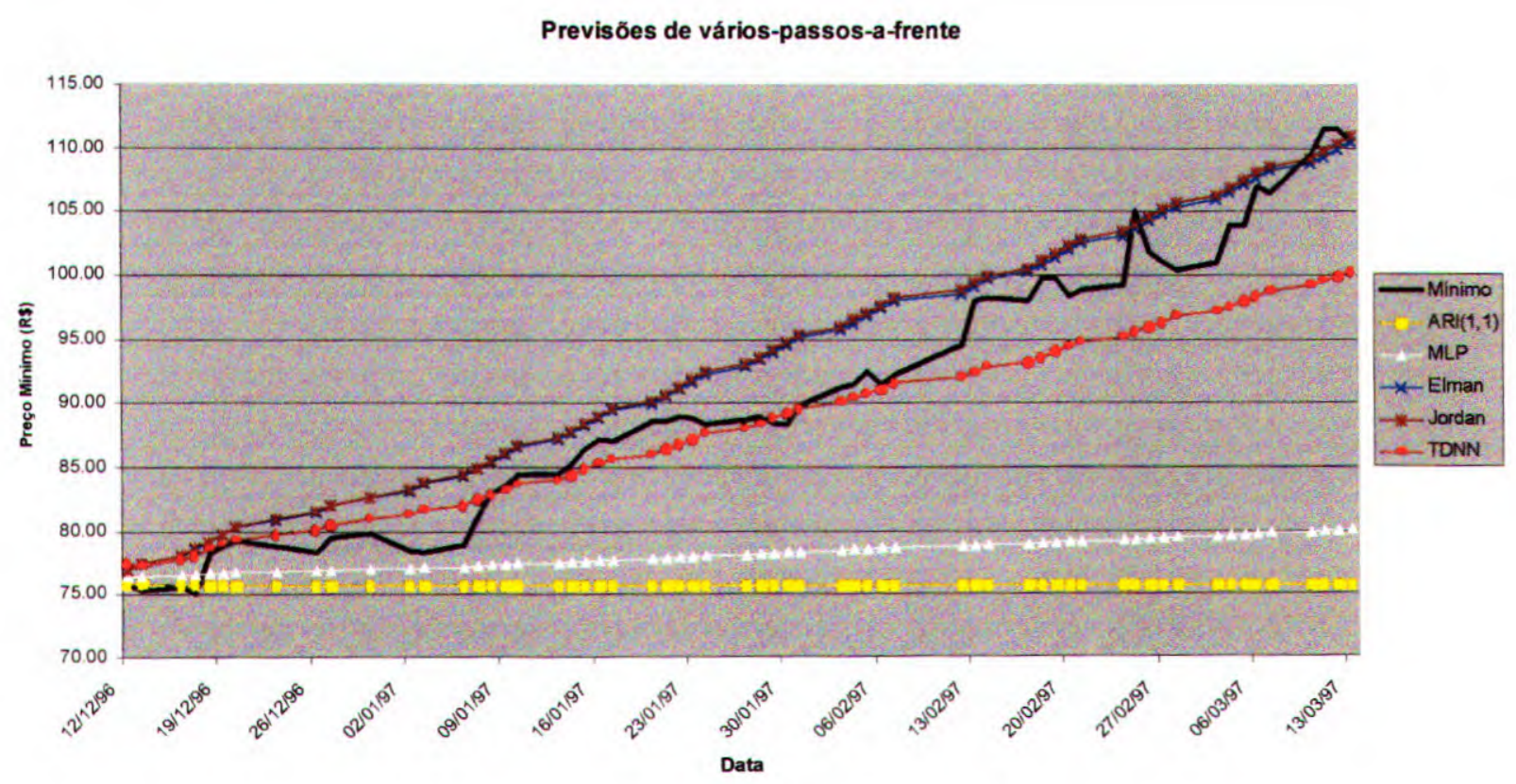

Figura 4.22: Previsões vários-passos-a-frente das séries do preço mínimo. 


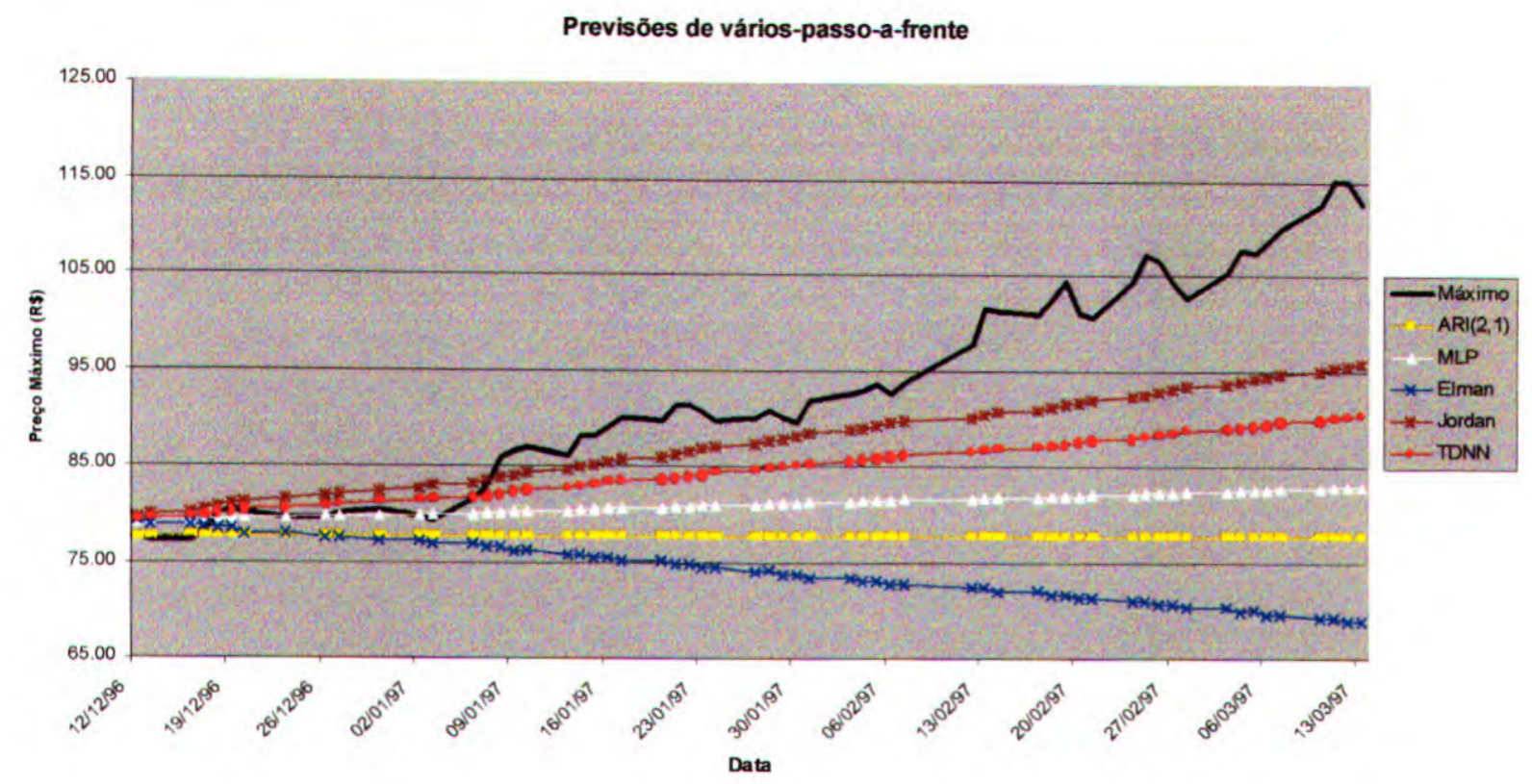

Figura 4.23: Previsões vários-passos-a-frente das séries do preço máximo.

\subsection{Considerações Finais}

As RNAs não são capazes por si próprias de construir um modelo parcimonioso de previsão. É necessário a ajuda de recursos externos para garantir que este requisito seja satisfeito.

Os recursos do método Box \& Jenkins foram de fundamental importância para a obtenção de previsores neurais de boa qualidade. Além de fornecer um parâmetro de comparação, suas técnicas de pré-processamento da série e identificação de modelos forneceram informações úteis para o projeto das arquiteturas das RNAs. Indubitavelmente, estas informações propiciaram o equiparamento de desempenhos de previsão entre as RNAs e os modelos estocásticos ajustados.

Os métodos de poda de RNAs podem ser uma solução interessante para o projeto de arquiteturas otimizadas em previsão. Além dos relacionamentos referentes às informações passadas da série que deseja prever, estes métodos podem ainda revelar dependências temporais com outras séries. Entretanto, existem certas dificuldades. Os métodos de poda só podem ser aplicados em RNAs feedforward e são muito dependente da arquitetura inicial e dos dados empregados durante as suas atuações. Bons resultados apenas foram obtidos após a diferenciação da séries cujas observações foram consideradas como variáveis de entrada. Além disso, existe uma forte necessidade de que as estimativas do erro de generalização da arquitetura da RNA sejam rápidas e razoavelmente precisas.

As RNAs com memória de longo e curto prazos conseguiram obter bons desempenhos somente após as séries sofrerem operações de diferenciação. Os erros de previsão 1-passo-a- 
frente destas RNAs não foi muito menor do que o dos outros previsores. Contudo, o que impressionou foram os resultados de previsão vários-passos-a-frente. Para boa parte dos casos, estas RNAs conseguiram extrair com sucesso os comportamentos futuros das séries.

Antes de utilizar métodos mais sofisticados de previsão, é necessário avaliar a relação custo/beneficios de seus modelos. Nem sempre compensa empregar recursos sofisticados para prever uma série temporal. Em algumas séries muito simples, como por exemplo a Libra Esterlina e Marco Alemão, é possível obter bons resultados com os modelos Box \& Jenkins ajustados e com as RNAs mais simples. Além disso, o aumento de complexidade com a utilização de série adicionais e comitês pode não justificar as pequenas melhoras obtidas. 


\section{Conclusão}

Este capitulo apresenta algumas conclusões preliminares e trabalhos futuros para esta dissertação. A seção 5.1 apresenta as principais conclusões obtidas a partir dos trabalhos desenvolvidos com Redes Neurais e métodos Box \& Jenkins para previsão de séries temporais financeiras. Alguns possiveis caminhos futuros são também apontados e discutidos através da seção 5.2 .

\subsection{Conclusões Preliminares}

Do ponto de vista estatístico, o campo de previsão de séries temporais já está bastante estruturado e formalizado. Atualmente, é possível fazer previsões através de métodos que utilizam informações passadas tanto da série de interesse individualmente bem como de séries adicionais. A maioria dos modelos destes métodos são lineares e destinam-se a realizar previsões do tipo 1-passo-a-frente. Contudo, o horizonte de previsão pode ser aumentado, utilizando indiretamente as previsões 1-passo-a-frente para realizar as previsões vários-passos-a-frente.

O principal representante do métodos estocástico de previsão é o método Box \& Jenkins que realiza análise de una série temporal em etapas. Basicamente, estas etapas buscam a eliminação de comportamentos não estacionários, quando necessária, e a escolha e ajuste do modelo linear mais adequado para represcntar a série.

A utilização de Redes Neurais Artificiais aparenta ser uma alternativa viável para a previsão de séries temporais. Ao contrário da maioria dos métodos tradicionais de previsão, as RNAs possuem modelos não lineares que podem ser facilmente ajustados para a realização deste tipo de tarefa através de um processo de treinamento. As RNAs são capazes de aprender mapeamentos complexos através da utilização de exemplos ou padrões. Este processo de aprendizagem consiste basicamente do ajuste dos pesos das conexões entre neurônios e seus respectivos limiares. Contudo, tal ajuste não pode apenas considerar o desempenho de treinamento da RNA. A capacidade de generalização também tem que ser levada em conta para garantir um desempenho futuro adequado. No contexto de previsão, este requisito deve ser ainda mais rigorosamente atendido.

As três abordagens de previsores neurais investigadas nesta dissertação obtiveram bons desempenhos na busca por arquiteturas mais parcimoniosas e com melhores capacidades de generalização para a previsão de séries temporais de cotação de moedas e de preços de ações. 
A análise estocástica da séries temporais foi primordial para obtenção de bons previsores neurais. As rede MLP não foram capazes de realizar eficientemente previsões para séries temporais não estacionárias. Nas primeiras observações do conjunto de teste, estas RNAs ainda conseguiram acompanhar o comportamento da série. Uma degradação de desempenho ocorreu à medida que o tempo se prolongava. Isto provavelmente aconteceu porque a RNA tentava se comportar como se ela estivesse manipulando observações do conjunto de treinamento ou validação. Para os preços de ações, em que havia uma tendência linear muito forte, as RNAs treinadas com dados originais das séries apenas visualizavam valores que flutuavam mais ou menos entre $R \$ 30,00$ e $R \$ 80,00$ em seus treinamentos. No conjunto de teste, onde o preço chegava a alcançar $\mathrm{R} \$ 115,00$, a RNA não conseguiu prever tais aumentos repentinos.

Em vista disto, as operações de diferenciação de ordem $d$ foram ferramentas muito úteis na eliminação da não estacionariedade. Infelizmente, este recurso não pode ser utilizado em qualquer tipo de série não estacionária. No problema de ações e moedas, onde crescimentos lineares e comportamentos de mudanças de níveis estão claros, esta diferenciação foi o que proporcionou as melhores previsões das RNAs. Contudo, após uma análise mais rigorosa, podese verificar que tal recurso não elimina a não estacionariedade por completo. No caso do preço mínimo de ações, por exemplo, pode-se perceber facilmente trechos com variâncias diferentes mesmo após ter ocorrido este pré-processamento. Em séries mais complexas, com comportamento cíclico por exemplo, somente as diferenciações não seriam capazes de transformá-las em estacionária.

Em termos práticos, a aplicação da difercnciação é uma tarefa simples e fácil. Entretanto, tais operações dificultaram um pouco a avaliação dos resultados do previsores neurais. Isto ocorreu porque eles empregam um particionamento aleatório da sćric temporal em treinamento e validação. Tal particionamento exigiu o registro da posição da saida desejada, que representa a observação a ser prevista, de cada exemplo de treinamento, validação e teste dentro da série temporal. Só assim foi possivel desfazer a diferenciação e desnormalizar a previsão.

As funções de auto-correlação e auto-correlação parcial são ferramentas que podem auxiliar com sucesso o projeto de arquiteturas de alguns modelos de RNAs para previsão. Estas funções são facilmente estimadas e permitem dimensionar a camada de entrada da RNA e indicar o tipo de arquitetura mais adequado. Por outro lado, a FAC e FACp somente medem correlações lineares entre observações passadas da própria série. Se fosse considerada a influência de outras variáveis, modelos de regressão linear múltipla talvez fossem ferramentas mais apropriadas. 
As Redes Neurais possuem uma grande facilidade na extração de correlações entre diversas variáveis adicionais que podem representar informações passadas sobre outras séries temporais. Entretanto, a utilização destas variáveis pode ou não contribuir para a diminuição da taxa de erro de previsão. No caso das séries de moedas, elas não se mostraram úteis, prejudicando o desempenho das redes. Já para as séries de preços de ações, a presença desta variáveis provocou quedas significativas das taxas de erro de previsão.

Os métodos de poda usados como ferramentas de seleção de variáveis constituem uma opção muito atraente para modelagem da arquitetura de RNAs. Isto é devido ao fato de que tais métodos podem ser aplicados para evidenciar correlações não lineares entre as entradas de uma rede. As heurísticas de poda podem ser facilmente empregadas como critérios de seleção das variáveis a serem eliminadas. O problema principal é provavelmente a escolha de uma condição de parada eficiente. Esta condição está estritamente relacionada ao aumento do erro de generalização. As estimativas deste erro devem ser precisas e computacionalmente rápidas. Além disso, a eliminação das entradas das RNAs é extremamente dependente dos dados empregados para treiná-las. Nesta dissertação, somente após a eliminação da não estacionariedade de todas as séries é que foi possivel obter melhoras significativas.

Ao contrário de que se pensava inicialmente, a condição de parada baseada no aumento do erro de validação das arquiteturas geradas através da poda não se mostrou tão ruim. Talvez a melhor alternativa ainda seja a utilização estimadores algébricos do erro de generalização para sistemas não lineares. Se estes estimadores forem confiáveis, a dependência do conjunto de dados pode ser facilmente superada.

As redes com memória de curto e longo períodos podem ser de grande utilidade neste tipo de tarefa. Inicialmente, o modelo TDNN e as redes recorrentes de Elman e Jordan não foram capazes de aprender a tcndência de crescimento linear da sćries de preços de ações. Entretanto, a diferenciação de primeira ordem eliminou boa parte deste comportamento e permitiu que estas redes diminuíssem um pouco mais as taxas de erros. As vantagens destes modelos foram claramente visualizadas com a realização de previsões vários-passos-a-frente onde a maioria das redes acompanhou o crescimento das séries.

A avaliação da complexidade do problema é essencial para o dimensionamento da necessidade recursos mais sofisticados de previsão. A utilização de métodos poda, de modelos de RNAs com memória de curto e longo prazo e de comitês nem sempre compensaram os custos envolvidos. Isto aconteceu principalmente para as séries de cotações de moedas. $\Lambda$ s previsões l- 
passo-a-frente e vários-passos-a-frente destas RNAs não geraram resultados significativos, ocorrendo casos em que as redes se confundiram e produziram previsões sem sentido.

\subsection{Trabalhos Futuros}

Apesar dos experimentos terem sido desenvolvidos com série reais de moedas e ações, seria muito interessante a continuação deste trabalho através da sua aplicação em situações reais de mercado. A participação de um especialista de mercado financeiro traria muitos beneficios, pois a sua experiências e conhecimento poderia indicar melhor quais informações deveriam ser usadas na entrada do modelo de previsão e quais séries seriam mais importantes para serem previstas.

As mesmas metodologias estudadas poderiam ser extendidas para outros problemas práticos de previsão. Tais problemas poderiam ainda continuar restritos à área financeira, como previsão de commodities ( preço da arroba do boi, saca do café, caixa de alface, etc.), previsão de indices financeiro (índice Dow Jones, etc.) e outros. Ou então, séries temporais de outras áreas de aplicação (por exemplo, séries de vazão de rios, de tratamento de esgoto, etc. ) poderiam ser modeladas seguindo esta mesma sistemática.

As técnicas de seleção de variáveis baseadas em métodos de poda de RNAs poderiam ainda ser melhoradas através da escolha de um outro critério de parada. Uma comparação entre o comportamento das taxas de erro do conjunto de validação e dos estimadores algébrico deveria ser realizada para uma melhor escolha da estimativa do erro de generalização das RNAs.

As atuações de outros modelos de RNAs com propriedades dinâmicas poderiam ser pesquisadas na tarefa de previsão de séries temporais. Além disso, seria muito interessante verificar a capacidade deste modelos em representar comportamento cíclicos, como os presentes em diversas séries de commodities e de vazão de rios.

Outras realizações muito importantes seriam as análises das previsões vários-passos-afrente dos modelos obtidos através da seleção de variáveis e de comitês. Estas previsões dariam subsídios para analisar se o aumento de complexidade é compensado pelos resultados obtidos. 


\section{Referências Bibliográficas}

ABELÉM, A. J.; PACHECO, M. A.; VELASCO, M. M. B. R. Modelagem de Redes Neurais Artificiais para Previsão de Séries Temporais, In: II SIMPÓSIO BRASILEIRO DE REDE NEURAIS, São Carlos, 1995. Anais. São Carlos, USP, 1995. p.107-112.

AKAIKE, H. Statistical Predictor Identification, Ann.Inst. Statist. Math., v. 22, p. 203-217, 1970.

BALLINI, R.; FRANÇA, E. H. F.; SOARES, S.; ANDRADE, M.G. Relação entre Modelos Auto-Regressivos e a Configuração de Rede Neural para Previsão de Séries Temporais Estacionárias, In: IV SIMPÓSIO BRASILEIRO DE REDE NEURAIS, Goiânia, 1997. Anais. Goiânia, UFG, 1997, p. 18-22.

BOLLERSLEV, T. Generalized Autoregressive Conditonal Heteroscedasticity", Journal of Econometrics, v. 31, p. 307-327, 1986.

BOX, G. E. P.; JENKIS, G. M.; PENSOIL, G. C. Time Series Analysis Forecasting and Control, San Francisco, Holden-Day Inc., 1970.

CLEMEN, R. T. Combining Forecasting: A review and annotated bibliography, International Journal of Forecasting, v.5, p. 559-583, 1989.

CONNOR, J. T; MARTIN, R. D. Recurrent Neural Networks and Robust Time Series Prediction, IEEE Transaction on Neural Networks, v.5, n. 2, p. 240-254, 1994.

DINIZ, H.; ANDRADE, L. C.; CARVALHO, A. C. P. L. F.; ANDRADE, M. G. Previsão de séries Temporais através de Redes Neurais Artificiais e Métodos Estocásticos, In: IV SIMPÓSIO BRASILEIRO DE REDE NEURAIS, Goiânia, 1997. Anais. Goiânia, UFG, 1997, p.13-17.

DINIZ, H.; ANDRADE, L. C.; CARVALHO, A. C. P. L. F.; ANDRADE, M. G. Previsão de Séries Temporais utilizando Redes Neurais Artificiais e Modclos de Box \& Jenkins, In: V SIMPÓSIO BRASILEIRO DE REDE NEURAIS, Belo Horizonte, 1998. Anais. Belo Horizonte, UFG, 1998, p.173-178.

DINIZ, H.; CARVALHO, A. C. P. L. F.; ANDRADE, M. G. Architecture Design of Artificial Neural Networks based on Box \& Jenkins Models for Time Series Prediction, In:, ICCIMA, Índia, 1999. Anais. India, a ser publicado.

DROSSU, R.; OBRADOVIC, Z. Rapid Design of Neural Networks for Time Series Prediction, IEEE Computational Sciences and Engineering, v.3, n.2, p.78-89, 1996.

EAGLE, R. F.; BOLLERSLEV, T. Autoregressive Conditional Heteroscedasticity with Estimates of the Variance of United Kingdom inflation, Econometrica, v. 50, p.987-1008, 1982.

EAGLE, R. F.; GONZALES-RIVERA, G. Semiparametric ARCH Models, Journal of Business and Economics Statistics, v. 9, p. 345-390, 1991. 
ELMAN, J. F. Finding Structure in Time, Cognitive Science, v.14, p. 179-211, 1990.

FERNANDES, L. G. L., PORTUgal, M. S., NAVAUX, P. O. A., Problema da Escolha da Topologia da Redes Neural na Previsão de Séries Temporais, In: III SIMPÓSIO BRASILEIRO DE REDES NEURAIS, A nais. Fortale7a, 1996. p.227-234.

GOUTTE, C. On the Use of a Pruning Prior for Neural Networks. In: NEURAL, NETWORKS SIGNAL PROCESSING V1 - PROCEEDINGS OF 1996 IEEE WOKSHOP, New Jersey, 1996. Anais. New Jersey, p.52-61.

HARRISON, P. J.; STEVENS, C. F. A Bayesian Approach to Short Term Forecasting, Opl. Res. Q., v. 22, p. 341-362.

HAYKIN, S. Neural Networks. A Comprehensive Foundation, New Jersey, Prentice Hall, 1994.

JORDAN, M. I. Serial Order: A Parallel Distributted Processing Approach, University of California, Institute for Cognitive Science, San Diego, 1986: (Relatório Técnico 8604).

KADOWAKI, M.; SOARES, S.; ANDRADE, G. M. Previsões de Vazões Mensais Utilizando Redes Neurais Multicamadas com Algoritmo Backpropagation, ln: IV SIMPÓSIO BRASILEIRO DE REDE NEURAIS, Goiânia, 1997. Anais. Goiânia, UFG, 1997, p.32-35.

KARNIN, E. D. A Simple Procedure for Pruning Back-Propagation Trained Neural Networks IEEE Transaction on Neural Networks, v. 1, n. 2, p. 239-242, 1990.

LAPEDES, A. FABER, R. Nonlinear signal processing using neural networks prediction and system modelling, Los Alamos, Los Alamos National Laboratory, 1987. (Relatório Técnico LAUR-262).

LE CUN, Y.; DENKER, J. S.; SOLLA, S. A. Optimal Brain Damage, In: ADVANCES IN NEURAL INFORMATION PROCESSING 2, 1990. Anais. NIPS, 1990, p. 598-605.

MOODY, J. E. The Effective Number of Parameters: An Analysis of Generalization and Regularization in Nonlinear Learning System, In: ADVANCES IN NEURAL INTORMATION PROCESSING SYSTEMS 4, San Mateo, 1992. Anais. NIPS, San Mateo, 1992, p. 847-854.

MOSTAFA, Y. S. A. Introduction to Financial Forecasting, Applied Intelligence, v.6, p.205-213, 1996.

MOZER, M. C.; SMOLENSKY, P. Using Relevance to Reduce Network Size Automatically, Connection Science, v. 1, n. 1, p. 67-69,1991.

PRECHELT, L. PROBEN I -- A set of Benchmarks and Benchmarking Rules for Neural Networks Training Algoritms., University of Karlsruhe, Kalsruhe,1994. (Relatório Técnico 21/94).

REED, R., Pruning Algorithms - A Survey, IEFE Transaction on Neural Networks, v.5, n.4, p.740-747, setembro, 1993. 
REHFUSS, S.; WU, L.; MOODY, J Trading with Commitees: A Comparative Study, In: THIRD INTERNATIONAL CONFERENCE, Londres, 1995. Anais. Londres, London Busisness School, 1995.

RIEDMULLER, M.; BR $\Lambda U N$, B. A direct adaptive method fòr faster backpropagation learning: the Rprop Algorithm, In: IEEE INTERNATIONAL CONFERENCE ON NEURAL NETWORKS (ICNN), San Francisco, 1993. Anais. San Francisco, 1993. p.586-591.

RUMELHART, D. E. ; HINTON, G.; WILLIAMS, R. Learning Internal Representations by Error Propagation, In: Parallel Distributed Processing: Exploration in the Microstructure of Cognition, v.1,1986.

SAAD, E. W. Comparative Study of Stock Trend Prediction Using Time Delay, Recurrent and Probabilistic Neural Networks, , IEEE Transaction on Neural Networks, v.9, n.6, p. 240-254, 1998.

SOUZA, R. C. Modelos Estruturais para Previsão de Séries Temporais: Abordagem Clássica e Bayesiana, Rio de Janeiro, Instituto de Matemática Pura e Aplicada,1989

SCHIFFMANN, W.; JOOST, M.; WERNER, R. Optimization of Backpropagation Algorithm for Training Multilayer Perceptrons Koblenz, Institute of Physics, University of Koblenz, 1992. (Relatório Técnico TR 16/1992)

TEIXEIRA, M. A. ZAVERUCHA, G., SILVA, V. N. A. L., RIBEIRO, G. F. Previsão de Carga Elétrica utilizando Redes de Elman, In: V SIMPÓSIO BRÁSILEIRO DE REDE NEURAIS, Belo Horizonte, 1998. Anais. Belo Horizonte, UFG, 1998, p.161-164.

THIMM G.; FIESLER E. Pruning of Neural Networls, Suiça, Institute for Perceptive Artificial Intelligence, 1997. (Relatório Técnico IDIAP-RR 97-03)

WAIBEL, A. HANAZAWA, T., HINTON, G. SHIKANO, K. LANG, K. J., Phoneme Recognition Using Time Delay Neural Networks, IEEE Transaction on Acoustic, Speech, and Signal Processing, v. 37, n.3, p. 328-333, 1989.

WEIGEND, A. S.; HUBERMAN, B. A.; RUMELHART, D. E. Nonlinear Modeling and Forecasting, Addison-Wesley, 1992.

WHITE, H. Economics Prediction Using Neural Networks: the case of IBM daily stock return, In: IEEE INTERNATIONAL CONFERENCE ON NEURAL NETWORKS, San Diego, 1988. Anais. San Diego, 1988. p.II-451-II-459.

фKSENDAL, B. Stochastic Differential Equations: An Introduction with Applications, SpringVerlag, 1992. 